\title{
Translabial 3D ultrasound for diagnosing levator ani defects in women with pelvic organ prolapse
}

Citation for published version (APA):

Notten, K. J. B. (2015). Translabial 3D ultrasound for diagnosing levator ani defects in women with pelvic organ prolapse. [Doctoral Thesis, Maastricht University]. Uitgeverij BOXPress. https://doi.org/10.26481/dis.20150521kn

Document status and date:

Published: 01/01/2015

DOI:

$10.26481 /$ dis.20150521kn

Document Version:

Publisher's PDF, also known as Version of record

\section{Please check the document version of this publication:}

- A submitted manuscript is the version of the article upon submission and before peer-review. There can be important differences between the submitted version and the official published version of record.

People interested in the research are advised to contact the author for the final version of the publication, or visit the DOI to the publisher's website.

- The final author version and the galley proof are versions of the publication after peer review.

- The final published version features the final layout of the paper including the volume, issue and page numbers.

Link to publication

\footnotetext{
General rights rights.

- You may freely distribute the URL identifying the publication in the public portal. please follow below link for the End User Agreement:

www.umlib.nl/taverne-license

Take down policy

If you believe that this document breaches copyright please contact us at:

repository@maastrichtuniversity.nl

providing details and we will investigate your claim.
}

Copyright and moral rights for the publications made accessible in the public portal are retained by the authors and/or other copyright owners and it is a condition of accessing publications that users recognise and abide by the legal requirements associated with these

- Users may download and print one copy of any publication from the public portal for the purpose of private study or research.

- You may not further distribute the material or use it for any profit-making activity or commercial gain

If the publication is distributed under the terms of Article $25 \mathrm{fa}$ of the Dutch Copyright Act, indicated by the "Taverne" license above, 


\section{TRANSLABIAL 3D ULTRASOUND FOR DIAGNOSING LEVATOR ANI DEFECTS IN WOMEN WITH PELVIC ORGAN PROLAPSE}

Kim J.B. Notten 
“It always seems impossible until it's done"

\section{Nelson Mandela}

The printing of this thesis was generously supported by:

Offermans Joosten Groep

Medical Dynamics

BMA bv Mosos

Chipsoft

Author:

Kim J.B. Notten

Cover photo:

Dennis van Sint Fiet (dennisvansintfiet.nl)

Cover model:

Judith Hermans

Layout:

Ivo Van den Broek

Published by:

Uitgeverij BOXPress, 's Hertogenbosch

Printed by:

Proefschriftenmaken.nl || Uitgeverij BOXPress

ISBN:

$978-94-6295-153-2$

(C) Kim J.B. Notten, Maastricht, 2015

All rights reserved. No part of the book may be reproduced or transmitted in any form or by any means, without permission of the copyright owner. 


\title{
TRANSLABIAL 3D ULTRASOUND FOR DIAGNOSING LEVATOR ANI DEFECTS IN WOMEN WITH PELVIC ORGAN PROLAPSE
}

\author{
PROEFSCHRIFT
}

ter verkrijging van de graad van doctor aan de Universiteit Maastricht, op gezag van de Rector Magnificus, Prof dr. L.L.G. Soete,

volgens het besluit van het College van Decanen,

in het openbaar te verdedigen

op donderdag 21 mei 2015 om 12.00 uur

door

Kim Josephina Bernadette Notten

geboren op 5 februari 1980 te Maastricht 


\section{Promotores:}

Prof. Dr. R.F.P.M. Kruitwagen

Prof. Dr. J.P.W.R. Roovers (Academisch Medisch Centrum, Amsterdam)

\section{Copromotor:}

Dr. M. Weemhoff (Atrium-Orbis, Heerlen)

\section{Beoordelingscommissie:}

Prof. Dr. J.G. Nijhuis (voorzitter)

Prof. Dr. J. Deprest (Katholieke Universiteit, Leuven)

Dr. G. A. van Koeveringe

Prof. Dr. L.P.S. Stassen

Prof. Dr. C.H. van der Vaart (Universitair Medisch Centrum Utrecht, Utrecht) 


\section{CONTENTS}

$\begin{array}{lll}\text { Chapter } 1 & \text { General introduction } & 7\end{array}$

Chapter 2 Do patients prefer mesh or anterior colporrhaphy for primary 13 correction of anterior vaginal wall prolapse: A labelled discrete choice experiment - BJOG 2014; Jul 7 [Epud ahead of print]

Chapter 3 Detecting levator ani defects and measuring levator biometry using translabial 3D ultrasound: a systematic review - Submitted

Chapter 4 Protocol Translabial 3D-Ultrasonography for diagnosing levator defects (TRUDIL): a multicentre cohort study for estimating the diagnostic accuracy of translabial 3D-ultrasonography of the pelvic floor as compared to MR imaging - BMC women's health 2011;11:23

Chapter 5 Translabial three-dimensional ultrasound compared with magnetic resonance imaging in detecting levator ani defects (TRUDIL study) Obstet Gynecol 2014;124:1190-7

Chapter 6 Are levator ani defects predictive for recurrent anterior vaginal 83 wall prolapse? (TRUDIL study) - Submitted

Chapter 7 Levator hiatal area as a risk factor for cystocele recurrence after surgery in a prospective study (TRUDIL study) - Accepted BJOG

Chapter 8 General Discussion

Chapter 9 Summary

Chapter 10 Nederlandse samenvatting

Chapter 11 Why should you care about my research?

Valorisation addendum

Chapter 12 Dankwoord 


\section{GENERAL INTRODUCTION}

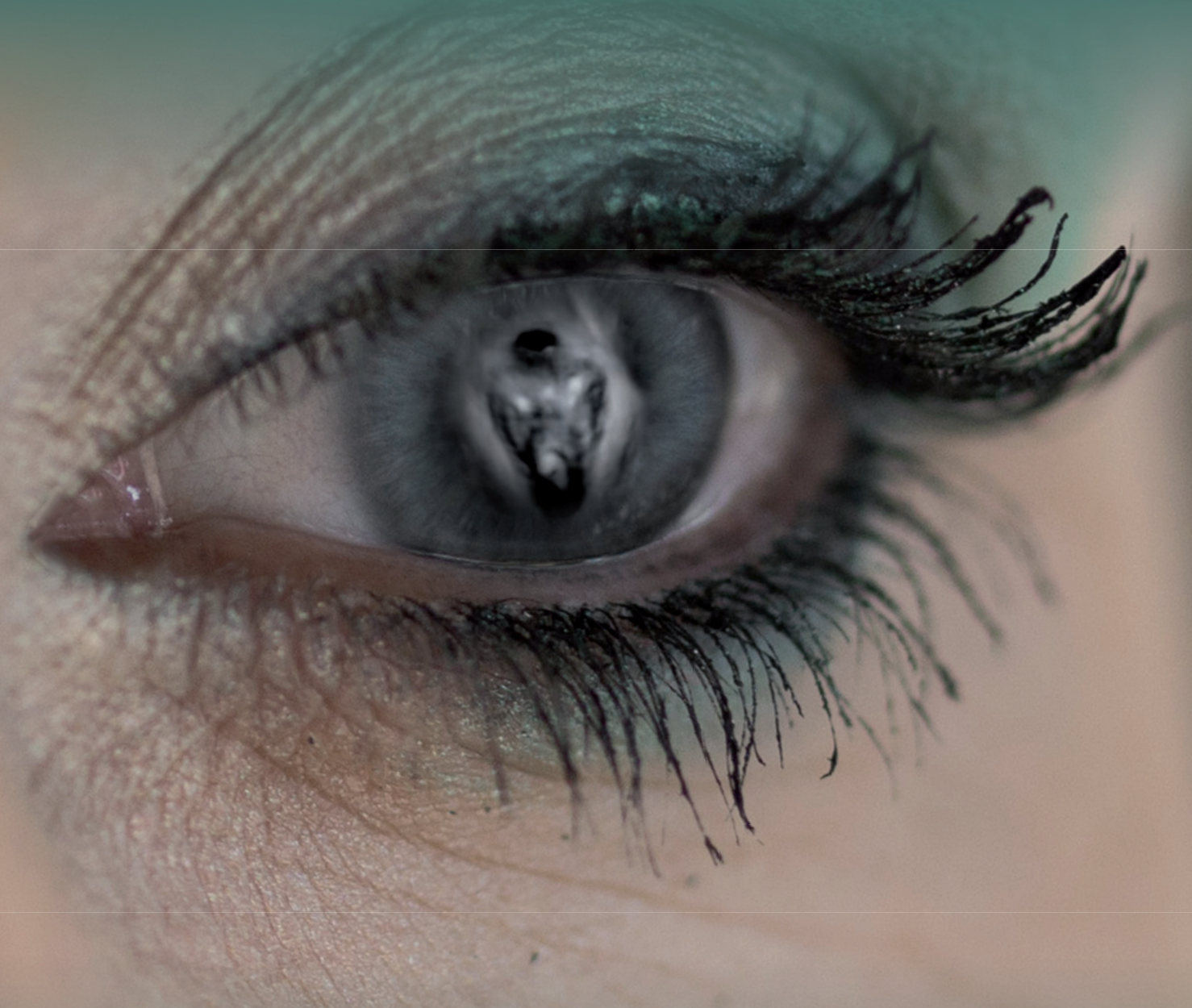




\section{GENERAL INTRODUCTION}

In 1943 Howard Gainey first described trauma to the levator ani muscle after childbirth, i.e. avulsion of the inferomedial aspects of the pubovisceral muscle of the arcus tendineus, which could be diagnosed with palpation. Gainey described an incidence of trauma to the levator ani muscle of approximately $20-30 \%$ in primiparous women. ${ }^{[1]}$ His publications then had in fact little, if any, impact.

It wasn't until approximately 60 years later that there have been descriptions of levator ani trauma again, visualized by magnetic resonance imaging (MRI). ${ }^{[2-5]}$ Although, no gold standard was available for detecting levator ani trauma, MRI was considered to be the best available reference standard because of its exquisite soft-tissue contrast, discriminatory capabilities and ability to define the different components of the levator ani muscle. ${ }^{[6,7]}$ However the lack of functional imaging capacity and the cost of MRI resulted in limited progress and the clinical implication of such trauma remained unclear.

Advances in translabial three-dimensional (3D) ultrasound to assess the pelvic floor, have led to the rediscovery of levator ani trauma. One of the latest developments in translabial 3D ultrasound, 'tomographic ultrasound imaging' or 'multi-slice imaging', allows a degree of quantification of levator ani trauma at limited costs. Because of these developments, translabial 3D ultrasound is nowadays increasingly used for diagnosing levator ani trauma. This method has practical advantages over MRI because it is less expensive, it is more accessible and it can provide 3D/4D assessment of the pelvic floor during routine clinical practice.

Since the rediscovery of levator ani trauma, this topic has become a focus of considerable research, especially in relation to pelvic organ prolapse (POP). POP is a common condition affecting more than half of the women above age $40 .{ }^{[8]}$ The complete etiology of POP is multifactorial and still not fully understood. ${ }^{\left[{ }^{[9]}\right.}$ Surgery is the treatment of choice for women with symptomatic POP if conservative treatments like pelvic floor muscle exercises and vaginal pessary therapy have failed. The estimated lifetime risk of needing surgical management for POP is $11 \% .{ }^{[10]}$ The anterior vaginal wall is the most commonly affected compartment in POP and is also the most prone for recurrence after surgery. ${ }^{[11,12]}$ Anterior colporrhaphy surgery, in which the woman's native tissue is used in the repair of an anterior vaginal wall prolapse has been the standard surgery technique. ${ }^{[13,14]}$ However, these operations are known to have a reoperation rate of up to $30 \%$ because of primary failure or secondary recurrence of signs and symptoms of POP. ${ }^{[10]}$ Because of this high re-operation rate, POP recurrence after pelvic floor surgery constitutes a major health care problem. In recent years, the use of synthetic mesh, to prevent anterior vaginal wall prolapse recurrences, has become increasingly popular. The use of mesh has proven to be anatomically effective; but there are concerns about the risk of 
complications such as exposure of the mesh or the occurrence of de novo dyspareunia. ${ }^{[15-18]}$ There now seems to be evidence which supports the idea that levator ani trauma is the missing link between childbirth and POP, as Margulies et al and Dietz et al reported odds ratios (OR) of respectively 6.6 and 5.7 for the presence of major levator trauma in women with POP. ${ }^{[19]}$ Levator ani trauma has been reported to occur in 13-36\% of women usually after the first vaginal delivery. ${ }^{[20]}$ Dietz et al found levator ani trauma using translabial 3D ultrasound, in $15.4 \%$ of parous women compared to $0 \%$ in non-parous women. ${ }^{[21]}$

Besides being associated with an increased risk of primary POP, levator ani muscle trauma also has been reported to lead to an increased risk of recurrence after POP surgery. ${ }^{[22,23]}$ Dietz et al investigated the association between levator ani trauma diagnosed with translabial 3D ultrasound and anterior vaginal wall recurrence after anterior colporrhaphy. They found a relative risk of recurrence in women with levator ani trauma of 2.9 195\% confidence interval (CI), 1.7- 4.5) compared to women without levator ani trauma. Weemhoff et al conducted a prospective observational cohort study in which complete defects of the levator ani muscle, diagnosed with translabial 3D ultrasound, were found to be a risk factor for anatomical recurrence with an $\mathrm{OR}$ of $2.4(95 \% \mathrm{Cl}, 1.3-4.7) .{ }^{[24.25]}$ These studies however performed translabial 3D ultrasound imaging after surgery, during the follow-up visit, instead of prior to surgery.

The only data evaluating the agreement between MRI and translabial 3D ultrasound in detecting levator ani defect showed a substantial agreement. ${ }^{[26]}$ Nevertheless, some hospitals incorporated translabial 3D ultrasound findings and claim that there is sufficient evidence to use ultrasound findings for treatment decisions while others have not yet incorporated translabial 3D ultrasound findings in their treatment decision, awaiting evidence showing that the patient benefits of such practice. This shows that the available literature is subject to different interpretation.

Before introducing translabial 3D ultrasound in daily practice, the diagnostic capacity of translabial 3D ultrasound has to be further evaluated. Furthermore it is expedient, to assess whether levator ani muscle trauma predicts anterior vaginal wall prolapse recurrence following anterior colporrhaphy.

This thesis describes a prospective multicenter cohort study performed in women with anterior vaginal wall prolapse, focusing on diagnosing levator ani defects and the clinical relevance of these defects in the etiology of POP recurrence. The primary goals of this study was to assess the diagnostic accuracy of translabial 3D ultrasound for diagnosing levator ani defects in women with POP compared to MRI as the reference standard, and to assess whether levator ani muscle trauma predicts anterior vaginal wall recurrence following anterior colporrhaphy. Secondary goal of this study include quantification of the interobserver agreement of levator ani defects. 


\section{REFERENCES}

1. Gainey HL. Post-partum observation of pelvic tissue damage. Am J Obstet Gynecol 1943; 46:457-66.

2. Kearney R, Miller JM, Ashton-Miller JA, DeLancey JO.Obstetric factors associated with levator ani muscle injury after vaginal birth. Obstet Gynecol 2006; 107: 144-149.

3. Kearney R, Miller JM, DeLancey JO. Interrater reliability and physical examination of the pubovisceral portion of the levator ani muscle, validity comparisons using MR imaging. Neurourol Urodyn 2006; 25 : 50-54.

4. Tunn R, DeLancey JO, Howard D, Thorp JM, Ashton-Miller JA, Quint LE. MR imaging of levator ani muscle recovery following vaginal delivery. Int Urogynecol J Pelvic Floor Dysfunct. 1999;10(5):300-7.

5. DeLancey JO, Kearney R, Chou Q, Speights S, Binno S. The appearance of levator ani muscle abnormalities in magnetic resonance images after vaginal delivery. Obstet Gynecol. 2003;101(1):46-53.

6. Strohbehn K, Ellis JH, Strohben JA, DeLaney JO. Magnetic resoncance imaging of the levator ani with anatomiccorrelation. Obstet Gynecol 1996: 87:277-55.

7. Chou Q, DeLancey JO. A structured system to evaluate urethral support anatomy in magnetic resonance imagines. Am J Obstet Gynecol 2001: 1851:44-50.

8. Slieker-ten Hove MC, Pool-Goudzwaard AL, Eijkemans MJ, Steegers-Theunissen RP, Burger CW, Vierhout ME: The prevalence of pelvic organ prolapse symptoms and signs and their relation with bladder and bowel disorders in a general female population. Int Urogynecol J Pelvic Floor Dysfunct 2009; 20:1037-1045

9. Schaffer JI, Wai CY, Boreham MK. Etiology of pelvic organ prolapse. Clin Obstet Gynecol 2005;48: 639-47.

10. Olsen AL, Smith VJ, Bergstrom JO, Colling JC, Clark AL: Epidemiology of surgically managed pelvic organ prolapse and urinary incontinence. Obstet Gynecol 1997; 89:501-506.

11. Miedel A, Tegerstedt G, Morlin B, Hammarstrom M: A 5-year prospective follow-up study of vaginal surgery for pelvic organ prolapse. Int Urogynecol J Pelvic Floor Dysfunct 2008; 19:1593-1601.

12. Miedel A, Tegerstedt G, Maehle-Schmidt M, Nyren O, Hammarstrom M: Symptoms and pelvic support defects in specific compartments. Obstet Gynecol 2008; 112:851-858.

13. Nichols DH, Randall CH. Vaginal Surgery, 4 edn. Philadelphia, PA: Lippincott Williams \& Wilkins, 1996.

14. Rock JA, Jones HW. Te Linde's Operative Gynecology, 9 edn. Philadelphia, PA: Lippincott Williams \& Wilkins, 2003.

15. Paraiso MF, Menefee S, Schaffer J, Varner E, Fitzgerald MP. Investigation of surgical procedures for pelvic organ prolapse, the mesh dilemma. J Minim Invasive Gynecol 2008; 15:521-2.

16. Tincello DG. The use of synthetic meshes in vaginal prolapse surgery. BJOG 2009;116:1-2.

17. Nguyen JN. The use of grafts for anterior vaginal prolapse repair: pros and cons. Curr Opin Obstet Gynecol 2008;20:501-5.

18. Butrick CW. Do guns kill people or...? The mesh dilemma. Int Urogynecol J Pelvic Floor Dysfunct 2010;21:133-4.

19. Margulies R, Huebner M, DeLancey J. Levator ani muscle defects: what origins and insertion points are affected? Int Urogynecol J 2006; 17 (S2): S118-S119. 
20. Schwertner-Triepelmann N, Thakar R, Sultan AH, Tunn R. Obstetric levator ani muscle injuries: current status. Ultrasound Obstet Gynecol 2012: 39:372-83.

21. Dietz HP, Steensma AB. The prevalence of major abnormalities of the evator ani in urogynaecological patients. Int urogynecol J 2010: 21(7): 861-7.

22. Model A.N, Shek K.L, Dietz H.P (2010) Levator defects are associated with prolapse after pelvic floor surgery. Eur J Obstet Gynecol Reprod Biol 2010:153 (2):220-3.

23. Wong V, Shek K, Rane A, Goh J, Krause H, Dietz H.P. Is levator avulsion a predictor of cystocele recurrence following anterior vaginal mesh placement? Ultrasound Obstet Gynecol 2013: 42 (2):230-4.

24. Dietz H.P, Chantarasorn V, Shek K.L. Levator avulsion is a risk factor for cystocele recurrence. Ultrasound Obstet Gynecol 2010:36 (1):76-80.

25. Weemhoff M, Vergeldt T.F, Notten K, Serroyen J, Kampschoer P.H, Roumen F.J. Avulsion of puborectalis muscle and other risk factors for cystocele recurrence: a 2-year follow-up study. Int Urogynecol J.2012: 23 (1):65-71.

26. Zhuang Rong R, Song Yang F, Chen Zi Q, et al. Levator avulsion using a tomographic ultrasound and magnetic resonance-based model. Am J Obstet Gynecol 2011; 205:232. 
DO PATIENTS PREFER MESH OR ANTERIOR COLPORRHAPHY FOR PRIMARY CORRECTION OF ANTERIOR VAGINAL WALL PROLAPSE: A LABELLED DISCRETE CHOICE EXPERIMENT

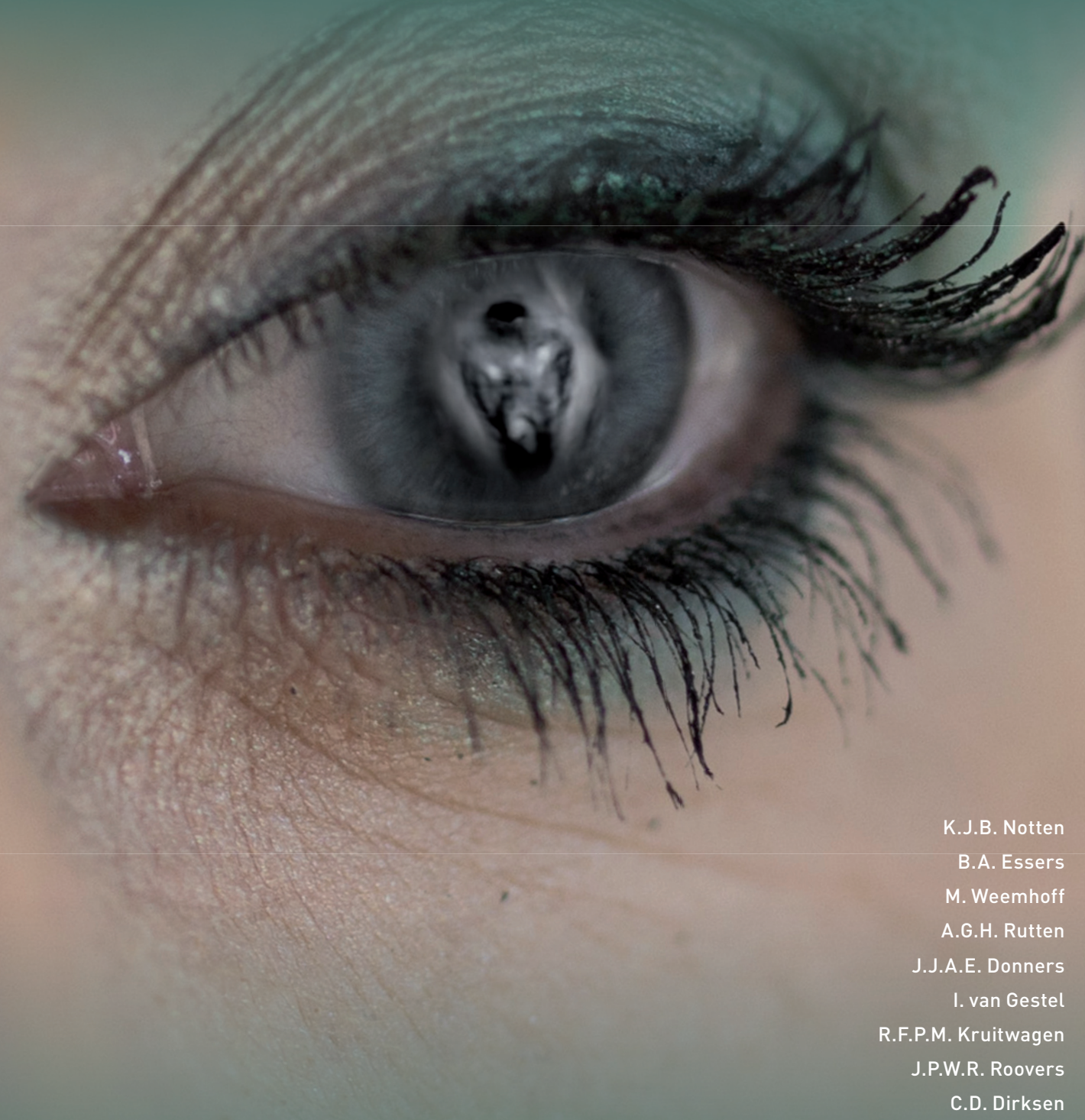




\section{ABSTRACT}

\section{Objective}

We investigated patients' preferences for anterior colporrhaphy or mesh surgery as surgical correction of anterior vaginal wall prolapse.

\section{Design}

Labelled discrete choice experiment.

\section{Setting}

Three Dutch teaching hospitals

\section{Population}

Women with anterior vaginal wall prolapse Pelvic Organ Prolapse Quantification stage 2 or more, indicated for anterior colporrhaphy $(n=100)$.

\section{Methods}

Discrete choice experiments are an attribute-based survey method for measuring preferences. In this experiment, women were asked to choose between two treatment scenarios, mesh surgery or anterior colporrhaphy. These surgical treatments differed in four treatment attributes: (i) recurrence rate, (ii) exposure rate, (iii) infection rate, (iv) dyspareunia. Data were analysed using a multinomial logit model.

\section{Main outcomes}

Women's preferences for anterior colporrhaphy or mesh surgery for the repair of vaginal wall prolapse.

\section{Results}

All treatment attributes, i.e. recurrence, exposure, infection and dyspareunia, proved to be significant in the woman's decision to choose for mesh surgery ( $p<0.001$ ), while only two attributes out of three, recurrence and infection, were significant for anterior colporrhaphy ( $p<0.001)$. The relative importance data showed that with regards to the four statistically significant attributes for mesh, dyspareunia was the most important attribute, and of the two significant attributes for anterior colporrhaphy, the risk of infection. Based on the attributes and levels in our discrete choice experiment, anterior colporrhaphy was preferred in $74 \%$ as a primary correction of anterior vaginal wall prolapse, followed by a preference for mesh in $26 \%$ of all choices. 


\section{Conclusion}

This study showed that next to the risk of recurrence, other aspects like risk of infection, dyspareunia and exposure play a role in the woman's preference for a surgical treatment. In addition, our results indicate that anterior colporrhaphy is preferred in the majority of the choices, followed by a preference for mesh surgery in a quarter of all choice sets. However, these results represent the average preference of a sample of women and cannot be taken as the preference of each individual.

In the medical decision-making context, information from the current study should be personalised to fit patient's unique circumstances. For patients to construct their own, individual preferences, they should be well informed about the existence and magnitude of the potential benefits and risks related to either anterior colporrhaphy or mesh surgery.

\section{Keywords}

Anterior colporrhaphy, anterior vaginal wall prolapse, discrete choice experiment, mesh related complications, mesh surgery, patients' preferences.

\section{INTRODUCTION}

Pelvic organ prolapse (POP) is a condition affecting more than half of the women above the age of forty. ${ }^{[1]}$ The first choice surgical treatment of anterior vaginal wall prolapse is anterior colporrhaphy, which is known to have a high re-operation rate of up to $30 \%$ because of recurrence. ${ }^{[2-4]}$

The introduction of vaginal polypropylene implants has decreased the recurrence rate, but the complication rate is higher compared to anterior colporrhaphy. ${ }^{[5]}$ For that reason, vaginal mesh surgery is mostly performed for recurrent POP surgery.

Specific complications related to mesh surgery are related to the host response against the foreign body and are expressed by healing problems (clinically expressed as exposure) or excessive scar tissue formation (clinically expressed as pelvic pain or dyspareunia). ${ }^{[6-10]}$ So, although the use of vaginal mesh reduces the risk on recurrent POP surgery, mesh-specific complications might negatively affect quality of life. Whether patients would accept mesh specific complications to benefit from a lower risk of recurrence, or if they prefer to accept a higher risk of recurrence in order to avoid mesh-related complications is not known yet. So far, patient perspectives regarding which type of prolapse surgery is offered, are under addressed. To investigate whether patients have a preference for either mesh or anterior colporrhaphy, and which attributes (various aspects of the surgery) are most important for this choice, we performed a discrete choice experiment (DCE). 


\section{METHODS}

A DCE was performed in three Dutch teaching hospitals. Women with at least a POPquantification stage 2 anterior vaginal wall prolapse who were scheduled for anterior colporrhaphy as a primary repair, with or without concomitant prolapse surgery, were asked to participate. POP was staged according to the POP-quantification staging system of the International Continence Society. ${ }^{[1]}$ Women undergoing concomitant stress incontinence surgery were excluded. After being informed about the study by their gynaecologist, women were contacted by telephone to limit the hospital visits because for a lot of people, time and transport to the hospital for research purposes would be a problem. A researcher explained the study background and objectives. Subsequently, a written information sheet was sent by post or e-mail and women were called to check for any questions about the study and their willingness to participate. When participation was confirmed, women were asked to complete the survey before the researchers' call. Subsequently, patient and researcher ran through every single question, any difficulties where immediately identified. Participants were given a case number so as to treat their data anonymously.

\section{Discrete choice experiment}

Discrete choice experiments are an attribute-based survey method for measuring preferences. ${ }^{[12]}$ They have long been used in transportation and marketing analysis but are also increasingly used for the evaluation of healthcare interventions and/or services. ${ }^{[13-15]}$ The underlying assumption of a DCE is that a treatment or intervention can be described by its attributes (for instance characteristics of a surgical treatment like complications or health benefits) and that the extent to which a woman values the treatment depends on the levels of the attributes. The levels are the different values of an attribute, obtained from literature, experts or patients. In our study, the levels are described as percentages and natural frequencies. For example, the attribute 'chance of recurrence' for anterior colporrhaphy has the values of $2 \%, 9 \%$ and $15 \%$ (i.e 2 out of 100,9 out of 100 and 15 out of 100 ).

Hypothetical scenarios are created in which different combinations of these levels and the attributes of the treatment are given. ${ }^{[16-18]}$ These scenarios can be presented as labelled (mesh versus anterior colporrhaphy) or unlabelled (surgery A versus B). Respondents are asked to choose between two (or more) hypothetical treatment scenarios. We used a labelled DCE because a specific aspect of mesh surgery, namely exposure, could not be realistically presented to patients using an unlabelled design. ${ }^{[19]}$ 


\section{Attributes and levels}

An initial selection of attributes was based on a literature study, focusing on mesh surgery and anterior colporrhaphy for the repair of a vaginal wall prolapse, expert interviews (three urogynaecologists) and two focus group interviews consisting of ten women each.

We performed a literature search through computerized databases including Medline (via Pubmed), Embase (via OvidSP), and the Cochrane library using both medical subject headings and text terms until 1 June 2010. We restricted the search to studies that were published in English.

For the structured literature search we used the keywords: (lanterior vaginal wall) OR (cystocele) OR (prolapse)) AND (lanterior colporrhaphy) OR (conventional surgery) OR (mesh)) AND complications). References that were cited in the selected studies were screened for other relevant publications. Abstracts were screened for eligibility. Full text was read in case the research reported on percentages of risk of recurrence and complications of either mesh surgery or anterior colporrhapy. The two focus groups each consisted of ten women who had undergone either an anterior colporrhapy surgery or mesh surgery, both with or without complications. The focus group was conducted by three trained researchers who acted as moderator, assistant moderator and assistant.

Before the focus groups a script with topics and questions was developed based on literature search and expert opinion. The moderator used this script to check whether all topics were discussed. Women who participated in the focus groups where asked to comment on, and complete the list of treatment attributes that were derived from the literature research. We also asked them if they missed any additional attributes that were considered to be relevant in choosing between the two surgical techniques that were not discussed in the focus groups. The interviews of both sessions where recorded. Data from the focus group was analysed using qualitative content analysis. ${ }^{[20]}$

Based on literature, experts and focus groups, 4 attributes were considered to be relevant, namely recurrence rate, exposure rate (only for mesh), infection rate, and dyspareunia.

The attribute 'levels' for both mesh surgery and anterior colporrhaphy surgery were obtained from literature. A range of probabilities per attribute were selected from literature and discussed with experts. Alternative specific levels were defined for recurrence rate, risk of exposure and dyspareunia for both mesh surgery or anterior colporrhapy and generic levels for infection risk (i.e. the same for mesh and anterior colporrhaphy), see Table 1. The selected alternative specific levels include values derived from literature, expert opinion and hypothetical values. The hypothetical values are levels that are not described in literature yet, but experts think might be achieved in the future. Hence, to extend the assessment of preferences beyond the currently available treatment options, we added for example a 
hypothetical recurrence rate of $2 \%$ for mesh surgery. The final list of attributes and their levels are illustrated in Table 1.

Table 1: Attributes and levels used in the discrete choice experiment.

\begin{tabular}{|c|c|c|c|}
\hline Attributes & $\begin{array}{c}\text { Mesh } \\
\text { Alternative- } \\
\text { specific level }\end{array}$ & $\begin{array}{l}\text { Anterior } \\
\text { colporrhaphy } \\
\text { Alternative- } \\
\text { specific level* }\end{array}$ & References \\
\hline $\begin{array}{l}\text { Risk of recurrence }[\%] \\
\text { After a successful prolapse surgery there is a } \\
\text { chance of recurrence of complaints. Depending } \\
\text { on the severity of symptoms a new treatment like } \\
\text { surgery or a pessary treatment can be considered. }\end{array}$ & $2, \quad 9, \quad 15$ & $15, \quad 25, \quad 32$ & {$[1,2,4,9,30]$} \\
\hline $\begin{array}{l}\text { Risk of exposure }[\%] \\
\text { The chance that the Mesh will expose through } \\
\text { the epithelium of the vagina. Exposure can cause } \\
\text { vaginal blood loss, vaginal fluor, bladder infections } \\
\text { and pain. Sometimes it is possible to treat this with } \\
\text { estrogen ointment, but in most cases a second } \\
\text { operation is needed to solve this problem. }\end{array}$ & $2, \quad 13, \quad 26$ & 0 & {$[6,9,10,25,31,32,35]$} \\
\hline $\begin{array}{l}\text { Risk of infection }(\%) \\
\text { The chance that an infection takes place. An infection } \\
\text { occurs when a bacteria or virus enters the body. } \\
\text { An infection can usually be treated with antibiotics. }\end{array}$ & $2, \quad 5, \quad 8$ & $2, \quad 5$ & [33] \\
\hline $\begin{array}{l}\text { Risk of dyspareunia }(\%) \\
\text { The chance of pain in the abdomen or } \\
\text { vagina which occurs during intercourse. }\end{array}$ & $2, \quad 17, \quad 38$ & $2, \quad 6, \quad 10$ & {$[9,31,33,34]$} \\
\hline
\end{tabular}

* The numbers represent the levels of each attribute expressed in percentages.

\section{Study design and survey}

The attributes were explained in the survey as described in Table 1. A fractional orthogonal labelled design, allowing for two-way interactions, was created using the software package Ngene (version 1.1). ${ }^{[21]}$ Thirty-six scenarios, i.e.18 choice sets were constructed. We blocked our 18 choice sets into two groups of nine labelled choice sets in which each set consisted of mesh surgery and anterior colporrhaphy (see Supporting information, Appendix S1:Questionnaire [example choice set]).

To test internal consistency, we added a final choice set (choice set 10), which was exactly the same as choice set 3 at the beginning of the survey. Internal consistency was evaluated 
by means of Cohen's Kappa. A kappa of <0.20 denotes poor agreement, 0.21-0.40 fair, 0.410.60 moderate, $0.61-0.80$ good and $0.81-1.00$ very good agreement. ${ }^{[22]}$

The survey started with an explanation of the study and a detailed written description of the attributes and levels of both surgical treatments. The main part of the survey comprised of nine labelled (i.e. mesh or anterior colporrhaphy) choice sets with one introductory example. In the choice set not only percentages of the levels were given, but also natural frequencies were described to have different presentations of the given information. The survey was pilot tested in five women for feasibility and understanding. None of the respondents reported any problems, after which the pilot version was converted to the final version.

Appendix S1: Questionnaire example choice set.

\begin{tabular}{|l|l|l|}
\hline $\begin{array}{l}\text { Characteristics } \\
\begin{array}{l}\text { The chance of recurrent } \\
\text { prolapse and/or complaints }\end{array}\end{array}$ & conventional surgery \\
\hline $\begin{array}{l}\text { The chance of the mesh device } \\
\text { gradually moving through } \\
\text { the vaginal wall (exposure) }\end{array}$ & 13 out of $100(13 \%)$ & 30 out of $100(30 \%)$ \\
\hline \begin{tabular}{l} 
The chance of infection \\
\hline $\begin{array}{l}\text { The chance of painful } \\
\text { intercourse (dyspareunia) }\end{array}$
\end{tabular} & 2 out of $100(2 \%)$ & not applicable \\
\hline
\end{tabular}

\section{Sample Size consideration}

Calculating the optimal sample size for estimating discrete choice models from DCE data is complicated as it depends on the true values of the unknown parameters estimated in the choice models. ${ }^{[17]}$ Nevertheless, the assumption is that, when blocking a design into different versions of a DCE questionnaire, one rarely requires more than 20 respondents per version to estimate reliable models. ${ }^{[17]}$ Since we blocked our design into two versions of the DCE questionnaire, each consisting of 10 choice-sets, a sample size of 100 respondents will be sufficient for a reliable statistical analysis. 


\section{Analyses}

The data were analysed using a multinomial logit model (Nlogit version 5). ${ }^{[23]}$ In this model, the specific utility function for mesh or anterior colporrhaphy can be described as:

$U$ (mesh) $=\beta_{0}+\beta_{1}$ chance of recurrence $+\beta_{2}$ chance of erosion $+\beta_{3}$ chance of infection $+\beta_{4}$ chance of dyspareunia $+\varepsilon$ mesh

U(anterior colporrhaphy $)=\beta_{5}$ chance of recurrence $+\beta_{3}$ chance of infection $+\beta_{6}$ chance of dyspareunia $+\varepsilon$ anterior colporrhapy

where $U$ is the utility that an individual derives from choosing either mesh or anterior colporrhapy; $\beta_{0}$ is an alternative specific constant reflecting patients' preference for the label mesh or anterior colporrhaphy; $\beta_{1}$ to $\beta_{6}$ are the attributes (regression coefficients) with their alternative specific values for mesh or anterior colporrhaphy except for chance of infection $\left(\beta_{3}\right)$ which has the same values for both treatments; and $\varepsilon$ is the unobserved or unexplained variance in preferences.

The sign of a coefficient reflects whether an attribute increases or decreases the utility (the expected benefit) of the respondents. A priori, we expected that respondents would consider all attributes to be important (so resulting in statistical significance of the attribute) and prefer a lower level of all attributes (i.e. a negative sign). No a priori assumption was formulated for the preferred alternative, i.e. mesh surgery or anterior colporrhaphy, as represented by the alternative specific constant being either statistically insignificant (i.e. label is not important) or significant (i.e. label is important).

Since the underlying scale of the attributes differs, it is not possible to directly compare the regression coefficients and their relative importance. Hence, part-worth utilities were calculated by multiplying the regression coefficient of each attribute with the range used for the attribute levels. Subsequently, the relative importance was determined for each attribute by dividing the part-worth utility of each attribute by the sum of all part-worth utilities of all the attributes included in the regression model. ${ }^{[2]}$ The relative importance provides insight into the weight of each attribute. Finally, based on the parameter estimates of the main effect model, a simulation was applied to test how changes in the attribute levels may impact the probability of choosing mesh or anterior colporrhaphy. ${ }^{[25]}$ To that end, we first estimated a scenario using the best levels for mesh and the worst levels for anterior colporrhaphy. A second scenario included the most realistic levels, i.e. values used in daily practice by experts for counselling, based on literature in combination with the opinion of two urogynaecologists experienced in prolapse surgery (Table 2). 
Table 2: Levels of mesh and anterior colporrhaphy for different scenarios.

\begin{tabular}{|c|c|c|}
\hline Attribute & $\begin{array}{l}\text { Best levels mesh, worst levels* } \\
\text { anterior colporrhaphy surgery } \\
\text { (scenario 1) }\end{array}$ & $\begin{array}{l}\text { Realistic levels** mesh, } \\
\text { anterior colporrhaphy } \\
\text { surgery based on literature } \\
\text { and expert opinion } \\
\text { (scenario 2) [reference] }\end{array}$ \\
\hline Recurrence mesh & 2 & $5 \quad[37]$ \\
\hline Exposure mesh & 2 & $10 \quad[7,27,28,29]$ \\
\hline Dyspareunia mesh & 2 & 35 [37] \\
\hline $\begin{array}{l}\text { Infection risk } \\
\text { Mesh } \\
\text { Anterior colporrhaphy }\end{array}$ & $\begin{array}{l}2 \\
8\end{array}$ & $\begin{array}{ll}5 & {[33]} \\
2 & \end{array}$ \\
\hline $\begin{array}{l}\text { Recurrence anterior } \\
\text { colporrhaphy surgery }\end{array}$ & 30 & $30 \quad[1,2]$ \\
\hline $\begin{array}{l}\text { Dyspareunia anterior } \\
\text { colporrhaphy surgery }\end{array}$ & 10 & $2[37,38]$ \\
\hline
\end{tabular}

* levels expressed in percentages, best levels and worst levels based on the range of levels used for the main effect model see Table 1.

** levels expressed in percentages, realistic levels are the levels which are used for counseling, 


\section{RESULTS}

\section{Respondents}

All women were recruited from July 2011 until November 2012, in three Dutch participating Hospitals. A total of 146 patients were asked to join the study, of which 100 (68\%) gave informed consent and completed the survey. The most common reasons for refusal were inability to complete the questionnaire on time before surgery, or no priority to participate in research. Baseline characteristics of the respondents are shown in Table S1: patient's baseline characteristics. The evaluation for the internal consistency of the choice sets, showed a kappa of 0.68 which indicates a good agreement.

Table S1: patient's baseline characteristics.

\begin{tabular}{|c|c|}
\hline Patient characteristics & Total Cohort $\mathrm{N}=100$ \\
\hline Median age in Years (range) $\mathrm{N}=100$ & $61(34-83)$ \\
\hline Median BMI (range) N=100 & $25.68(15-21)$ \\
\hline \multicolumn{2}{|l|}{ Marital status } \\
\hline Single $(\%) N=16$ & 16 \\
\hline Married/ relationship (\%) N=84 & 84 \\
\hline \multicolumn{2}{|l|}{ Education } \\
\hline Advanced vocational school or University (\%) N=14 & 14 \\
\hline Lower vocational school (\%) N=78 & 78 \\
\hline Primary education $(\%) \mathrm{N}=7$ & 7 \\
\hline Other $(\%) \mathrm{N}=1$ & 1 \\
\hline
\end{tabular}




\section{Results of main effects model}

The results of the main effects model are presented in Table 3. Respondents considered all four attributes of mesh surgery (recurrence, exposure, infection and dyspareunia) and two out of three attributes, i.e. recurrence and infection for anterior colporrhaphy to be important. All attributes had the expected negative sign meaning respondents preferred a lower level of recurrence, infection, erosion and dyspareunia. The alternative specific constant, which measures whether respondents show an underlying preference for the label mesh or anterior colporrhaphy apart from the defined attributes and levels, was not statistically significant.

\section{Results of the relative importance data}

The relative importance and the rank order of the different attributes are presented in Table 3. The order of the relative importance data show that in case of mesh surgery, dyspareunia was the most important attribute followed by exposure, recurrence and infection. For anterior colporrhaphy, the risk of infection was the most important attribute followed by the risk of recurrence.

Table 3: Results of the regression model.

\begin{tabular}{|c|c|c|c|c|c|}
\hline \multirow[t]{2}{*}{ Attributes } & \multicolumn{5}{|c|}{ Main effect model } \\
\hline & Coefficient & P-value & $95 \%$ C.I & $\begin{array}{c}\text { Relative } \\
\text { importance } \\
\text { mesh* }\end{array}$ & $\begin{array}{c}\text { Relative } \\
\text { importance } \\
\text { anterior } \\
\text { colporrhaphy* }\end{array}$ \\
\hline Constant & 0.01 & 0.77 & -0.62 to 0.84 & & \\
\hline Recurrence (mesh) & -0.06 & 0.0001 & -0.10 to -0.32 & $0,22(2)$ & \\
\hline Exposure (mesh) & -0.04 & 0.0000 & -0.06 to -0.19 & $0,22(2)$ & \\
\hline $\begin{array}{l}\text { Infection (mesh and } \\
\text { anterior colporrhaphy) }\end{array}$ & -0.09 & 0.0000 & -0.13 to -0.05 & 0,15 (3) & $0.58(1)$ \\
\hline Dyspareunia (mesh) & -0.04 & 0.0000 & -0.57 to -0.03 & $0,40(1)$ & \\
\hline $\begin{array}{l}\text { Recurrence } \\
\text { (anterior colporrhaphy) }\end{array}$ & -0.03 & 0.0442 & -0.05 to -0.01 & & 0.42 (2) \\
\hline $\begin{array}{l}\text { Dyspareunia } \\
\text { (anterior colporrhaphy) }\end{array}$ & 0.09 & 0.69 & -0.04 to 0.06 & & \\
\hline
\end{tabular}

* Relative importance data referring to the importance of each significant attribute for either mesh or anterior colporrhaphy, the numbers in parentheses refer to the order of importance meaning 1 is considered to be the most important attribute of all significant attributes followed by two and tree. 


\section{Results of different scenarios between mesh and anterior colporrhaphy}

Results in Table 4 show that in the base choice model the probability for choosing mesh was $26 \%$ compared with $74 \%$ choosing anterior colporrhaphy. In scenario 1 , by using the best attribute levels for mesh (2\% erosions, $2 \%$ infections, $2 \%$ dyspareunia and $2 \%$ recurrence) and the worst levels for anterior colporrhaphy $(8 \%$ infections, $10 \%$ dyspareunia, $30 \%$ recurrence), the probability of choosing mesh increased from 26 to $63 \%$. Using realistic levels in scenario 2 for both mesh $10 \%$ erosions, $5 \%$ infections, $35 \%$ dyspareunia and 5\% recurrence) and anterior colporrhaphy (2\% infections, $2 \%$ dyspareunia, $30 \%$ recurrence), the probability of choosing mesh decreases to $21 \%$.

Table 4: Simulation analysis for different scenarios.

\begin{tabular}{|c|c|c|c|c|c|c|}
\hline Choice & \multicolumn{2}{|c|}{ Main effect model } & \multicolumn{2}{|c|}{ Scenario 1} & \multicolumn{2}{|c|}{ Scenario 2} \\
\hline & & & $\begin{array}{r}\text { Best le } \\
\text { compared wi } \\
\text { anterior c }\end{array}$ & $\begin{array}{l}\text { Is mesh } \\
\text { worst levels } \\
\text { porrhaphy }\end{array}$ & $\begin{array}{r}\text { Realistic } \\
\text { compared } \\
\text { levels anteri }\end{array}$ & $\begin{array}{l}\text { vels mesh } \\
\text { ith realistic } \\
\text { colporrhaphy }\end{array}$ \\
\hline & $\begin{array}{c}\text { Percentage } \\
\text { share }\end{array}$ & $\begin{array}{c}\text { Number of } \\
\text { observations }\end{array}$ & $\begin{array}{c}\text { Percentage } \\
\text { share }\end{array}$ & $\begin{array}{c}\text { Number of } \\
\text { observations }\end{array}$ & $\begin{array}{c}\text { Percentage } \\
\text { Share }\end{array}$ & $\begin{array}{c}\text { Number of } \\
\text { observations }\end{array}$ \\
\hline Mesh & $26 \%$ & 238 & $63 \%$ & 564 & $21 \%$ & 184 \\
\hline $\begin{array}{l}\text { Anterior } \\
\text { colporrhaphy }\end{array}$ & $74 \%$ & 662 & $37 \%$ & 336 & $79 \%$ & 716 \\
\hline Total & $100 \%$ & 900 & $100 \%$ & 900 & $100 \%$ & 900 \\
\hline
\end{tabular}

\section{DISCUSSION}

\section{Main findings}

We studied whether women prefer vaginal mesh surgery or anterior colporrhaphy as primary surgical treatment of an anterior vaginal wall prolapse. Regarding mesh surgery, women valued all attributes, namely recurrence, exposure, infection and dyspareunia as important whereas for anterior colporrhaphy, only two out of three attributes, i.e. infection and recurrence, were considered to be important for their preference. Based on current knowledge about the magnitude of the mesh-specific and native tissue-specific benefits, women in this study showed, in $74 \%$ of the choices a preference for anterior colporrhaphy as primary surgical correction of anterior vaginal wall prolapse whereas in $26 \%$ of the choice sets also a preference for mesh surgery was expressed. 


\section{Strengths and limitations}

A few limitations need to be addressed about the methodology of our study. First, our design (forced labelled design) did not include an opt-out option, which means that respondents were not allowed to decline either treatment. However, our patients agreed to be operated on and in clinical practice the proportion of women that actually declines treatment is negligible. Furthermore, the choice experiment was limited to valuation of anterior colporrhaphy and mesh surgery only. There are more surgical options and for that reason our study may not provide information about preferences for the full range of surgical options. However, the included options cover more than $90 \%$ of the performed surgical procedures and for that reason the results of this study are applicable to current clinical practice.

One could criticize the preset cut-off values of the attributes. In literature, the reported values of these attributes vary a lot. Values of complications vary between studies and over time, as mesh materials and surgical techniques have continuously changed (and improved). Furthermore the complication rates have not consistently been registered during the last years. To deal with the variation in reported complication rates, we performed a comprehensive literature search in which we studied all mesh specific complications and their possible risk rates. We discussed the range of these complication rates with three experts in urogynaecology. Based on this discussion, we also added some hypothetical levels of the selected attributes to extend the assessment of preferences beyond the currently available treatment options meaning using levels which are not yet feasible. As a result, the levels of the complication rates, as mentioned in Table 1, include all relevant values.

We included patients who were indicated for prolapse surgery. We selected this setting because we considered it to be important that patients recognized the burden of having a prolapse. Although these women did not get any specific additional information about any surgery, they knew that they were not planned to undergo mesh surgery.

It could be that these patients were biased because of this information concerning not having mesh surgery. Therefore we planned to include a control group which consisted of 100 patients with anterior vaginall wall prolapse, but who were not indicated for surgery yet. Furthermore the patients of this control group were not informed about any surgery method. However, we decided to stop recruiting because of negative publicity concerning the meshes in the Dutch media during this inclusion period of the control group. The negative news contained information about complications like exposure and dyspareunia, which resulted in womens' aversion against mesh and therefore refusal to participate. The general opinion in the society became anti-mesh, regardless of the 
information that was given on the risk levels of the complications. The control group was no longer comparable to our study group and could not be used for this purpose. We therefore stopped recruiting women for the control group. However, concerning the possible bias, the results in our study population showed that there was no statistically significant underlying preference for the label anterior colporrhaphy as represented by the alternative specific constant. This indicates that they primarily made their choice based on the attributes and levels and not solely on the name, anterior colporrhapy or mesh. We therefore assume that bias among women in our setting is minimal.

\section{Interpretation}

To the best of our knowledge there are no other studies comparing patients' preferences for surgical treatments of anterior vaginal wall prolapse. The study from Hinoul et al. [26] investigated surgeons' preferences. They objectified which of six attributes, selected by an expert panel (gynaecologists), of an innovative surgical mesh procedure affect the surgeons willingness to perform a mesh procedure in the surgical treatment of POP. Of the attributes that were examined, surgeons considered the level of scientific evidence, as well as the risk of exposure the most important factors for their willingness to adopt a new surgical technique.

We noticed that the risk on dyspareunia was not confirmed as a statistically significant attribute with regard to anterior colporrhaphy whereas with regard to mesh surgery it was. A possible explanation might be that in comparison with mesh, women rate the risk of dyspareunia as less likely to occur and therefore less important when choosing anterior colporrhaphy.

If we use realistic scenarios, i.e. scenarios with recurrence and complication rates based on levels used in counselling by experts, the probability of choosing for mesh decreased from $26 \%$ in our base choice model to $21 \%$. However, if all attribute levels for mesh were at best (recurrence $2 \%$, exposure $2 \%$, dyspareunia $2 \%$ and infection $2 \%$ ) and those of the anterior colporrhaphy at worst (recurrence 30\%, infection $8 \%$ and dyspareunia $10 \%$ ) , the probability of preferring mesh increased from $26 \%$ to $63 \%$. This shows that developments in attribute levels potentially lead to changes in patients' preferences.

This is also illustrated when we calculate the utility score for either mesh or anterior colporrhaphy surgery by using the parameter estimates and levels of the attributes in the regression equation. If we use the best levels of the four attributes for mesh and for anterior colporrhaphy, mesh is preferred over anterior colporrhaphy. However, if for example the exposure rate increases from $2 \%$ to $6 \%$ and the three other significant attributes stay equal at the best levels, the patients' preference changes to anterior colporrhaphy surgery over mesh. 
Understanding which treatment attributes influence patients' preferences helps to optimize the selection of current treatment options. Our findings suggest that overall, women predominantly prefer anterior colporrhaphy, which is our standard approach of primary surgical correction of anterior vaginal wall prolapse. Our study made clear that in addition to the risk of recurrence, other factors play a role in patients' preference concerning mode of surgery. These factors should be taken into account, when counselling a individual patient about the available surgical options to correct an anterior vaginal wall prolapse.

\section{CONCLUSION}

Based on the attributes and levels in our discrete choice experiment, anterior colporrhaphy was preferred in $74 \%$ of the choices as a primary correction of anterior vaginal wall prolapse, followed by a preference for mesh in $26 \%$ of all choice sets. These results represent the average preference of a sample of women, based on balancing the risks of infection, dyspareunia and recurrence of both procedures and the risk of exposure of mesh surgery. As such, these results cannot be taken as the preference of each individual patient. In the medical decision-making context, information from the current study should be personalised to fit patient's unique circumstances. For patients to construct their own, individual preferences, they should be well informed about the existence and magnitude of these risks. 


\section{REFERENCES}

1. Slieker-ten Hove MC, Pool-Goudzwaard AL, Eijkemans MJ, Steegers-Theunissen RP, Burger CW, Vierhout ME: The prevalence of pelvic organ prolapse symptoms and signs and their relation with bladder and bowel disorders in a general female population. Int Urogynecol J Pelvic Floor Dysfunct 2009;20:1037-45.

2. Olsen AL, Smith VJ, Bergstrom JO, Colling JC, Clark AL: Epidemiology of surgically managed pelvic organ prolapse and urinary incontinence. Obstet Gynecol 1997; 89:501-506.

3. Clark AL, Gregory T, Smith VJ, Edwards R. Epidemiologic evaluation of reoperation for surgically treated pelvic organ prolapse and urinary incontinence. Am J Obstet Gynecol 2003; 189:1261-1267.

4. Nguyen JN, Burchette RJ. Outcome after anterior vaginal prolapse repair: a randomized controlled trial. Obstet Gynecol 2008; 111:891-898.

5. Sivaslioglu AA, Unlubilgin E, Dolen I. A randomized comparison of polypropylene Mesh surgery with site-specific surgery in the treatment of cystocele. Int Urogynecol J 2008; 19:467-471.

6. Iglesia CB, Sokol Al, Sokol ER, Kudish BI, Gutman RE, Peterson JL et al. Vaginal mesh for prolapse: a randomized controlled trial. Obstet Gynecol 2010; 116:293-303.

7. Abed H, Rahn DD, Lowenstein L, Balk EM, Clemons JL, Rogers RG et al. Incidence and management of graft erosion, wound granulation, and dyspareunia following vaginal prolapse repair with graft materials: a systematic review. Int Urogynecol J 2011; 22:789-798.

8. Nieminen K, Hiltunen R, Heiskanen E, Takala T, Niemi K, Merikari M et al. Symptom resolution and sexual function after anterior vaginal wall repair with or without polypropylene mesh. Int Urogynecol J 2008; 19:1611- 1616.

9. Bako A, Dhar R. Review of synthetic mesh-related complications in pelvic floor reconstructive surgery. Int Urogynecol J 2009; 20:103-111.

10. Ridder de D. Should we use meshes in the management of vaginal prolapse. Curr Opin Urol 2008; 18:377-382.

11. Bump RC, Mattiasson A, Bø K, Brubaker LP, DeLancey JO, Klarskov P et al. The standardization of terminology of female pelvic organ prolapse and pelvic floor dysfunction. Am J Obstet Gynecol 1996; 175:10-17.

12. Amaya-amaya M, Gerard K, Ryan M. Using Discrete choice experiments to value health and health care. Springer, 2008

13. Fiddelers AA, Niemann FH, Dumoulin JC, van Montfoort AP, Land JA, Evers JL et al. During IVF treatment patient preference shifts from singletons towards twins but only a few patient's show an actual reversal of preference. Hum Reprod 2011; 26(8):2092-100.

14. Essers BA, Dirsen CD, Prins MH, Neymann HA. Assessing the public's preference for surgical treatment of primary basal cell carcinoma: a discrete-choice experiment in the south of the Netherlands. Dermatol Surg 2010; 36(12):1950-5.

15. Bekker de - Grob EW, Ryan M, Gerard K. Discrete choice experiments in health economics: a review of the literature. Health Econ 2012; 21: 145-172.

16. Ryan M. Discrete choice experiments in Healthcare. BMJ 2004; 328::360-361.

17. Lancser E, Louviere J. Conducting Discrete Choice Experiments to Inform Healthcare Decision Making. Pharmacoeconomics 2008; 26:661-667.

18. Louvierre JJ, Hensher DA, Swart JD. Stated choice methods: Analysis and application. Cambridge: Cambridge University Press, 2000. 
19. Kruijshaar ME, Essink-Bot ML, Donkers B, Looman CW, Siersema PD, Steyerberg EW. A labeled discrete choice experiment ads realisms to the choices presented: preferences for surveillance tests for Barrets esophagus. BMC Med Res Methodol 2009; 9:31.

20. Bowling A. Unstructured Interviewing and Focus Groups. Research Methods in Health.Investigating Health and Health Services. Buckingham: Open University Press, 1997.

21. http://www.choice-metrics.com. Accessed 26 May 2014

22. Lantz CA, Nebenzahl. Behavior and interpretation of the kappa statistic: resolution of the two paradoxes. J Clin Epidemiol. 1996; 49: 431-4

23 http://www.limdep.com/products/nlogit. Accessed 26 May 2014

24. Malhotra NK, Birks DF. Marketing Research: an applied approach. New Jersey: Pearson EducationLimited, Prentice Hall, 2006.

25. Hensher DA, Rose JM, Greene WH. Applied Choice Analysis: A primer. Cambridge: Cambridge University Press, 2005.

26. Hinoul P, Goossens A, Roovers JP. Factors determining the adoption of innovative needle suspension techniques with mesh to treat urogenital prolapse: a conjoint analysis study. Eur J obstet Gynecol Reprod Biol 2010; 151:212-21.

27. Altman D, Väyrynen T, Engh ME, Axelsen S, Falconer C. Anterior colporrhaphy versus transvaginal mesh for pelvic-organ prolapse. N Engl J Med 2011; 364:1826-1836.

28. Maher C, Feiner B, Glazener CMA. Surgical management of pelvic organ prolapse in women. Cochrane Database of Syst Rev2010, (4): CD004014.

29. Nieminen K, Hiltunen R, Takala T, Heiskanen E, Merikari M, Niemi K et al.Outcomes after anterior vaginal wall repair with mesh: a randomized, controlled trial with a 3 year follow-up. Am J Obstet Gynecol 2010;203(235):e1-e8.

30. Diez-Itza I, Aizpitarte I, Becerro A: Risk factors for the recurrence of pelvic organ prolapse after vaginal surgery: a review at 5 years after surgery. Int Urogynecol J Pelvic Floor Dysfunct 2007;18:1317-1324.

31. Rardin CR, Washington BB. New Considerations in the Use of Vaginal Mesh for Prolapse Repair. J Minim Invasive Gynecol 2009;16:360-364.

32. Nugyen JN. The use of grafts for anterior vaginal prolapse repair: pros and cons. Am J Obstet Gynecol 2008;20:501-505.

33. Falagas ME, Velakoulis S, lavazzo C, Athanasiou S. Mesh-related infections after pelvic organ prolapse repair surgery. Eur J Obstet Gynecol Reprod Biol 2007;134:147-156.

34. Milani R, Salvatore S, Soligo M, Pifarotti P, Meschia M, Cortese M. Functional and anatomical outcome of anterior and posterior vaginal prolapse repair with prolene mesh. BJOG 2005;112:107-111.

35. Hiltunen R, Nieminen K, Takala T, Heiskanen E, Merikari M, Niemi K et al. Low-weight polypropylene mesh for anterior vaginal wall prolapse: a randomized controlled trial. Obstet Gynecol. 2007;110:455.

36. Tayrac de R, Cornille A, Englin G, Gilboud O, Mansoor A, Alonso S et al. Comparison between transobturator trans-vaginal mesh and traditional Anterior colporrhaphy in the treatment of anterior vaginal wall prolapse: results of a French RCT. Int Urogynecol J 2013;24:1651-61.

37. Vollebregt A, Fischer K, Gietelink D, Vaart van der $\mathrm{CH}$. Primary surgical repair of anterior vaginal prolapse: a randomised trial comparing anatomical and functional outcome between Anterior colporrhaphy and trocar-guided transobturator anterior mesh. BJOG 2011;118:1518-27.

38. Vollebregt A, Fischer K, Gietelink D, Vaart van der $\mathrm{CH}$. Effects of vaginal prolapse surgery on sexuality in women and men; results from a RCT on repair with and without mesh. J Sex Med 2012;9:1200-11. 


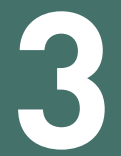

DETECTING LEVATOR ANI DEFECTS AND MEASURING LEVATOR BIOMETRY USING TRANSLABIAL 3D ULTRASOUND: A SYSTEMATIC REVIEW

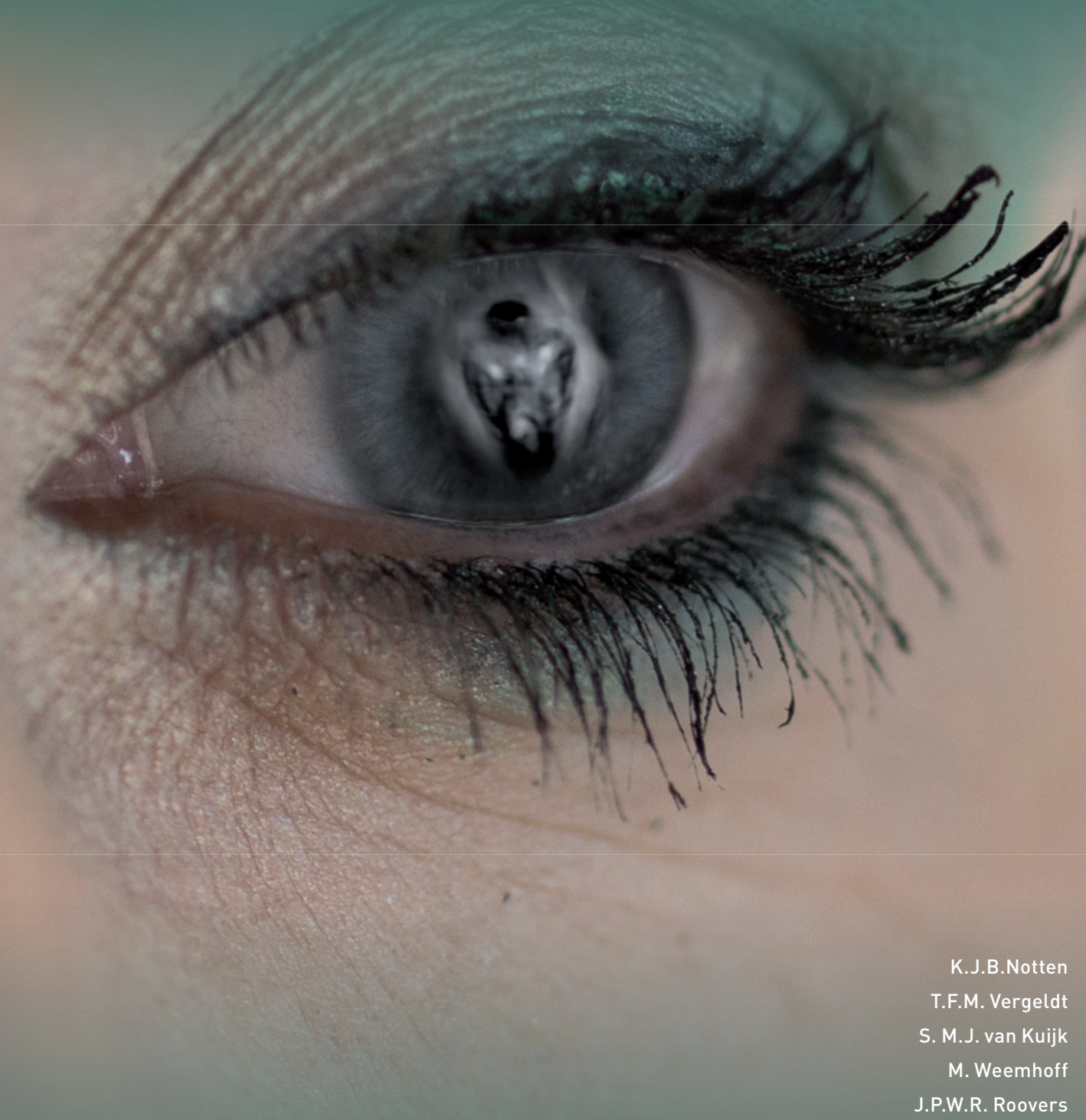




\section{ABSTRACT}

\section{Objectives}

To review the diagnostic performance and clinical implications of translabial 3D ultrasound for the assessment of levator ani defects and biometry in women with pelvic organ prolapse.

\section{Search Strategy}

An electronic literature search through computerized databases including Medline lvia Pubmed), Embase (via OvidSP), and the Cochrane Library.

\section{Selection criteria}

Articles that reported on women with pelvic organ prolapse, diagnostic accuracy of translabial 3D ultrasound for the detection of levator ani defects or for pelvic floor biometry, or clinical relevance of levator ani defects in women with pelvic organ prolapse, were included.

\section{Data Collection}

The Preferred Reporting Items for Systematic Reviews and Meta-Analyses (PRISMA) guidelines to report on diagnostic accuracy were followed. In the absence of a validated checklist, study quality was assessed based on a defined set of domains.

\section{Main Results}

We included 27 articles. Detecting levator ani defects on translabial 3D ultrasound compared to MRI showed a kappa of 0.86 (95\% confidence interval (CI), 0.75-0.96), whereas measuring hiatal biometry on translabial 3D ultrasound compared to MRI showed an ICC between 0.80 and 0.97. Subsequently, diagnosing levator ani defects with translabial 3D ultrasound in six studies, showed a range in kappa's of 0.57 to 0.89 and for measuring the levator hiatal area in eight studies a range in ICC's of 0.56-0.98 was found. Furthermore, five studies showed that levator ani defects increases the risk of cystocele and uterine prolapse. Four studies showed an association between levator ani defects and recurrent pelvic organ prolapse. Finally eight studies showed that a larger hiatus was associated with pelvic organ prolapse. No evidence was found for an association between a larger hiatus and recurrent POP after pelvic floor surgery. 


\section{Conclusion}

Translabial 3D ultrasound is reproducible for diagnosing levator ani defects and ballooning hiatus. Both levator ani defects and larger hiatal biometry increases the risk of cystocele and uterine prolapse. There is also an association between levator ani defects and recurrent pelvic organ prolapse after surgery.

\section{Keywords}

Review, pelvic organ prolapse, levator defects, hiatal area, translabial ultrasound

\section{INTRODUCTION}

Pelvic organ prolapse (POP) is a bothersome condition that occurs $40 \%$ of adult women. ${ }^{[1,2,3]}$ The lifetime risk to undergo surgery is $11 \%$ and due to the high recurrence risk, about $30 \%$ of all procedures is performed for recurrent POP. ${ }^{[4]}$ To optimize treatment selection and counseling it is important to identify patients with increased risk on recurrence. One of the factors that has been related to recurrent POP is trauma of the levator ani muscle. Such trauma is a complication of vaginal delivery and generally seems to manifest as a partial or complete detachment of the levator ani from the inferior ramus of the symphysis. ${ }^{[5]}$ Magnetic resonance imaging (MRI) has been shown to visualize levator ani defects effectively, but since some years translabial three- and four-dimensional (3D/4D) ultrasound can provide information on biometrical properties of the pelvic floor and morphology of the levator ani muscle reliably. ${ }^{[6]}$

Ultrasound imaging currently plays a limited role in the diagnostic work-up of POP or post-treatment follow-up. Most hospitals have not yet incorporated translabial ultrasound findings in their treatment decision awaiting evidence showing that the patient benefits of such practice. Others claim that there is sufficient evidence to base treatment decisions on ultrasound findings, suggesting that the available literature is subject to different interpretation. In this review we aim to provide an overview of peerreviewed studies on the use of translabial 3D ultrasound for the diagnosis of levator ani defects and measuring the levator ani biometry. 


\section{The following key questions were answered:}

1a. How is the diagnostic performance of translabial 3D ultrasound for diagnosing levator ani defects?

1b. Is diagnosing levator ani defects with translabial 3D ultrasound reproducible?

1c. Are levator ani defects, diagnosed with translabial 3D ultrasound, associated with primary POP?

$1 \mathrm{~d}$. Is it possible to predict the success rate of POP surgery based on the presence of a levator ani defect on translabial 3D ultrasound?

2a. How is the diagnostic performance of translabial 3D ultrasound for measuring levator ani biometry?

2b. Is measuring levator ani biometry with translabial 3D ultrasound reproducible?

2c. Is a ballooning hiatus, diagnosed with translabial 3D ultrasound, associated with primary POP?

$2 \mathrm{~d}$. Is it possible to predict the success rate of POP surgery based on the presence of a ballooning hiatus measured with $3 \mathrm{D}$ translabial ultrasound?

\section{METHODS}

\section{Selection of studies}

We selected original studies evaluating the diagnostic accuracy of translabial 3D ultrasound for the detection of levator ani defects and studies which evaluated pelvic floor biometry in women. Peer-reviewed articles that evaluated diagnostic accuracy and/or inter- and intrarater agreement of translabial 3D ultrasound were considered eligible for this review.

\section{Information sources and search strategy}

We performed a systematic literature search through computerized databases including Medline (via Pubmed), Embase (via OvidSP), and the Cochrane Library using both medical subject headings (MeSH) and text terms from January the $1^{\text {st }} 2003$ to June the $1^{\text {st }} 2014$. We restricted the search to studies that were published in English. The structured search was designed to be sensitive and can be reproduced using the following keywords and logical operators: (lpelvic floor) OR (levator ani) OR (pubovisceral) OR (pelvic organ) OR (prolapse)) AND ((sensitivity and specificity) OR (sensitivity) OR (specificity) OR (diagnostic accuracy) OR (intraclass correlation coefficient) OR (bland-altman) OR (kappa) OR (therapy) OR (prognosis)) AND ((ultrasonography) OR (ultrasound) OR (translabial) OR (transperineal)). 


\section{Study selection}

Two authors ( $\mathrm{KN}$ and SvK) independently assessed the title and abstract of each of the studies for eligibility. In case of disa1al 3D ultrasound for the detection of levator ani defect or for measuring pelvic floor biometry i.e. levator ani hiatus, or reported on the clinical relevance of using translabial 3D ultrasound for levator ani defects in women with POP. We evaluated the full articles to describe the number of patients in the study, the inclusion criteria, the study design, patient characteristics (i.e. age and body mass index (BMI)) and outcome measures that were reported.

\section{Quality assessment}

The present study was undertaken in accordance with parts of the Preferred Reporting Items for Systematic Reviews and Meta-Analyses (PRISMA) guidelines that can be applied to studies of diagnostic accuracy. ${ }^{[7]}$

However, in the absence of a validated checklist specifically designed to determine the quality of diagnostic performance studies to be included in meta-analyses, we assessed study quality on expert opinion guided by a list of domains we deemed crucial. All domains were assessed qualitatively. We included items on the article's study population, prevention of selection bias, test reader blinding, reproducibility of study methods, statistical analysis, and presentation of the main results. No studies were excluded based on quality assessment.

\section{RESULTS}

\section{Study selection}

The results of the search related to levator ani defects are shown in Figure 1. The computerised Pubmed, Embase and Cochrane Library search identified 1042 publications. After reading all abstracts, we selected 17 relevant articles. After reading the full texts, 4 of these articles were excluded because they did not answer the research questions. No additional studies were identified by crosschecking reference lists. The remaining 13 included articles reported on 4265 women (range 69-764). Of the 13 articles included, 5 were prospective observational studies ${ }^{\left[{ }^{8-12]}\right.}, 2$ were cross sectional studies ${ }^{[13,14]}$, and 6 were retrospective observational studies. ${ }^{[6,15-19]}$ Overall, the quality of the included studies was assessed as adequate: all studies clearly defined the study population; the methods were clearly described and reproducible; the methods used for the analyses were correct; the main results were well presented and yielded answers to the study aims; timeframes of 
recruiting were not mentioned in 3 studies ${ }^{[8,14,15]}$; the test readers were not blinded to other test results and patients complaints in 2 studies $^{[15,16]}$; in 10 studies it was unclear if selection bias was prevented. $[6,10,12-19]$

Figure 1: Flowchart inclusion articles about levator ani defects

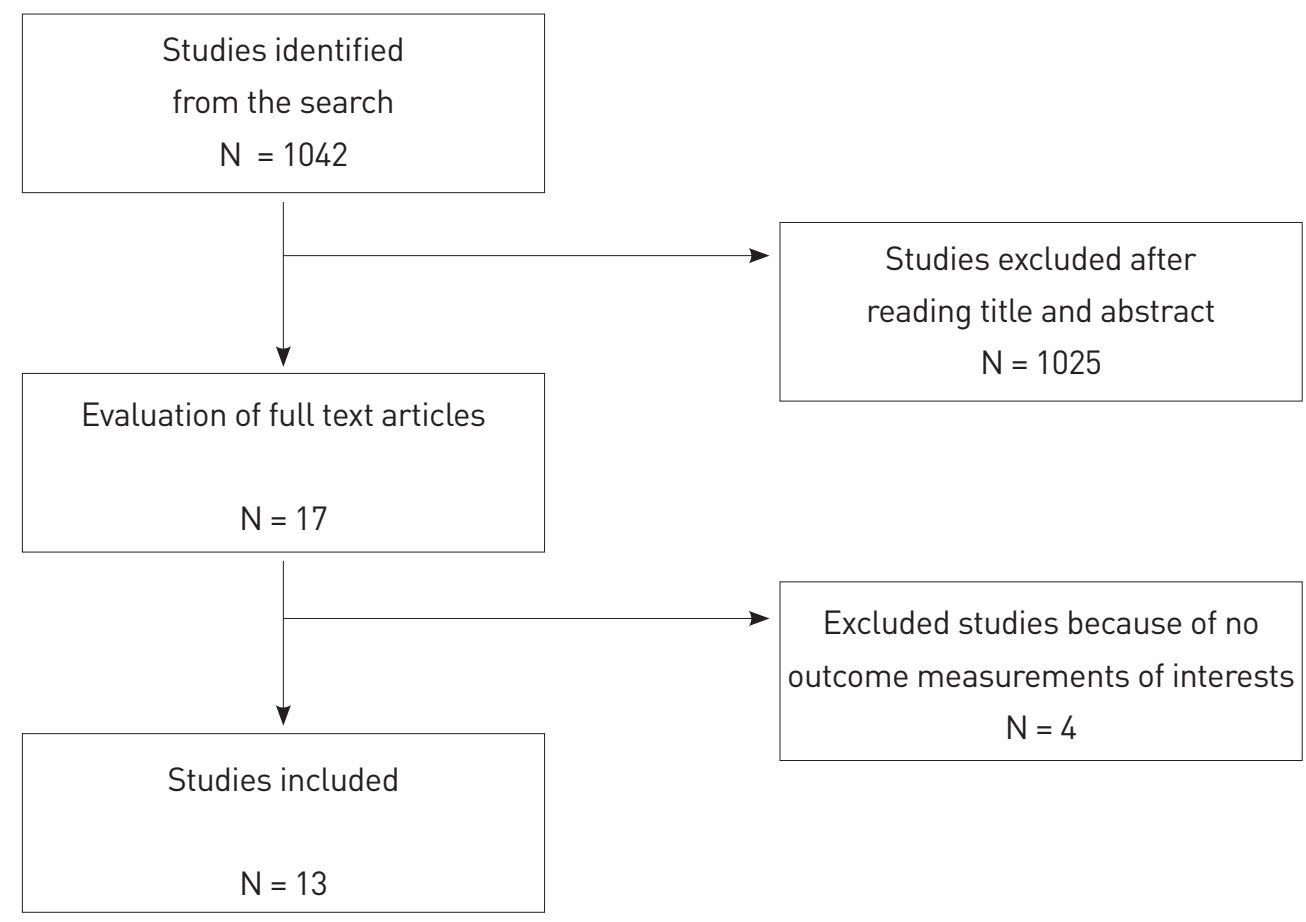

The results related to measuring hiatal biometry are shown in Figure 2. The computerised Pubmed, Embase and Cochrane Library search identified 1042 publications. After reading all abstracts, we selected 20 relevant articles. After reading the full texts, 7 of these articles were excluded because they did not answer the research questions. One additional study was identified by crosschecking reference lists. The 14 articles that were included reported on 2856 women (range 17-605). Of the 14 studies included, 1 was a prospective observational study ${ }^{[20]}, 9$ were cross sectional studies ${ }^{[13,21-28]}$, and 4 were retrospective observational studies. ${ }^{[17,29-31]}$ Overall, the quality of the included studies was assessed as adequate: all studies clearly defined the study population; the methods were clearly described and reproducible; the methods used for the analyses were correct; the main results were well presented and yielded answers to the study aims; timeframes of recruiting were not 
mentioned in 5 studies ${ }^{[5,21,22,24,29]}$; the test readers were not blinded to other test results and patients complaints in 2 studies ${ }^{[28,31]}$; in 10 studies it was unclear if selection bias was prevented. ${ }^{[5,13,17,24,25,27-31]}$

\section{Study characteristics}

Details of the studies are summarised in Table 1 and Table 2. All studies summarized in Table 1 report on detection of levator ani defects using translabial 3D ultrasound. All studies summarized in Table 2 report on ballooning hiatus diagnosed with translabial 3D ultrasound.

Figure 2: Flowchart inclusion articles about hiatal measurements

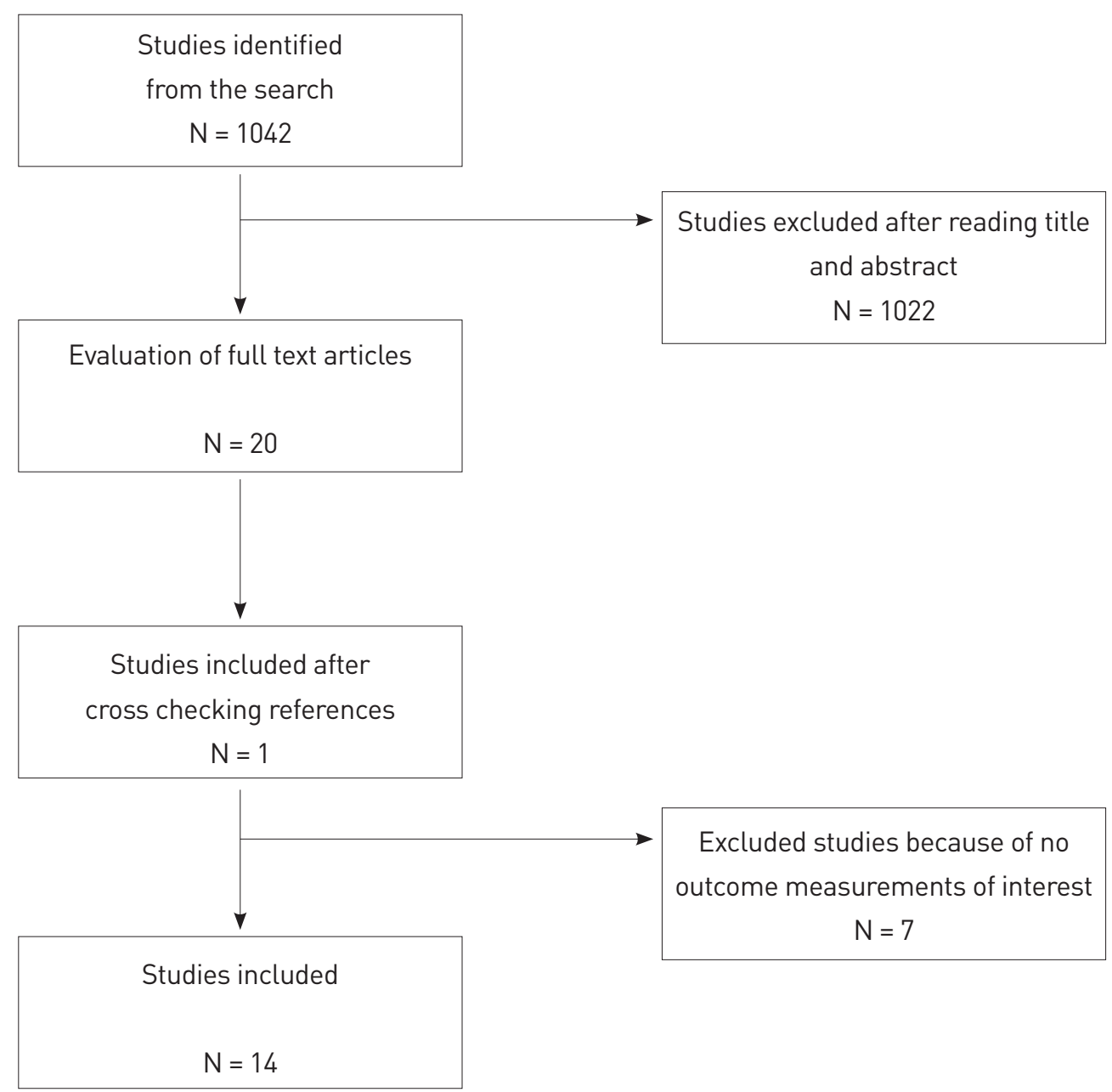


Table 1: Included studies on levator ani defect.

\begin{tabular}{|c|c|c|c|c|}
\hline Article & $\mathbf{N}$ & Inclusion criteria & Study design & Outcome measure(s) \\
\hline Dietz et al $(2006)^{8}$ & 333 & $\begin{array}{c}\text { Women referred for urodynamic } \\
\text { assessment with complaints } \\
\text { of pelvic floor and/or bladder } \\
\text { dysfunctions }\end{array}$ & $\begin{array}{l}\text { Prospective } \\
\text { observational } \\
\text { study }\end{array}$ & $\begin{array}{l}\text { Levator ani defects in } \\
\text { relation to POP }\end{array}$ \\
\hline Dietz et al (2007) ${ }^{9}$ & 262 & $\begin{array}{l}\text { Women presenting with } \\
\text { symptoms of lower urinary } \\
\text { tract and pelvic floor } \\
\text { dysfunction }\end{array}$ & $\begin{array}{l}\text { Prospective } \\
\text { observational } \\
\text { study }\end{array}$ & $\begin{array}{l}\text { Levator ani defects in } \\
\text { relation to POP }\end{array}$ \\
\hline Dietz et al (2010) ${ }^{10}$ & 83 & $\begin{array}{l}\text { Women who underwent } \\
\text { anterior colporrhaphy } \\
\text { procedure without mesh } \\
\text { augmentation }\end{array}$ & $\begin{array}{l}\text { Prospective } \\
\text { observational } \\
\text { study }\end{array}$ & $\begin{array}{l}\text { Levator ani defects } \\
\text { in relation to POP } \\
\text { recurrence }\end{array}$ \\
\hline Weemhoff et al (2011) ${ }^{11}$ & 156 & $\begin{array}{l}\text { Women undergoing anterior } \\
\text { colporrhaphy }\end{array}$ & $\begin{array}{l}\text { Prospective } \\
\text { observational } \\
\text { study }\end{array}$ & $\begin{array}{l}\text { Levator ani defects } \\
\text { and other risk factors } \\
\text { in relation to POP } \\
\text { recurrence }\end{array}$ \\
\hline Zhuang et al (2011) ${ }^{12}$ & 69 & $\begin{array}{l}\text { Women who were to undergo } \\
\text { surgery for POP repair }\end{array}$ & $\begin{array}{l}\text { Prospective } \\
\text { observational } \\
\text { study }\end{array}$ & $\begin{array}{l}\text { Interobserver } \\
\text { repeatability between } \\
\text { translabial 3D ultrasound } \\
\text { and MR imaging in the } \\
\text { assessment of levator } \\
\text { ani defects }\end{array}$ \\
\hline Volloyhaug et al (2012) ${ }^{13}$ & 295 & $\begin{array}{l}\text { Women presenting with } \\
\text { symptoms of lower urinary } \\
\text { tract and pelvic floor } \\
\text { dysfunction }\end{array}$ & $\begin{array}{l}\text { Cross sectional } \\
\text { study }\end{array}$ & $\begin{array}{l}\text { Levator ani defects } \\
\text { in relation to } \\
\text { measurements of the } \\
\text { genital hiatus and the } \\
\text { perineal body }\end{array}$ \\
\hline Kruger et al (2013) ${ }^{14}$ & 72 & $\begin{array}{c}\text { Women over } 60 \text { years, urinary } \\
\text { incontinence, and pelvic floor } \\
\text { dysfunction, attended or going } \\
\text { to attend physiotherapy for } \\
\text { treatment }\end{array}$ & $\begin{array}{l}\text { Cross sectional } \\
\text { study }\end{array}$ & $\begin{array}{l}\text { Levator ani defects on } \\
\text { ultrasound in relation } \\
\text { to digital assessment } \\
\text { parameters to detect } \\
\text { levator ani defects }\end{array}$ \\
\hline Abdool et al $(2009)^{15}$ & 414 & $\begin{array}{l}\text { Women presenting with } \\
\text { symptoms of lower urinary } \\
\text { tract and pelvic floor } \\
\text { dysfunction }\end{array}$ & $\begin{array}{l}\text { Retrospective } \\
\text { observational } \\
\text { study }\end{array}$ & $\begin{array}{l}\text { Levator ani defects } \\
\text { in relation to POP } \\
\text { recurrence }\end{array}$ \\
\hline Model et al $(2010)^{16}$ & 737 & $\begin{array}{l}\text { Women who had presented } \\
\text { for the investigation pelvic } \\
\text { organ prolapse and lower } \\
\text { urinary tract dysfunction }\end{array}$ & $\begin{array}{l}\text { Retrospective } \\
\text { observational } \\
\text { study }\end{array}$ & $\begin{array}{l}\text { Levator ani defects } \\
\text { in relation to POP } \\
\text { recurrence }\end{array}$ \\
\hline Dietz et al (2011) ${ }^{16}$ & 764 & $\begin{array}{l}\text { Women with symptoms of } \\
\text { lower urinary tract and pelvic } \\
\text { floor dysfunctions }\end{array}$ & $\begin{array}{l}\text { Retrospective } \\
\text { observational } \\
\text { study }\end{array}$ & $\begin{array}{l}\text { Levator ani defects in } \\
\text { relation to POP }\end{array}$ \\
\hline
\end{tabular}


Table 1: Included studies on levator ani defect.

\begin{tabular}{|c|c|c|c|c|}
\hline Article & $\mathbf{N}$ & Inclusion criteria & Study design & Outcome measure(s) \\
\hline Dietz et al (2012) ${ }^{17}$ & 605 & Women presenting with POP & $\begin{array}{l}\text { Retrospective } \\
\text { observational } \\
\text { study }\end{array}$ & $\begin{array}{l}\text { Levator ani defects and } \\
\text { biometry of the levator } \\
\text { hiatus in relation to POP }\end{array}$ \\
\hline Dietz et al (2012) ${ }^{18}$ & 266 & $\begin{array}{l}\text { Women presented for } \\
\text { urodynamic testing and pelvic } \\
\text { floor dysfunction }\end{array}$ & $\begin{array}{l}\text { Retrospective } \\
\text { observational } \\
\text { study }\end{array}$ & $\begin{array}{l}\text { Diagnosing levator ani } \\
\text { defects with digital } \\
\text { palpation and two } \\
\text { ultrasound methods }\end{array}$ \\
\hline Wong et al (2013) ${ }^{19}$ & 209 & $\begin{array}{l}\text { Women who previously } \\
\text { received anterior } \\
\text { transobturator mesh } \\
\text { procedure }\end{array}$ & $\begin{array}{l}\text { Retrospective } \\
\text { observational } \\
\text { study }\end{array}$ & $\begin{array}{l}\text { Levator ani defects } \\
\text { in relation to POP } \\
\text { recurrence }\end{array}$ \\
\hline
\end{tabular}

$\mathrm{N}=$ number of patients

$\mathrm{POP}=$ pelvic organ prolapse

$3 \mathrm{D}=$ three-dimensional

$\mathrm{MR}=$ magnetic resonance

Table 2: Included studies on measuring levator ani biometry.

\begin{tabular}{|c|c|c|c|c|}
\hline Article & $\mathbf{N}$ & Inclusion criteria & Study design & Outcome measure[s] \\
\hline Dietz et al (2005) 20 & 52 & Nulliparous women & $\begin{array}{l}\text { Prospective } \\
\text { observational } \\
\text { study }\end{array}$ & $\begin{array}{l}\text { Biometry of the levator } \\
\text { hiatus in relation to POP }\end{array}$ \\
\hline Brækken et al (2008) ${ }^{21}$ & 17 & Female volunteers & $\begin{array}{c}\text { Cross sectional } \\
\text { study }\end{array}$ & $\begin{array}{l}\text { Intra-observer } \\
\text { agreement of measuring } \\
\text { levator ani biometry }\end{array}$ \\
\hline Majida et al (2009) ${ }^{22}$ & 17 & Female volunteers & $\begin{array}{l}\text { Cross sectional } \\
\text { study }\end{array}$ & $\begin{array}{l}\text { Inter-observer } \\
\text { agreement of measuring } \\
\text { levator ani biometry }\end{array}$ \\
\hline Majida et al (2010) ${ }^{23}$ & 18 & Female volunteers & $\begin{array}{l}\text { Cross sectional } \\
\text { study }\end{array}$ & $\begin{array}{l}\text { Comparison between } \\
\text { translabial 3D } \\
\text { ultrasound and MR } \\
\text { imaging in measuring } \\
\text { levator ani biometry }\end{array}$ \\
\hline Chen et al (2011) ${ }^{24}$ & 103 & $\begin{array}{l}\text { Women presenting with } \\
\text { symptoms of lower urinary } \\
\text { tract and pelvic floor } \\
\text { dysfunction }\end{array}$ & $\begin{array}{l}\text { Cross sectional } \\
\text { study }\end{array}$ & $\begin{array}{l}\text { Biometry of the levator } \\
\text { hiatus in relation to POP } \\
\text { and urinary incontinence }\end{array}$ \\
\hline Majida et al (2011) ${ }^{25}$ & 157 & $\begin{array}{l}\text { Women who were at least one } \\
\text { year beyond childbirth, with or } \\
\text { without symptoms of POP }\end{array}$ & $\begin{array}{l}\text { Cross sectional } \\
\text { study }\end{array}$ & $\begin{array}{l}\text { Biometry of the levator } \\
\text { hiatus in relation to POP }\end{array}$ \\
\hline
\end{tabular}


Table 2: Included studies on measuring levator ani biometry.

\begin{tabular}{|c|c|c|c|c|}
\hline Article & $\mathbf{N}$ & Inclusion criteria & Study design & Outcome measure(s] \\
\hline Dietz et al $(2011)^{26}$ & 100 & $\begin{array}{l}\text { Women presenting with } \\
\text { symptoms of lower urinary tract } \\
\text { and pelvic floor dysfunction }\end{array}$ & $\begin{array}{l}\text { Cross sectional } \\
\text { study }\end{array}$ & $\begin{array}{l}\text { Biometry of the levator } \\
\text { hiatus, measured } \\
\text { with two differenent } \\
\text { ultrasound methods, in } \\
\text { relation to POP }\end{array}$ \\
\hline Khunda et al (2012) ${ }^{27}$ & 188 & $\begin{array}{l}\text { Women presenting with } \\
\text { symptoms of lower urinary } \\
\text { tract and pelvic floor } \\
\text { dysfunction }\end{array}$ & $\begin{array}{l}\text { Cross sectional } \\
\text { study }\end{array}$ & $\begin{array}{l}\text { Biometry of the levator } \\
\text { hiatus in relation to } \\
\text { measurements of the } \\
\text { genital hiatus and the } \\
\text { perineal body }\end{array}$ \\
\hline Ying et al (2012) ${ }^{28}$ & 100 & $\begin{array}{c}\text { Nulliparous women and } \\
\text { women presenting with POP }\end{array}$ & $\begin{array}{c}\text { Cross sectional } \\
\text { study }\end{array}$ & $\begin{array}{l}\text { Biometry of the levator } \\
\text { hiatus in relation to POP }\end{array}$ \\
\hline Volloyhaug et al (2012) ${ }^{13}$ & 295 & $\begin{array}{l}\text { Women presenting with } \\
\text { symptoms of lower urinary } \\
\text { tract and pelvic floor } \\
\text { dysfunction }\end{array}$ & $\begin{array}{l}\text { Cross sectional } \\
\text { study }\end{array}$ & $\begin{array}{l}\text { Biometry of the levator } \\
\text { hiatus in relation to } \\
\text { measurements of the } \\
\text { genital hiatus and the } \\
\text { perineal body }\end{array}$ \\
\hline Dietz et al (2008) ${ }^{29}$ & 544 & Women presenting with POP & $\begin{array}{l}\text { Retrospective } \\
\text { observational } \\
\text { study }\end{array}$ & $\begin{array}{l}\text { Biometry of the levator } \\
\text { hiatus in relation to POP }\end{array}$ \\
\hline Dietz et al (2012) ${ }^{17}$ & 605 & Women presenting with POP & $\begin{array}{l}\text { Retrospective } \\
\text { observational } \\
\text { study }\end{array}$ & $\begin{array}{l}\text { Levator ani defects and } \\
\text { biometry of the levator } \\
\text { hiatus in relation to POP }\end{array}$ \\
\hline Pineda et al (2013) ${ }^{30}$ & 577 & $\begin{array}{l}\text { Women presenting with } \\
\text { symptoms of lower urinary } \\
\text { tract and pelvic floor } \\
\text { dysfunction }\end{array}$ & $\begin{array}{l}\text { Retrospective } \\
\text { observational } \\
\text { study }\end{array}$ & $\begin{array}{l}\text { Biometry of the levator } \\
\text { hiatus in relation to POP }\end{array}$ \\
\hline Andrew et al $(2013)^{31}$ & 81 & $\begin{array}{l}\text { Women who underwent } \\
\text { surgery for prolapse repair }\end{array}$ & $\begin{array}{l}\text { Retrospective } \\
\text { observational } \\
\text { study }\end{array}$ & $\begin{array}{c}\text { Biometry of the levator } \\
\text { hiatus in relation to POP } \\
\text { surgery }\end{array}$ \\
\hline
\end{tabular}

$\mathrm{N}=$ number of patients

$\mathrm{POP}=$ pelvic organ prolapse

$3 \mathrm{D}=$ three-dimensional

$\mathrm{MR}=$ magnetic resonance 


\section{Results studies reporting on levator ani defects}

\section{1a. How is the diagnostic performance of translabial 3D ultrasound for diagnosing levator ani defects?}

We identified 1 prospective observational study which answered our research question. Zhuang et al (2011) assessed 69 Chinese women with POP prospectively by translabial 3D ultrasound and magnetic resonance (MR) imaging. ${ }^{[12]}$ On tomographic ultrasound imaging (TUI), levator ani defects were found in $39 \%$ of women. The agreement between observers for the diagnosis of levator ani defects by TUI was $96 \%$, which equated to a Cohen's kappa of 0.86 (95\% confidence interval (CI), 0.75-0.96), and was defined as good agreement. Agreement between tomographic 3D scans and the MR imaging 3D model was $92 \%$, with a kappa of 0.79 ( $95 \% \mathrm{Cl}, 0.62-0.96)$, which was defined as substantial agreement.

\section{1b. Is diagnosing levator ani defects with translabial 3D ultrasound reproducible?}

Six articles where selected, of which 3 prospective observational studies ${ }^{[8,9,12]}, 2$ cross sectional studies ${ }^{[13,14]}$, and 1 retrospective observational study ${ }^{[18]}$, for answering this research question. All studies but 1 were single centre studies in which the inter-observer agreement was tested for diagnosing levator ani defects. The study by Dietz et al (2007) recruited women from 2 different centres. ${ }^{[9]}$ All studies measured a Cohen's Kappa and were interpreted in terms of 'poor' (0-0.20), 'fair' (0.21-0.40), 'moderate' (0.41-0.60), 'good' (0.61-0.80) and 'very good' (0.81-1.00) agreement, as described by Altman et al. ${ }^{[32]}$ The 6 selected studies found a Kappa ranging from 0.57 tot 0.89, depicted in Table 3.In 2 studies the inter-observer agreement for diagnosing levator ani defects with translabial $3 \mathrm{D}$ ultrasound was indicated as a moderate agreement ${ }^{[14,18]}$, in 1 study the inter-observer agreement was good ${ }^{[9]}$, and in 3 studies the inter-observer agreement was very good. ${ }^{[8,12,13]}$

\section{1c. Are levator ani defects, diagnosed with translabial 3D ultrasound, associated with primary POP?}

Five observational studies were selected for answering this question of which 2 studies were prospective ${ }^{[8,9]}$ and 2 studies were retrospective. ${ }^{[6,15,17]}$ All studies reported on the association between findings on translabial 3D ultrasound and different aspects of pelvic floor dysfunction. In 1 study odds ratios (OR) were reported ${ }^{[17]}$, while in the other 4 studies the outcome measurements were defined differently. 
Table 3: Overview of Kappa's with regard to the inter-observer agreement for diagnosing levator ani defects with translabial 3D ultrasound

\begin{tabular}{|l|l|l|}
\hline Study & N & \multicolumn{1}{|c|}{ Cohen's Kappa (95\% CI) } \\
\hline Dietz et al (2006) ${ }^{8}$ & 50 & $0.83(0.59-1.0)$ \\
\hline Dietz et al (2007) ${ }^{9}$ & 20 & $0.61(\mathrm{NA})$ \\
\hline Zhuang et al (2011) ${ }^{12}$ & 69 & $0.86(0.75-0.96)$ \\
\hline Dietz et al (2012) ${ }^{18}$ & 43 & $0.57(0.32-0.76)$ \\
\hline Volloyhaug et al (2013) ${ }^{13}$ & 20 & $0.89(0.73-0.96)$ \\
\hline Kruger et al (2013) ${ }^{14}$ & 68 & $0.57(0.32-0.82)$ \\
\hline
\end{tabular}

$N=$ number of patients, $\mathrm{Cl}=$ confidence interval, $N A=$ not applicable

\section{Prospective observational studies}

In a prospective observational study in 2006 with 338 women with lower urinary tract symptoms and pelvic floor dysfunction, Dietz et al found defects of the pubovisceral muscle using translabial 3D ultrasound, in $15.4 \%$ of parous compared to $0 \%$ in non-parous women ${ }^{[8]}$ These defects were associated with anterior and central compartment prolapse lall $p$ < 0.01). In another prospective observational study from Dietz et al (2007), 262 women with complaints of lower urinary tract dysfunction and POP underwent an interview, clinical assessment and translabial 3D ultrasound imaging. ${ }^{[9]}$ Levator ani defects were diagnosed in $19 \%$ ( $n=50$ ) of women. Of these 50 women, 42 were diagnosed with anterior vaginal wall prolapse (84\%). The percentage of women with POP in the group of women without levator ani defects was not described. They found a significant linear association between the degree of a defect as seen on translabial 3D ultrasound and higher POP stage.

\section{Retrospective observational studies}

Abdool et al, who is part of the research group of Dietz, investigated in 2009 the association between levator ani defects and different types of POP in a population of 414 women with complaints of POP, incontinence or both. ${ }^{[15]}$ They found a strong positive association between a unilateral and a bilateral levator ani defect and anterior vaginal wall prolapse (both $p<0.01$ ) and with a rectocele $(p=0.01$ and $p<0.01$ respectively). Only a bilateral defect was associated with uterine prolapse $(p=0.04)$.

In 2011, Dietz et al found a significant association between a complete levator ani defect, diagnosed with TUI, and POP ( $p<0.01)$ in a retrospective cohort study among 764 women 
with complaints of lower urinary tract dysfunction and POP complaints. ${ }^{[6]}$ This association was not found between partial levator ani defects and POP.

In 2012, Dietz et al compared the results of the Pelvic Organ Quantification system (POP-Q) with levator ani defects diagnosed with translabial 3D ultrasound in 605 women with urinary tract and POP symptoms. ${ }^{[1]]}$ They found an independent association between unilateral levator ani defects and symptoms of POP with an OR of 1.88 (95\% Cl, 1.06-3.35) and between bilateral levator ani defects and symptoms of POP with an OR of 2.22 (95\% $\mathrm{Cl}, 1.15-4.27)$. Unilateral levator ani defects were significantly association with cystocele IOR 2.66, 95\% Cl, 1.46-4.85), with uterine prolapse (OR 2.87, 95\% Cl, 1.11-7.41) and with POP in general (OR 2.76, 95\% Cl 1.42-5.37), measured with POP-Q. Bilateral levator ani defects were also significantly associated with cystocele, uterine prolapse and POP in general (respectively OR 5.31, 95\% Cl, 2.49-11.32, OR 5.3, 95\% Cl, 2.17-12.92 and OR 4.01, 95\% Cl, 1.77-9.10). A rectocele was not associated with an unilateral of bilateral levator ani defect.

\section{1d. Is it possible to predict the success rate of POP surgery based on the presence of a levator ani defect on translabial 3D ultrasound?}

We have selected 2 prospective observational studies ${ }^{[10,11]}$, and 2 retrospective observational studies ${ }^{[16,19]}$ to answer this research question.

\section{Prospective observational studies}

Dietz et al (2010) investigated the association between levator ani defects and cystocele recurrence after anterior colporraphy. ${ }^{[10]}$ Of 83 women, 24 (29\%) reported symptoms of recurrent POP and 33 (40\%) had recurrent cystocele on clinical examination using the POP-Q assessment. On translabial 3D ultrasound examination, a levator ani defect was detected in 29 patients (35\%). The relative risk of recurrence in women with levator ani defect was 2.9 (95\% Cl, 1.7-4.5).

Weemhoff et al (2012) conducted a prospective observational cohort study in which women underwent an interview, physical examination and translabial 3D ultrasound 2 years after anterior colporraphy to identify risk factors for recurrent cystocele. ${ }^{[11]}$ Complete defects of the puborectalis muscle were found to be risk factors for anatomical recurrence with an OR of 2.4 (95\% Cl, 1.3- 4.7).

\section{Retrospective observational studies}

Model et al and Wong et al, who are both part of the research group of Dietz, found a significant association between a levator ani defect and recurrent POP after prolapse surgery. ${ }^{[16,19]}$ Model et al (2010) evaluated 737 datasets of patients with symptoms of pelvic floor dysfunction. ${ }^{[16]}$ The prevalence of POP was calculated for patients with 
previous hysterectomy, for patients with previous anterior colporrhaphy, for patients with colposuspenion and for patients with previous anti-incontinence or other POP surgery, with and without confirmed levator ani defects. In all groups levator ani defects were significantly associated with objective POP (RR between 2.3 and 3.3, OR between 3.4 and 6). Wong et al (2013) concluded in 209 patients that a levator ani defect doubles the risk of cystocele recurrence after anterior colporraphy with transobturator mesh. ${ }^{[19]}$

\section{Results studies reporting on measurements pelvic floor i.e hiatal biometry}

\section{2a. How is the diagnostic performance of translabial 3D ultrasound for measuring levator ani biometry?}

There was 1 cross sectional study concerning validation of translabial ultrasound. In 2010, Majida et al compared the measurements of the pubovisceral muscle using translabial 3D ultrasound with MRI as the reference test in 18 female volunteers. ${ }^{[23]}$ The area and anteroposterior and transverse diameters of the levator ani hiatus in the axial plane in which hiatal dimensions were minimal, were measured both with translabial 3D ultrasound and MRI. One single investigator previewed the ultrasound and MRI images. The ones with the best image quality (visible symphysis pubis and inner and posterior margins of pubovisceral musclel were selected. The images with the minimal hiatus dimensions were searched and measured three times from the same volume recording and the mean of these three values was used for statistical analysis. They found a good to very good agreement with ICC's between 0.80 and 0.97 .

\section{2b. Is measuring levator ani biometry with translabial 3D ultrasound reproducible?}

We found 8 articles that studied the reproducibility of translabial 3D ultrasound for the measurement of the levator ani hiatus, of which 6 cross sectional studies [13, 21, 22, 24, 26, 27], and 2 retrospective cohort studies. ${ }^{[30,31]}$ All studies were single centre studies. Two studies investigated the intra-observer agreement ${ }^{[21,24]}$, while the rest tested the inter-observer agreement between 2 observers.

Brækken et al (2008) and Majida et al (2009) assessed 17 female volunteers. ${ }^{[21,22]}$ They found a moderate to good intra-observer agreement for measuring hiatal area (ICC 0.56 , $95 \% \mathrm{Cl}, 0.13-0.81$ ), the anterior-posterior dimension (ICC $0.61,95 \%, \mathrm{Cl} 0.21-0.84$ ) and the transverse dimension of the levator ani hiatus (ICC $0.72,95 \% \mathrm{Cl}, 0.39-0.88$ ), and a good to very good inter-observer agreement between 2 observers for measuring hiatal area (ICC 0.92 at rest, ICC 0.92 during contraction and ICC 0.98 during Valsalva), the anterior-posterior dimension (ICC 0.96 at rest, ICC 0.82 during contraction and ICC 0.90 during Valsalva) and the transverse dimension of the levator ani hiatus (ICC 0.96 at 
rest), with no description of $95 \% \mathrm{Cl}$. Chen et al (2011) recruited 103 patients, of which 36 women with POP, 36 women with stress urinary incontinence and 31 normal controls. ${ }^{[2]}$ They estimated the displacement of the bladder neck, sagittal hiatal diameter, levator ani hiatal angle and levator ani hiatus area on translabial 3D ultrasound. Twenty datasets were randomly retrieved for analysis of intra-observer reproducibility, that were assessed twice by the same observer on 2 occasions 1 week apart. They found a good intra-observer agreement for all different parameters with ICC's between 0.77 and 0.90 . Measuring the hiatal area at rest and during Valsalva showed an ICC of $0.87(95 \% \mathrm{Cl}, 0.71-0.95)$ and 0.81 (95\% Cl, 0.58-0.92) respectively.

Dietz et al (2011) performed an offline analysis of 100 translabial 4D volume datasets of women seen in a tertiary urogynaecological clinic. ${ }^{[26]}$ They compared hiatal measurements obtained in sectional planes and rendered volumes. A test-retest series in 20 women showed a good inter-observer agreement between 2 observers for the measurement of hiatal dimensions with an ICC of $0.85(95 \% \mathrm{Cl}, 0.81-0.88)$ in sectional planes and an ICC of 0.88 (95\% Cl, 0.85-0.90) in rendered volumes.

Khunda et al (2012), who is part of the research group of Dietz, demonstrated a good interobserver agreement between 2 observers for measuring hiatal area during Valsalva (ICC $0.89,95 \% \mathrm{Cl}, 0.73-0.95$ ) and for measuring anterior-posterior diameter during Valsalva (ICC $0.85,95 \% \mathrm{Cl}, 0.62-0.94$ ). ${ }^{[27]}$ The study included datasets of 188 urogynaecology patients assessed in a cross-sectional retrospective study. For the inter-observer reliability datasets of 20 women were used. These findings were confirmed by Volloyhaug et al in 2013 in another sample of 20 women using an extended database of the same population. ${ }^{[13]}$ They found an ICC of 0.90 (95\% Cl, 0.70-0.96) for measuring hiatal area during Valsalva. In a retrospective analysis in 2013, Pineda et al, who is part of the research group of Dietz, showed a good inter-observer agreement (ICC $0.71,95 \% \mathrm{Cl}$ not described) between 2 observers for measuring the anterior-posterior diameter of the hiatal area during Valsalva in a sample of 20 women seen at a tertiary urogynaecological unit. ${ }^{[30]}$

Andrew et al (2013), also part of the research group of Dietz, showed a good interobserver agreement for measuring hiatal biometry in women who were seen at a tertiary urogynaecological unit and who had undergone POP surgery in the past. ${ }^{[31]}$ A test-retest series of 10 volumes for each measurement was conducted by 2 observers. They yielded ICC's of 0.81 (95\% Cl, 0.35-0.95) for area at rest, of 0.74 (95\% Cl, 0.29-0.93) for area during Valsalva and of $0.75(95 \% \mathrm{Cl}, 0.26-0.93)$ for area during pelvic floor contraction. 


\section{2c. Is a larger hiatus (ballooning hiatus), diagnosed with translabial 3D ultrasound, associated with primary POP?}

The relationship between hiatal biometry, diagnosed with translabial 3D ultrasound, and signs and symptoms of POP has been described in 8 articles, of which 1 prospective observational study ${ }^{[20]}, 4$ cross sectional studies ${ }^{[24,25,27,28]} 3$ retrospective observational studies ${ }^{[17,29,30]}$. The first publication concerning hiatal biometry of the levator ani measurements with translabial 3D ultrasound was published in 2005.

\section{Prospective observational study}

In a prospective observational study, Dietz et al (2005) assessed 52 nulligravid female Caucasian volunteers with translabial 3D ultrasound at rest and during Valsalva. ${ }^{[20]}$ Biometric parameters of the pubovisceral muscle and levator ani hiatus were determined in the axial and coronal planes. They found significant correlations between the size of the hiatus and pelvic organ descent. With respect to the hiatal area at rest, they found a significant linear correlation with a cystocele (Pearson's $r$-0.34, $p=0.02$ ), with uterine descent (Pearson's $r$ $-0.50, p<0.01$ ) and with a rectocele (Pearson's $r-0.41, p<0.01$ ). During Valsalva they also found a significant correlation between size of the hiatus and cystocele (Pearson's $r-0.63, p$ $<0.01$ ), uterine descent (Pearson's $r-0.66, p<0.01$ ) and rectocele (Pearson's $r-0.60, p<0.01$ ).

\section{Cross sectional studies}

In a population of 103 women with and without POP, Chen et al (2011) found that women with POP had a significant larger levator ani hiatus than women without POP complaints measured at rest and during contraction. ${ }^{[24]}$ At rest they found a hiatal area of $20.06 \mathrm{~cm}^{2}$ $( \pm 3.77)$ in women with POP ( $n=33$ ) compared to $15.20 \mathrm{~cm}^{2}( \pm 2.54)$ in controls ( $n=29$ ) (Spearman's $r 0.56, p<0.01)$. During Valsalva they found a hiatal area of $16.10 \mathrm{~cm}^{2}( \pm 2.88)$ in women with POP and $12.21 \mathrm{~cm}^{2}( \pm 2.13$ ) in women without POP (Spearman's r 0.55, $p<0.01$ ).

Khunda et al (2012) assessed 188 urogynaecology patients who underwent an interview, clinical examination and translabial 3D ultrasound. ${ }^{[27]}$ They demonstrated significantly larger hiatal measurements in the patients with signs and symptoms of POP compared with those without such signs and symptoms. Majida et al (2011) found in a population of 157 women with or without symptoms, a positive association with a clinically significant POP in the anterior but not in the posterior compartment and the area of the levator ani hiatus ( $p<0.01) .{ }^{[25]}$ They did not find an independent association between area of the levator ani hiatus and symptoms of pelvic floor dysfunction (Pearson's r 0.62). Ying et al (2012) included 50 women with POP and 50 nulliparous women in their prospective study.[28] Both groups underwent translabial 3D ultrasound. The results showed that the size of the levator ani hiatus of POP women was larger than that in nulliparous women at rest, during Valsalva and during contraction ( $p<0.01$ ). 


\section{Retrospective studies}

In 2008, in a population of 544 women who were seen in a tertiary urogynaecological unit, Dietz et al found that levator ani hiatal area as measured by translabial 3D ultrasound examination was strongly associated with symptoms and clinical signs of POP ( $p<0.01)^{\left[{ }^{[29]}\right.}$ Receiver operating characteristic (ROC) analysis showed an area under the curve (AUC) of 0.65 (95\% Cl, 0.60-0.70) for hiatal area at rest and $0.71(95 \% \mathrm{Cl}, 0.66-0.76)$ for hiatal area during Valsalva.

In 2012, Dietz et al evaluated 605 women with symptoms of lower urinary tract and pelvic floor dysfunction in a retrospective cohort study. ${ }^{[17]}$ They found a strong association between a ballooning hiatus and signs and symptoms of POP. Hiatal area during Valsalva was associated with symptoms of POP with an OR of 1.06 (95\% Cl, 1.03-1.08). The presence of a cystocele, uterine prolapse, rectocele, or POP in general was also associated with hiatal area with OR's of respectively 1.09 (95\% Cl, 1.06-1.12), 1.09 (95\% Cl, 1.04-1.13), 1.09 (95\% Cl, 1.07-1.13) en $1.11(95 \% \mathrm{Cl}, 1.08-1.14)$.

In a retrospective analysis of 577 women seen at a tertiary urogynaecological unit, Pineda et al found a strong association between POP and hiatal anterior-posterior diameter during Valsalva ( $p<0.01$ ). ${ }^{[30]}$ ROC curve analyses confirmed the relationship with an AUC of 0.64 (95\% Cl, 0.59-0.68) for anterior-posterior diameter during Valsalva. They also found a relationship with midsagittal anterior-posterior diameter and clinical findings of significant POP (AUC 0.71, 95\% Cl, 0.67-0.76), as well as with significant POP diagnosed on translabial 3D ultrasound (AUC $0.75,95 \% \mathrm{Cl}, 0.71-0.79$ ).

\section{2d. Is it possible to predict the success rate of POP surgery based on the presence of a ballooning hiatus measured with translabial 3D ultrasound?}

There were no articles found which could answer the above question.

\section{DISCUSSION}

\section{Main findings}

The diagnostic performance of the translabial 3D ultrasound remains unclear because there are little comparative studies available in which translabial 3D ultrasound is compared to the reference test MRI, for detecting levator ani defects or for measuring hiatal biometry. One comparative study for detecting levator ani defects and 1 small study on measuring hiatal biometry showed a good agreement between findings on translabial 3D ultrasound compared to MRI. Subsequently, diagnosing levator ani defects and measuring the levator ani hiatal area with translabial 3D ultrasound is reproducible. Furthermore, evidence shows that both 
levator ani defects and a larger hiatal biometry increases the risk of cystocele and uterine prolapse but the relationship to rectocele seems less clear. All included studies regarding the possibility to predict the success rate of POP surgery based on the presence of a levator ani defect found an association between recurrent POP and levator ani defects. No evidence was found for an association between a larger hiatus and recurrent POP after pelvic floor surgery.

\section{Strengths and limitations}

We can conclude that our reviews' generalizability has some limitations. Even though the aims of the studies were very similar, there were many differences in the methods used and primary outcomes that were reported. As a result of this heterogeneity it is difficult to assess study quality and compare the different articles, and more importantly, perform a meta-analysis on relevant primary outcomes such as sensitivity and specificity.

\section{Interpretation of the evidence}

To interpret this overview of the literature objectively, some limitations of the selected studies need to be addressed.

Concerning the reproducibility of detecting levator ani muscle defects with translabial 3D ultrasound, 5 of the 6 included studies were derived from the same research group in which reproducibility was tested between 2 observers (trainer and trainee). Studies on external validation and reproducibility between observers in a multicenter setting have not been published yet.

The 5 studies that were selected to answer the question whether levator ani muscle defects are associated with primary POP, were all published by the same research group. The population in this tertiary center consists of women with symptoms of urinary tract dysfunction and pelvic floor dysfunction. None of these studies compared women with POP to women without POP. It is possible that levator ani defects are more often present in a selected patient group who visit a tertiary center because of symptoms of pelvic floor dysfunction. The available studies show, within a selected population with POP, that levator defects are associated with primary POP, however studies on the prevalence of levator defects in the asymptomatic parous population or studies comparing levator defects in POP patients and controls have not been published.

To answer the question whether it is possible to predict the success rate of prolapse surgery based on the presence of a levator ani defect on translabial 3D ultrasound, we selected 2 prospective and 2 retrospective studies. Three of the 4 studies $^{[10,16,19]}$, were derived from the same research group. In the prospective studies, the translabial ultrasound was performed after surgery at the time the incidence of recurrent POP was studied and not preoperatively. It is possible that the existence of the prolapse itself or surgery can influence the ultrasound 
appearance of the pelvic floor anatomy and therefore levator ani defects can be interpreted differently. These facts can lead to systematic bias.

The diagnostic performance of translabial 3D ultrasound for measuring levator ani biometry was only investigated once. ${ }^{[23]}$ In this study ultrasound and MRI images were assessed by a single investigator, which could have caused bias.

Of the 8 studies that investigated the reproducibility of measuring levator ani biometry with translabial 3D ultrasound, 5 were published by the same research group. ${ }^{[13,26,27,30,31]}$ Two other studies used the same population of which 1 assessed the intra-observer agreement, and 1 assessed the inter-observer agreement. ${ }^{[21,22]}$ All 8 studies tested a sample of 20 women or less.

Of the 8 studies that assessed the association between a larger hiatus diagnosed with translabial 3D ultrasound and primary POP, 3 studies compared women with POP or POP symptoms to women without POP or POP symptoms in a general population of women. ${ }^{[24,25,28]}$ The other 5 studies were derived from the same research group, of which 1 study included nulligravid volunteers ${ }^{[20]}$ and 4 studies included women with symptoms of lower urinary tract and pelvic floor dysfunction ${ }^{[17,27,29,30]}$. The use of a selected group of women and the lack of a control group with women without POP could have caused bias.

\section{CONCLUSION}

Current literature suggest that translabial 3D ultrasound in single center setting is reproducible for diagnosing levator ani defects and ballooning hiatus; external validation by studies on reproducibility in a multicenter setting are needed. Levator ani defects are, in a selected population of patients with pelvic floor dysfunction, associated with POP and recurrent POP after surgery. Studies on levator ani defects in asymptomatic patients and comparison with POP patients still has to take place. Only little research is performed on the diagnostic performance of the translabial 3D ultrasound to detect levator ani defects or measure hiatal biometry. Further research should focus on diagnostic accuracy of using translabial 3D ultrasound. 


\section{REFERENCES}

1. Slieker-ten Hove MC, Pool-Goudzwaard AL, EijkemansMJ, Steegers-Theunissen RP, Burger CW, Vierhout ME. The prevalence of pelvic organ prolapse symptoms and signs and their relation with bladder and bowel disorders in a general female population. Int Urogynecol J Pelvic Floor Dysfunct 2009; 20 (9):1037-45.

2. Smith DA. Pelvic organ prolapse. A new option offers effectiveness and ease of use. Adv Nurse Pract 2007; 15 (8):39-42.

3. Wu JM, Hundley AF, Fulton RG, Myers ER. Forecasting the prevalence of pelvic floor disorders in U.S. Women: 2010 to 2050. Obstet Gynecol 2009; 114 (6):1278-83.

4. Olsen A.L, Smith VJ, Bergstrom JO, Colling JC, Clark AL. Epidemiology of surgically managed pelvic organ prolapse and urinary incontinence. Obstet Gynecol 1997; 89 (4):501-6.

5. Dietz HP, Lanzarone V. Levator trauma after vaginal delivery. Obstet Gynecol 2005; 106 (4):707-12.

6. Dietz HP, Bernardo MJ, Kirby A, Shek KL. Minimal criteria for the diagnosis of avulsion of the puborectalis muscle by tomographic ultrasound. Int Urogynecol J 2011; 22 (6):699-704.

7. Moher D, Liberati A, Tetzlaff J, Altman DG. Preferred reporting items for systematic reviews and metaanalyses: the PRISMA statement. J Clin Epidemiol 2009; 62 (10):1006-12.

8. Dietz HP, Steensma AB. The prevalence of major abnormalities of the levator ani in urogynaecological patients. BJOG 2006; 113 (2):225-30.

9. Dietz HP. Quantification of major morphological abnormalities of the levator ani. Ultrasound Obstet Gynecol 2007; 29 (3):329-34.

10. Dietz HP, Chantarasorn V, Shek KL. Levator avulsion is a risk factor for cystocele recurrence. Ultrasound Obstet Gynecol 2010; 36 (1):76-80.

11. Weemhoff M, Vergeldt TF, Notten KJ, Serroyen J, Kampschoer PH, Roumen FJ. Avulsion of puborectalis muscle and other risk factors for cystocele recurrence: a 2-year follow-up study. Int Urogynecol J 2012; 23 (1):65-71.

12. Zhuang RR, Song YF, Chen,ZQ, Ma M, Huang HJ, Chen JH, et al. Levator avulsion using a tomographic ultrasound and magnetic resonance-based model. Am J Obstet Gynecol 2011; 205 (3):232 e1-8.

13. Volloyhaug I, Wong V, Shek KL, Dietz HP. Does levator avulsion cause distension of the genital hiatus and perineal body? Int Urogynecol J 2013; 24 (7):1161-5.

14. Kruger JA, Dietz HP, Budgett SC, Dumoulin CL. Comparison Between Transperineal Ultrasound and Digital Detection of Levator Ani Trauma. Can We Improve the Odds? Neurourol Urodyn 2014; 33(3):307-11.

15. Abdool Z, Shek KL, Dietz HP. The effect of levator avulsion on hiatal dimension and function. Am J Obstet Gynecol 2009; 201 (1):89 e1-5.

16. Model AN, Shek KL, Dietz HP. Levator defects are associated with prolapse after pelvic floor surgery. Eur J Obstet Gynecol Reprod Biol 2010; 153 (2):220-3.

17. Dietz HP, Franco AV, Shek KL, Kirby A. Avulsion injury and levator hiatal ballooning: two independent risk factors for prolapse? An observational study. Acta Obstet Gynecol Scand 2012; 91 (2):211-4.

18. Dietz HP, Moegni F, Shek KL. Diagnosis of levator avulsion injury: a comparison of three methods. Ultrasound Obstet Gynecol 2012; 40 (6):693-8.

19. Wong V, Shek K, Rane A, Goh J, Krause H, Dietz HP. Is levator avulsion a predictor of cystocele recurrence following anterior vaginal mesh placement? Ultrasound Obstet Gynecol 2013; 42 (2):230-4.

20. Dietz HP, Shek C, Clarke B. Biometry of the pubovisceral muscle and levator hiatus by three-dimensional pelvic floor ultrasound. Ultrasound Obstet Gynecol 2005; 25 (6):580-5. 
21. Braekken IH, Majida M, Ellstrom-Engh M, Dietz HP, Umek W, Bo K. Test-retest and intra-observer repeatability of two-, three- and four-dimensional perineal ultrasound of pelvic floor muscle anatomy and function. Int Urogynecol J Pelvic Floor Dysfunct 2008; 19 (2):227-35.

22. Majida M, Braekken IH, Umek W, Bo K, Saltyte Benth J, Ellstrom Engh M. Interobserver repeatability of three- and four-dimensional transperineal ultrasound assessment of pelvic floor muscle anatomy and function. Ultrasound Obstet Gynecol 2009; 33 (5):567-73.

23. Majida M, Braekken IH, Bo K, Benth JS, Engh ME. Validation of three-dimensional perineal ultrasound and magnetic resonance imaging measurements of the pubovisceral muscle at rest. Ultrasound Obstet Gynecol 2010; 35 (6):715-22.

24. Chen R, Song Y, Jiang L, Hong X, Ye P. The assessment of voluntary pelvic floor muscle contraction by three-dimensional transperineal ultrasonography. Arch Gynecol Obstet 2011; 284 (4):931-6.

25. Majida M, Braekken I, Bo K, Benth J, Engh M. Anterior but not posterior compartment prolapse is associated with levator hiatus area: a three- and four-dimensional transperineal ultrasound study. BJOG 2011; 118 (3):329-37.

26. Dietz HP, Wong V, Shek KL. A simplified method for determining hiatal biometry. Aust N Z J Obstet Gynaecol 2011; 51 (6):540-3.

27. Khunda A, Shek KL, Dietz HP. Can ballooning of the levator hiatus be determined clinically? Am J Obstet Gynecol 2012; 206 (3):246 e 1-4.

28. Ying T, Li Q, Xu L, Liu F, Hu B. Three-dimensional ultrasound appearance of pelvic floor in nulliparous women and pelvic organ prolapse women. Int J Med Sci 2012; 9 (10):894-900.

29. Dietz HP, Shek C, De Leon J, Steensma AB. Ballooning of the levator hiatus. Ultrasound Obstet Gynecol 2008; $31(6): 676-80$.

30. Pineda M, Shek K, Wong V, Dietz HP. Can hiatal ballooning be determined by two-dimensional translabial ultrasound? Aust N Z J Obstet Gynaecol 2013; 53 (5):489-93.

31. Andrew BP, Shek KL, Chantarasorn V, Dietz HP. Enlargement of the levator hiatus in female pelvic organ prolapse: cause or effect? Aust N Z J Obstet Gynaecol 2013; 53 (1):74-8.

32. Altman D.G. Practical statistics for medical research. London: Chapman \& Hall/CRC; 1999. 
PROTOCOL FOR TRANSLABIAL 3D-ULTRASONOGRAPHY FOR DIAGNOSING LEVATOR DEFECTS (TRUDIL): A MULTICENTRE COHORT STUDY FOR ESTIMATING THE DIAGNOSTIC ACCURACY OF TRANSLABIAL 3D-ULTRASONOGRAPHY OF THE PELVIC FLOOR AS COMPARED TO MR IMAGING

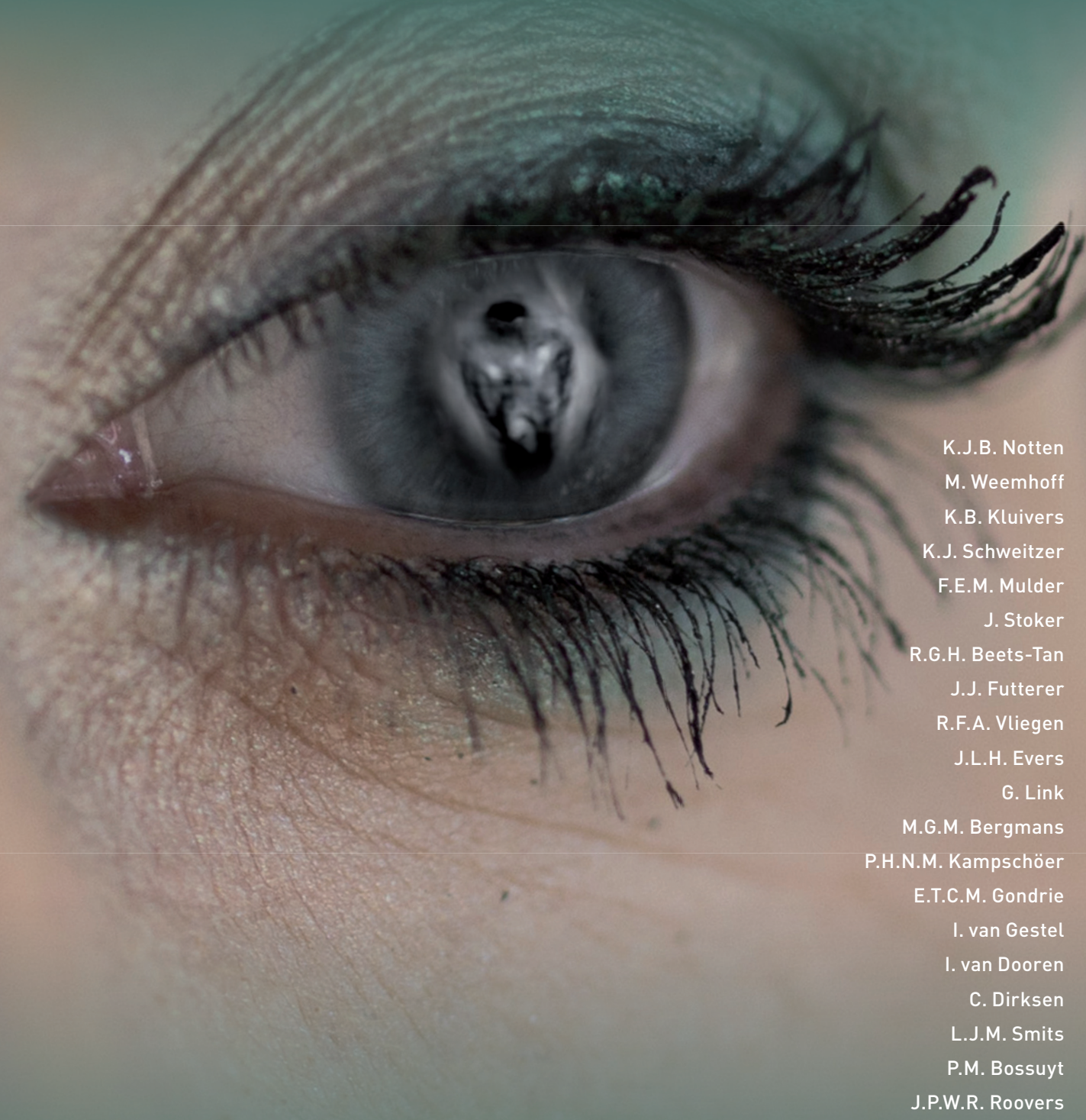




\section{ABSTRACT}

\section{Background}

Pelvic organ prolapse (POP) is a condition affecting more than half of the women above age 40. The estimated lifetime risk of needing surgical management for POP is $11 \%$. In patients undergoing POP surgery of the anterior vaginal wall, the re-operation rate is $30 \%$. The recurrence risk is especially high in women with a levator ani defect. Such defect is present if there is a partially or completely detachment of the levator ani from the inferior ramus of the symphysis. Detecting levator ani defects is relevant for counseling, and probably also for treatment. Levator ani defects can be imaged with MRI and also with Translabial 3D ultrasonography of the pelvic floor.

The primary aim of this study is to assess the diagnostic accuracy of translabial 3D ultrasonography for diagnosing levator defects in women with POP with Magnetic Resonance Imaging as the reference standard. Secondary goals of this study include quantification of the inter-observer agreement about levator ani defects and determining the association between levator defects and recurrent POP after anterior repair. In addition, the cost-effectiveness of adding translabial ultrasonography to the diagnostic work-up in patients with POP will be estimated in a decision analytic model.

\section{Methods/Design}

A multicentre cohort study will be performed in nine Dutch hospitals. 140 consecutive women with a POPQ stage 2 or more anterior vaginal wall prolapse, who are indicated for anterior colporrhaphy will be included. Patients undergoing additional prolapse procedures will also be included. Prior to surgery, patients will undergo MR imaging and translabial 3D ultrasound examination of the pelvic floor. Patients will be asked to complete validated disease specific quality of life questionnaires before surgery and at six and twelve months after surgery. Pelvic examination will be performed at the same time points. Assuming a sensitivity and specificity of $90 \%$ of $3 \mathrm{D}$ ultrasound for diagnosing levator defects in a population of 120 women with POP, with a prior probability of levator ani defects of $40 \%$, we will be able to estimate predictive values with good accuracy (i.e. confidence limits of at most $10 \%$ below or above the point estimates of positive and negative predictive values).

Anticipating 3\% unclassifiable diagnostic images because of technical reasons, and a further safety margin of $10 \%$ we plan to recruit 140 patients.

\section{Trial registration}

Nederlands trial register NTR2220. 


\section{BACKGROUND}

Pelvic organ prolapse (POP) is a condition affecting more than half of the women above age 40. ${ }^{[1]}$ The estimated lifetime risk of needing surgical management for pelvic organ prolapse is $11 \% .{ }^{[2]}$ In the Netherlands yearly 13,000 patients undergo surgical correction for $\mathrm{POP}^{[3]}$. These operations are known to have a re-operation rate of up to $30 \%$ because of primary failure or secondary recurrence of signs and symptoms of POP ${ }^{[2]}$ Because of this high re-operation rate, prolapse recurrence after pelvic floor surgery constitutes a major health care problem. Therefore identifying patients with an individual higher risk for recurrence of POP after surgery can possibly lead to individualized counseling and choice of treatment and possibly to reduction of the proportion of re-operations.

Several risk factors associated with surgical failure have been investigated in a number of studies. Cystocele is the most commonly affected compartment in pelvic organ prolapse and is also the most prone for recurrence after surgery. ${ }^{[4,5]}$ Younger women and women with a more advanced prolapse, a previous hysterectomy, and vaginal childbirth are at an increased risk of prolapse recurrence after surgery. ${ }^{[6-9]}$

Recently, using Magnetic Resonance Imaging (MRI), trauma to the levator ani muscle has been shown to be a common consequence of vaginal delivery ${ }^{[10-12]}$, affecting $20-30 \%$ of parous women as compared to $0 \%$ in nulliparous women. ${ }^{[13]}$ Trauma to the levator ani muscle generally seems to manifest as a partial or complete detachment of the levator ani from the inferior ramus of the symphysis. ${ }^{[14]} A$ relationship has been established between levator defects and POP. This at least partly explains the link between vaginal childbirth and POP, and possibly also with POP recurrence after surgery. ${ }^{[15,16]}$

In a population of urogynecological patients, women with levator defects postpartum were about twice as likely to show POP stage II or higher - especially cystocele and uterine prolapse - as those with an intact levator muscle. ${ }^{[15]}$ In a general population, women with POP appeared to have more levator defects than controls without POP (55\% compared to $16 \%$ ). ${ }^{[17]}$ In a previous study we showed anatomical recurrence of cystocele was associated with major levator defects with an odds ratio (OR) of 2.5 (95\% confidence interval (CI) 1.1-5.7, $p=0.03)$. ${ }^{[18]}$ Dietz et al reported an even stronger association (OR 7.0, 95\% Cl 2.6-19.1, $\mathrm{p}<0.01$ ). ${ }^{[19]}$

Recent advancements in imaging allow assessment of the levator ani muscle imaging with 3D pelvic floor ultrasound, comparing it to MR imaging as the reference standard. Several studies using MR imaging pelvic floor ultrasound have demonstrated that levator defects occur after vaginal birth. ${ }^{[10,12,15,17]}$ Because accurate assessment of pelvic floor injury may help explain symptoms and potentially guide future treatment options, it is important to study on imaging in detecting these levator defects. Moreover using 3D pelvic ultrasound for diagnosing levator defects is non-invasive, patient friendly, less expensive and it has practical advantages 
like shorter examination time and less exclusion criteria like prosthesis, claustrophobia etc compared to MR imaging. Translabial 3D ultrasonography allows imaging of the levator ani muscle including assessment of its integrity. ${ }^{[10,20]}$ However until now no accuracy studies have been published concerning the use of 3D ultrasonography to diagnose levator defects. Few publications mention inter-observer variability in diagnosing levator defects. Steensma and co-workers have conducted a test-retest series of 50 volume datasets of patients with pelvic floor dysfunction for diagnosing levator defects to assess inter-observer reliability, which yielded a Cohen's kappa of 0.83 (95\% $\mathrm{Cl} 0.59-1.0)$, meaning excellent agreement. ${ }^{[11]}$ In another study on grading the size of levator defects, the same research group has reported moderate agreement between different observers reflected in an intraclass correlation coefficient (ICC) of 0.53 (95\% Cl 0.13-0.76). ${ }^{[20]}$ The main objective of our study is to estimate the diagnostic accuracy of translabial 3D ultrasonography of the pelvic floor as compared to MR imaging, the reference standard, for diagnosing levator defects in women with POP. The second aim of this study is to estimate the level of agreement between observers and determine whether levator defects are a risk factor for recurrence after POP surgery. In addition, the cost-effectiveness of introducing translabial ultrasonography in the work-up of a patient with POP will be estimated in a decision analytic model.

\section{METHODS/DESIGN}

\section{Study aims}

1. Estimating the diagnostic accuracy of translabial 3D ultrasonography of the pelvic floor as compared to MR imaging for diagnosing levator defects in women with POP.

2. Measuring the inter-observer agreement in diagnosing and in grading levator defects with 3D ultrasonography.

3. Measuring the association between levator defects and recurrent POP after anterior repair.

4. Evaluating potential cost-effectiveness of introducing 3D ultrasonography for diagnosing levator defects in the work-up of patients with POP.

\section{Study design}

The TRUDIL study is a multicentre cohort study in nine teaching and non-teaching hospitals in The Netherlands.

\section{Ethical considerations}

The study has been approved by the institutional review board of the Maastricht University Medical Centre, in Maastricht. Ethical approval for this study was obtained on 22-02-2010, number 08-2-093. Local approval was obtained in all participating centers. 


\section{Identifying eligible patients}

Eligible patients will be identified by gynecologists in each of the nine participating hospitals in The Netherlands. All consecutive women with at least a cystocele POPQ stage II who are scheduled for conventional anterior colporrhaphy alone or in combination with other POP surgery, without the use of mesh-materials, will be asked to participate in this study. Patients will be excluded in case of previous POP or incontinence surgery, in case of planned surgery with mesh materials, or in case of POP surgery in combination with incontinence surgery. Women with a contra-indication for undergoing MR imaging will also be excluded [see Figure 1]. All eligible patients will receive an information sheet about this study from their attending gynecologist. About one week after counseling has taken place, a research nurse or the gynecologist will call the patient to check for any upcoming questions about the study and her willingness to participate. If the patient is willing to participate, informed consent will be signed. The patient and the attending gynecologist will not be informed on the findings in the study until the study has been finished, therefore these findings do not affect the choice of treatment for these women.

Figure 1: Study inclusion and exclusion criteria

Inclusion

- The patient has at least a POPQ stage II descent of the anterior compartment

- The patient is scheduled for anterior colporrhaphy alone or in combination with other POP surgery

\section{Exclusion}

- Previous POP surgery

- If there is the intention to use mesh-materials

- Previous incontinence surgery or planned additional incontinence surgery (TVT,TOT etc)

- Contra indications for MR imaging (e.g pace-maker, artificial valves, prosthesis)

\section{Interventions}

Diagnostic work-up

Of each patient, baseline characteristics will be recorded. Participants will be interviewed and examined for prolapse by their attending gynecologist. POP will be staged according to the POPQ staging system of the International Continence Society. ${ }^{[21]}$

All patients will undergo MR imaging and 3D ultrasonography before surgery takes place. The assessment of 3D ultrasound and MR imaging of the levator ani muscle will be performed by experienced observers who have performed and assessed more than hundred 3D translabial ultrasounds or pelvic floor MR images before the start of the study. All images will be stored according to a detailed protocol [see Additional files 1 and 2 on the next pages]. 


\section{ADDITIONAL FILE 1}

\section{Protocol Ultrasound}

All patients will undergo a 3D ultrasound on a Voluson GE Kretz Ultrasound machine before surgery takes place. All ultrasound images will be made according to a strict protocol. The ultrasound data sets will be stored anonymously. The data sets are assessed by two independent examiners using 4D-view, an application of GE Kretz Voluson for offline assessments of ultrasound volume data sets. Both observers are blinded for all clinical data. All datasets with discongruent judgments of the degree of trauma of the levator ani muscle, will be discussed in a consensus meeting joined by at least three experts in $3 \mathrm{D} / 4 \mathrm{D}$ translabial ultrasound. The attending gynecologist nor the patient is informed on the results of the ultrasound imaging before the follow-up of 1 year is completed.

\section{Settings GE Voluson ultrasound machine}

In the main 2D setting the ultrasound recording is performed using an angle of $70^{\circ}, 2 \mathrm{focal}$ zones and normal optimized tissue imaging (OTI normal). High speckle reduction imaging (SRI 4-6) is combined with high harmonic imaging ( $\mathrm{HI}$ high). Images are further optimized by using Cross Beam Compound Resolution Imaging (X-Beam CRI 2-4). Converting into main $3 \mathrm{D}$ setting it is necessary to enlarge the angle as much as possible. On the GE Kretz Voluson 730 this will be $85^{\circ}$, on the Voluson E8 this will be $90^{\circ}$. The setting for quality has to be high.

\section{Protocol for performing 3D/4D pelvic floor ultrasound}

Ultrasonography images are acquired using an $8-4 \mathrm{MHz}$ transabdominal transducer covered with a latex condom (Voluson 730 expert, GE Kretz Ultrasound, Zipf, Austria). The translabial ultrasound examinations are performed with the patient in the supine position with slightly flexed legs. Patients will be requested to empty their bladder prior to the examination. No opacification of structures will be performed. The transabdominal transducer is placed against the introitus. The transducer is manipulated until a precise midsagittal view is acquired in the $2 \mathrm{D}$ setting. The midsagittal orthogonal plane includes four reference points: the end of the central axis of the symphysis pubis, the urethra, the anorectal canal and the levator muscle. The ultrasound machine is then switched to the $3 \mathrm{D}$ setting and the box of interest is selected at the minimal anteroposterior diameter of the levator hiatus, from the posterior margin of the symphysis pubis to the anterior margin of the puborectal muscle where it defines the anorectal angle. Two cineloops of contractions of the pelvic floor are recorded and afterwards two cineloops of a valsalva manoeuvre are recorded. The beginnings of all four cineloops are showing the situation at rest. 


\section{Assessment of the volume images}

The recorded volumes will be analysed off-line using Kretz 4D-view V 5.1 software. In a 4D-cineloop of a contraction of the pelvic floor the rendered images in the midsagital $(A)$, frontal $(B)$ and transversal $(C)$ ortogonal plane are analysed. In the cineloop in the A-plane the moment of maximal contracted muscle is selected for analysis. The maximal contracted state is at maximal cranioventral displacement of the levator muscle in the midsagittal view. The box of interest in the midsagittal orthogonal plane includes the four reference points: the end of the central axis of the symphysis pubis, the urethra, the anorectal canal and the levator muscle. In the B-plane the symphysis pubis has to be seen symmetrically on both sides. In the C-plane the symphysis arc, the anorectal canal and the levator sling has to be visualised symmetrically on both sides. If it is not possible to obtain these images, there possibly might exist a levator defect. Other contraction images must be analysed to exclude artefacts because of the recording process. After acquiring the correct C-plane Tomographic Ultrasound imaging is performed. Tomographic Ultrasound Imaging (TUI) is a technique to show the levator ani muscle in multiple slices of $2.5 \mathrm{~mm}$. With this technique levator damages can be assessed. The levator muscle will be assessed in three different slices (reference image*,

and the two more cranially slices +1 and +2 ) for the left and the right muscles separately. The slices are magnified by a factor 1.3. The scoring is performed conform the method as described by Delancey for MR imaging. The percentage of missing muscle is estimated. If no damage is visible a score of 0 will be assigned, if less than half of the muscle is missing a score of 1 will be assigned, if more than half of the muscle is missing a score of 2 will be assigned, and if the complete muscle bulk is lost a score of 3 will be given. Then the scores are summed for the left and right side separately. A total score of 0 denotes no defect; a defect score of 1-3 is a minor defect except when there is a unilateral score of 3 indicating a major defect, score 4-6 indicates a major levator defect too. Asymmetry which can not be resolved by manipulating the axes is suggestive for a unilateral defect. Lateralization of the vagina (like a hanging mouth or butterfly configuration) is another sign for levator defects. Thinning of the attachment of the levator sling to the symphysis pubis with normal configuration indicates a partial defect. The urethral levator gap is assessed by measuring the distance between the center of the urethra and the most lateral parts of the attachment of the levator muscle to the ramus inferior of the symphysis pubis. Measurements in the reference and the two more cranially located slices limage*,+1 and +2 ) can reinforce a suspicion of a levator defect. Finally hiatal area will be measured during rest, during contraction and at maximal valsalva. 


\section{ADDITIONAL FILE 2}

\section{Protocol MR imaging}

MR images will be made according to a strict protocol and images will be stored anonymously. All MR data are evaluated offline by two independent examiners according to protocol using a dicom viewer. The observers are blinded for all clinical data. If there are differences in judgment of the degree of trauma of the levator ani muscle, then a consensus meeting will be convened. Five trained radiologist will come to a final conclusion in this meeting. The attending gynecologist nor the patient is informed on the results of the ultrasound imaging before the follow-up of 1 year is completed.

\section{Protocol for MR scanning}

The MR imaging examination is performed with the patient in supine position with parallel and slightly flexed legs. Patients were requested to void for $0.5 \mathrm{~h}$ prior to their examination. No premedication is given. The urethra, bladder, vagina, and rectum are not opacified. MR images are acquired using either a 1.5 or 3 tesla MR scanner (Siemens/ GE/Philips) and a surface coil. MR images of the pelvis are obtained in the sagittal plane using either a Half-Fourier acquisition single-shot turbo spin-echo sequence $(2000$ $\mathrm{ms} / 90 \mathrm{~ms}$ repetition time/echo time; $150^{\circ}$ flip angle) or true fast imaging with steady state precession. The entire pelvis from symphysis to second or third lumbar vertebrae is scanned. Consequently axial and coronal T2-weighted turbo/fast spin echo sequence l $>3500 \mathrm{~ms}$, < 100ms repetition time/ echo time; $150^{\circ}$ flip angle, slice thickness $3 \mathrm{~mm}$. and $0.5 \times 0.5$ in plane resolution) is acquired covering the entire pelvis from symphysis to the fifth lumbar vertebrae. In addition a 3-dimensional T2-weighted turbo/fast spin echo sequence $k 1 \times 1 \times 1 \mathrm{~mm}$.) may be acquired in addition.

\section{Assessment of the MR images}

By using a dicom viewer all MR images are assessed off line. In the axial and coronal plane the attachment of the levator muscle to the ramus inferios of the sympysis pubis is identified. Asymmetry which can not be resolved by manipulating the axes is suggestive for a unilateral defect. Lateralization of the vagina llike a hanging mouth or butterfly configuration) is another sign for levator defects. Thinning of the attachment of the levator sling to the symphysis pubis with normal configuration indicates a partial defect.

The scoring is performed conform the method as described by Delancey for MR imaging. The percentage of missing muscle is estimated. If no damage is visible a score of 0 will be assigned, if less than half of the muscle is missing a score of 1 will be assigned, if more 
than half of the muscle is missing a score of 2 will be assigned, and if the complete muscle bulk is lost a score of 3 will be given. Then the scores are summed for the left and right side separately. A total score of 0 denotes no defect; a defect score of 1-3 is a minor defect except when there is a unilateral score of 3 indicating a major defect, score 4-6 indicates a major levator defect too. The urethral levator gap is assessed by measuring the distance between the center of the urethra and the most lateral parts of the attachment of the levator muscle to the ramus inferior of the symphysis pubis. 
Translabial 3D ultrasound will be performed after emptying the bladder. 3D ultrasonographic volume data sets will be collected and stored. Afterwards, all volumes will be interpreted independently offline by two examiners who are blinded to the associated clinical data. If disagreement exists, an expert panel, which consist of three trained gynecologists, will decide on a final conclusion in a consensus meeting.

For reading the MR images the same protocol will be followed. Images will be interpreted by two independent examiners and if disagreement exists consensus will be reached by three trained radiologists in a consensus meeting. The radiologists and the gynecologist are also blinded for each others assessment.

\section{Follow-up}

Case record forms on the surgical data and complications will be completed. Follow-up appointments will be made six weeks, six months and twelve months postoperatively. At these measurement time points a physical examination for staging POP will be performed by an independent examiner to diagnose any anatomical recurrence. Validated Quality of Life and subjective feelings of recurrence questionnaires will be handed out before the surgery takes place and at six and twelve months after the surgery (EuroQol-5D, patient global impression of severity/improvement). For all these visits case record forms will be completed.

\section{Outcome measures}

\section{Primary outcome}

The diagnostic test performance of translabial 3D ultrasonography as compared to MR imaging in detecting levator defects.

\section{Secondary outcomes}

1. Measuring the inter-observer agreement in diagnosing and in grading levator defects with 3D ultrasonography.

2. Measuring the association between levator defects and recurrent POP after anterior repair.

3. Evaluating potential cost-effectiveness of introducing 3D ultrasonography for diagnosing levator defects in the work-up of patients with POP.

\section{Data collection}

The data will be recorded in a web based registry. Participants receive a case number to treat their data anonymously and to blind the observers. The observers are also blinded to all ultrasonography, MR imaging data and clinical data. The patient and the attending gynecologist will not be informed of the findings in the study until the study has been finished. 


\section{Sample size consideration}

Ultrasound studies describe a prevalence of $20-40 \%$ of levator defects in patients with POP. ${ }^{[15,17]}$ One MRI study detected levator defects in 55\% of the women with POP. Calculating a sample size for the diagnostic test characteristics is complicated by the fact that only a few studies have been published about reproducibility of 3D ultrasound and in this study no other test characteristics were given. Assuming a sensitivity and specificity of $90 \%$ of $3 \mathrm{D}$ ultrasound for diagnosing levator defects in a population of 120 women with POP, with a prevalence of levator ani defects of $40 \%$, we will be able to estimate predictive values with an accuracy of $10 \%$ below or above the point estimate of positive predictive values and negative predictive values. Including 120 patients yields at least $80 \%$ to demonstrate that inter-observer agreement is substantial (Kappa $\geq 0.61$ ), using a 0.05 significance level in one-sided testing, while expecting a $40 \%$ prevalence of levator defects and anticipating a value of the kappa statistic of 0.78 or better. In order to be able to detect a difference in recurrence rate after anterior colporrhaphy of $25 \%$ or more $135 \%$ in women with a levator defect vs $10 \%$ in women without levator defect), with an alpha of $5 \%$ and a power of $80 \%$, a population of 102 patients with at least POPQ stage II prolapse in the anterior compartment, of whom 41 (40\%) women with a levator defect, will be sufficient.

We are aiming to include 140 patients in this study, taking into consideration 3\% technical problems in performing 3D ultrasonography or MR imaging, which can result in nonevaluable images, and a further safety margin of $10 \%$.

\section{Economic evaluation}

Potential cost-effectiveness of translabial 3D ultrasound in the diagnostic work-up of a patient with POP to diagnose levator defects in order to identify patients at risk for recurrence, and subsequent adjustments of the type of surgery, will be determined by comparing diagnostic strategies. The incremental costs-effectiveness ratio(s) will be expressed as the incremental costs per recurrence avoided. As only part of the data needed to estimate potential costeffectiveness of the 3D ultrasound will be collected empirically, a decision analytic model will be constructed. ${ }^{[22,23]}$ The comparative sensitivity, specificity and costs of $3 \mathrm{D}$ ultrasound versus MR imaging for the diagnostic work-up of patients with POP will explicitly be incorporated in the model. The cost analysis will be performed from a hospital perspective, according to Dutch guidelines and will be estimated from study entry to twelve months follow up. ${ }^{[2]}$

\section{Statistical analysis}

Accuracy of 3D ultrasonography for diagnosing levator defects will be expressed in terms of sensitivity, specificity, standardized predictive values and their $95 \%$-confidence interval. 
For the calculation of $95 \%$-confidence intervals the Wilson formula for proportions will be used. ROC analysis will be performed for the grading of the size of levator defects with 3D ultrasound. Inter-observer and intra-observer agreement of diagnosing levator defects with 3D ultrasound will be evaluated by means of Cohen's Kappa coefficient and intra class coefficient. Logistic regression will be performed to determine whether levator defects constitute an independent risk factor for recurrence after POP surgery.

\section{Time plan}

Patient recruitment started in March 2010 and is planned to continue until June 2011. The follow-up period is 12 months and therefore will continue until June 2012. This study is conducted in cooperation with several centers collaborating in the Dutch Urogynecology Research Consortium. Most participating hospitals have a research nurse, who contributes to the counseling of the patient and the web-based data collection.

\section{Knowledge transfer}

The outcome of this study will be important for the debate on the value of 3D ultrasound of the pelvic floor in a patient with pelvic organ prolapse for detecting levator defects. If the diagnostic accuracy of 3D ultrasonography in diagnosing levator defects and the clinical relevance of levator defects in this study will be confirmed, further implementation into guidelines and training of urogynecologists and ultrasonographers will be taken care of. It is also important to inform gynecologists if this relevance cannot be confirmed, if only to prevent any treatment based on a technique that is not relevant or accurate enough. The results of this study will be presented at national and international scientific meetings, and will be published in international scientific journals. 


\section{REFERENCES}

1. Slieker-ten Hove MC, Pool-Goudzwaard AL, Eijkemans MJ, Steegers-Theunissen RP, Burger CW, Vierhout ME: The prevalence of pelvic organ prolapse symptoms and signs and their relation with bladder and bowel disorders in a general female population. Int Urogynecol J Pelvic Floor Dysfunct 2009; 20:1037-1045.

2. Olsen AL, Smith VJ, Bergstrom JO, Colling JC, Clark AL: Epidemiology of surgically managed pelvic organ prolapse and urinary incontinence. Obstet Gynecol 1997; 89:501-506.

3. Prismant; 2007.

4. Miedel A, Tegerstedt G, Morlin B, Hammarstrom M: A 5-year prospective follow-up study of vaginal surgery for pelvic organ prolapse. Int Urogynecol J Pelvic Floor Dysfunct 2008; 19:1593-1601.

5. Miedel A, Tegerstedt G, Maehle-Schmidt M, Nyren O, Hammarstrom M: Symptoms and pelvic support defects in specific compartments. Obstet Gynecol 2008; 112:851-858.

6. Diez-Itza I, Aizpitarte I, Becerro A: Risk factors for the recurrence of pelvic organ prolapse after vaginal surgery: a review at 5 years after surgery. Int Urogynecol J Pelvic Floor Dysfunct 2007; 18:1317-1324.

7. Whiteside JL, Weber AM, Meyn LA, Walters MD: Risk factors for prolapse recurrence after vaginal repair. Am J Obstet Gynecol 2004; 191:1533-1538.

8. Model AN, Shek KL, Dietz HP: Levator defects are associated with prolapse after pelvic floor surgery. Eur J Obstet Gynecol Reprod Biol 2010; 153:220-223.

9. Salvatore S, Athanasiou S, Digesu GA, Soligo M, Sotiropoulou M, Serati M, Antsaklis A, Milani R: Identification of risk factors for genital prolapse recurrence. Neurourol Urodyn 2009; 28:301-304.

10. Kearney R, Miller JM, Ashton-Miller JA, DeLancey JO: Obstetric factors associated with levator ani muscle injury after vaginal birth. Obstet Gynecol 2006; 107:144-149.

11. Dietz HP, Steensma AB: The prevalence of major abnormalities of the levator ani in urogynaecological patients. Bjog 2006; 113:225-230.

12. Dietz HP, Gillespie AV, Phadke P: Avulsion of the pubovisceral muscle associated with large vaginal tear after normal vaginal delivery at term. Aust N Z J Obstet Gynaecol 2007; 47:341-344.

13. DeLancey JO, Kearney R, Chou Q, Speights S, Binno S: The appearance of levator ani muscle abnormalities in magnetic resonance images after vaginal delivery. Obstet Gynecol 2003; 101:46-53.

14. Dietz HP, Lanzarone V: Levator trauma after vaginal delivery. Obstet Gynecol 2005; 106:707-712.

15. Dietz HP, Simpson JM: Levator trauma is associated with pelvic organ prolapse. Bjog 2008; 115:979-984.

16. Singh K, Jakab M, Reid WM, Berger LA, Hoyte L: Three-dimensional magnetic resonance imaging assessment of levator ani morphologic features in different grades of prolapse. Am J Obstet Gynecol 2003; 188:910-915.

17. DeLancey JO, Morgan DM, Fenner DE, Kearney R, Guire K, Miller JM, Hussain H, Umek W, Hsu Y, AshtonMiller JA: Comparison of levator ani muscle defects and function in women with and without pelvic organ prolapse. Obstet Gynecol 2007; 109:295-302.

18. Weemhoff M, Vergeldt T, Notten K, Serroyen J, Kampschoër P, Roumen F: Levator defects and other risk factors for cystocyle recurrence: a 2 year follow up study. Int Urogynecol 2012; 23(1):66-75.

19. Dietz HP, Chantarasorn V, Shek KL: Levator avulsion is a risk factor for cystocele recurrence. Ultrasound Obstet Gynecol 2010; 36:76-80.

20. Dietz HP: Quantification of major morphological abnormalities of the levator ani. Ultrasound Obstet Gynecol 2007; 29:329-334. 
21. Bump RC, Mattiasson A, Bo K, Brubaker LP, DeLancey JO, Klarskov P, Shull BL, Smith AR: The standardization of terminology of female pelvic organ prolapse and pelvic floor dysfunction. Am J Obstet Gynecol 1996; 175:10-17.

22. Brennan A, Akehurst R: Modelling in health economic evaluation. What is its place? What is its value? Pharmacoeconomics 2000; 17:445-459.

23. Buxton MJ, Drummond MF, Van Hout BA, Prince RL, Sheldon TA, Szucs T, Vray M: Modelling in economic evaluation: an unavoidable fact of life. Health Econ 1997; 6:217-227.

24. Oostenbrink: Handleiding voor kostenonderzoek, methoden en standaard kostprijzen voor economische evaluaties in de gezondheidszorg, 2004. 
TRANSLABIAL THREE-DIMENSIONAL ULTRASOUND COMPARED TO MAGNETIC RESONANCE IMAGING IN DETECTING LEVATOR ANI DEFECTS

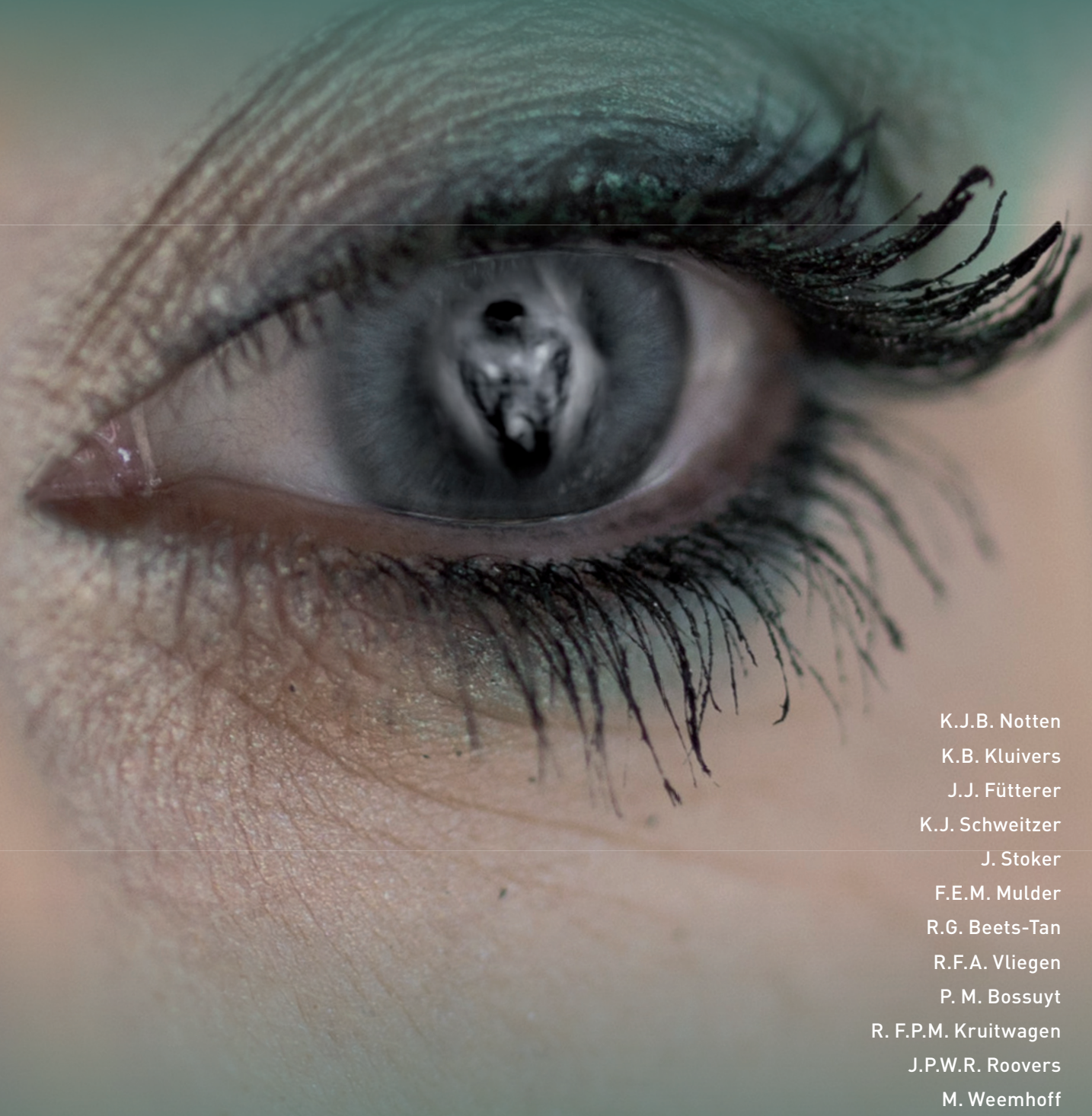




\section{ABSTRACT}

\section{Objective}

To assess the diagnostic performance of translabial three-dimensional ultrasonography in detecting major levator ani defects in women with pelvic organ prolapse (POP) compared to magnetic resonance imaging (MRI). To assess the interobserver agreement in detecting levator ani defects with translabial three-dimensional ultrasonography.

\section{Methods}

In a multicenter cohort study, 140 women indicated for primary surgery of Pelvic Organ Prolapse Quantification (POP-Q) stage II or more cystocele were included. Patients undergoing mesh surgery or concomitant stress incontinence surgery were excluded. All consenting patients underwent translabial three-dimensional ultrasonography and MRI of the pelvic floor, prior to surgery. Two observers (out of a pool of 4 observers) assessed translabial three-dimensional ultrasonography images; two other observers lout a pool of 5 observers) assessed magnetic resonance images for levator ani muscle damage. In case of disagreement, the images were discussed in a consensus meeting.

\section{Results}

Sensitivity was 0.78 (32/41) (95\% Cl: 0.65 to 0.91$)$, specificity was 0.86 (81/94) (95\% Cl: 0.79 to 0.93 ) in detecting major levator ani defects with translabial three-dimensional ultrasonography compared to MRI. There was a good agreement scoring levator ani defects on translabial three-dimensional ultrasonography, with a kappa of 0.67 (95\% Cl: 0.58 to 0.76 ); agreement in recognizing major levator ani defects was moderate, with a kappa of 0.53 ( $95 \% \mathrm{Cl}: 0.37$ to 0.69 ).

\section{Conclusion}

Translabial three-dimensional ultrasonography shows reasonable agreement with magnetic resonance imaging in detecting major levator defects. Because of the moderate interobserver agreement it will be difficult to implement ultrasonography in daily practice.

\section{Clinical Trial Registration}

Trial Register Netherlands 2220, http://www.trialregister.nl. 


\section{INTRODUCTION}

The levator ani muscle seems to play a key role in pelvic floor dysfunction. Major levator ani defects are associated with pelvic organ prolapse (POP) and POP recurrence. ${ }^{[1,2,3,4,5]}$ Levator ani defects can be detected by palpation, Magnetic Resonance Imaging (MRI), and translabial three-dimensional ultrasonography imaging ${ }^{[6,7,7]}$ No gold standard is available but MRI is considered to be the best available reference standard because of its exquisite softtissue contrast and discriminatory capabilities..$^{[4,9]}$

Translabial three-dimensional ultrasonography has practical advantages as it is less expensive, easily accessible and more readily available for gynaecologists. To be an acceptable alternative to MRI, translabial three-dimensional ultrasonography must have reasonable diagnostic performance and reproducibility. Limited data are available on the agreement between MRI and translabial three-dimensional ultrasonography imaging. One study comparing these two imaging modalities in detecting levator ani defects reported a kappa of $0.65 .{ }^{[10]}$

In practice, comparing these two imaging techniques is difficult because different classification systems are used for grading levator ani defects. Dietz et al described a scoring system for translabial three-dimensional ultrasonography which has proven to be good..$^{[11,12,13]}$ DeLancey et al described a scoring system for MRI which showed a good interobserver reliability. ${ }^{[14,15,16]}$

The objective of our research was to estimate the diagnostic performance of translabial threedimensional ultrasonography in detecting levator ani defects in women with POP compared to $\mathrm{MRI}$ as a reference test. The secondary objective was to assess interobserver agreement in detecting levator ani defects with translabial three-dimensional ultrasonography.

\section{MATERIALS AND METHODS}

We performed a prospective multicenter diagnostic study in nine hospitals in the Netherlands: 4 academic centers and 5 teaching hospitals. This study was called the TRUDIL study (TRanslabial 3D-Ultrasonography for Dlagnosing Levator defects). The study was approved in all participating institutions by the institutional review board of the Maastricht University Medical Center, Netherlands (Trial Register Netherlands 2220). ${ }^{[17]}$ Patients were recruited from June 2010 until November 2012.

Women with POP-Q stage II or more cystocele, indicated for anterior colporraphy were eligible for this study. Exclusion criteria included inability to understand the Dutch language, 
contra-indication for undergoing MRI (i.e. pacemakers), previous prolapse surgery or planned surgery with mesh material or incontinence surgery.

Patients were asked to participate in this study by their gynaecologist. Prior to surgery, a pelvic examination was performed including POP-Q staging ${ }^{[11]}$ and all consenting patients underwent translabial three-dimensional ultrasonography and MRI to assess levator ani defects. The imaging examinations were in random order in time.

Data were recorded in a web based registry and all participants received a case number. Observers were blinded from all translabial three-dimensional ultrasonography data, MRI data and clinical data. The patient and the attending gynaecologist where not informed about the findings in the study.

Translabial three-dimensional ultrasonography was performed using a GE Voluson E8 system with a 4-8 $\mathrm{MHz}$ curved array transabdominal volume transducer covered with a condom. The translabial three-dimensional ultrasonography examinations were performed with the patient in the supine position with slightly flexed legs. Patients were requested to empty their bladder prior to the examination.

The transducer was positioned against the introitus, with slight pressure and continued tissue contact. Imaging was performed at rest, on maximum pelvic floor muscle contraction and on maximum strain manoeuvre. ${ }^{[1]}$ Patients were instructed to perform a strain manoeuver by giving the instruction to inhale, hold their breath, and press down as if they were straining while having a bowel movement. A pelvic floor contraction was instructed as preventing the escape of flatus or urine without using the gluteal and abdominal muscles.

In the mid-sagittal plane, four reference points were visualised: the end of the central axis of the symphysis pubis, the urethra, the anorectal canal and the levator ani muscle. ${ }^{[1]]}$ In this plane the minimal antero-posterior diameter of the levator hiatus, from the posterior margin of the symphysis pubis to the anterior margin of the puborectal muscle, was identified. Two four-dimensional volume cines were recorded containing a maximal pelvic floor muscle contraction and two four-dimensional volume cines containing a strain manoeuvre.

The MRI examination was performed with the patient in supine position with parallel and slightly flexed legs. Patients were requested to empty their bladder prior to the examination. No premedication was given. The MRI was performed in rest. The urethra, bladder, vagina, and rectum were not opacified. Magnetic resonance images were acquired using either a 1.5 or 3 tesla MRI scanner (Siemens/GE/Philips) and a pelvic phased array coil. MRI of the pelvis was obtained in the sagittal plane using either a Half-Fourier acquisition single-shot turbo spin-echo sequence $\left(2000 \mathrm{~ms} / 90 \mathrm{~ms}\right.$ repetition time/echo time; $150^{\circ} \mathrm{flip}$ angle) or true fast imaging with steady state precession. The entire pelvis from symphysis to second or third lumbar vertebrae was scanned. Consequently axial and coronal T2-weighted turbo/fast spin echo sequence ( $3500 \mathrm{~ms}$, < $100 \mathrm{~ms}$ repetition time/ echo time; $150^{\circ}$ flip angle, slice 
thickness $3 \mathrm{~mm}$ and $0.5 \times 0.5$ in plane resolution) was acquired covering the entire pelvis from symphysis to the fifth lumbar vertebrae. In addition a three dimensional T2-weighted turbo/ fast spin echo sequence $(<1 \times 1 \times 1 \mathrm{~mm})$ was acquired. Figure 1 shows an example of a levator ani defect on MRI.

Figure 1: Example MRI no levator ani defect (left) and bilateral major levator ani defect (right).
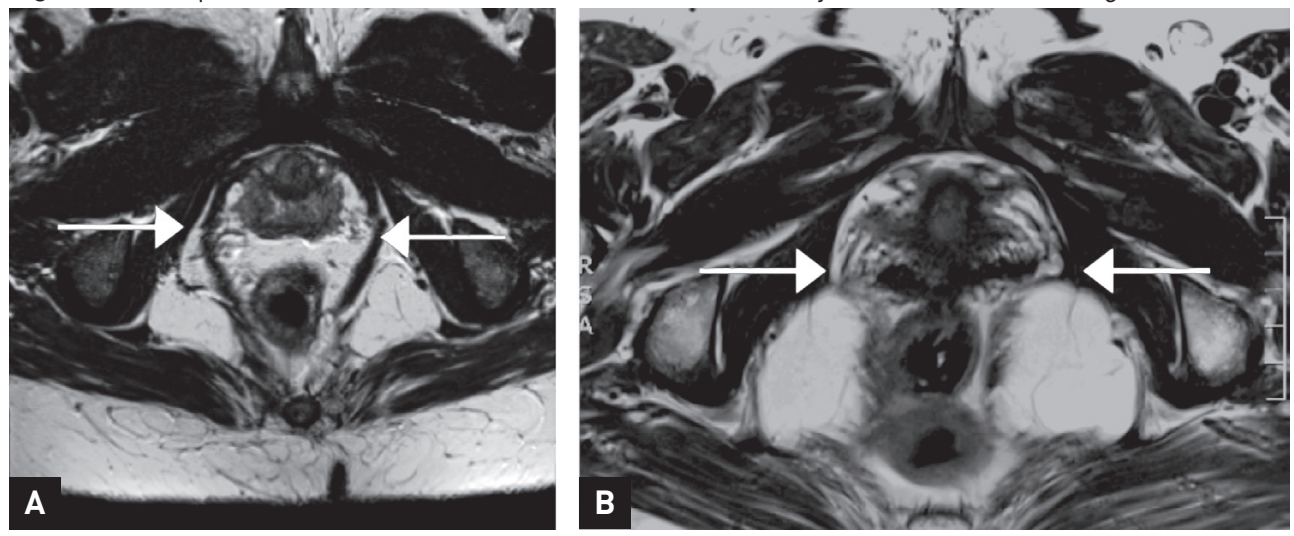

The recorded ultrasonography volumes were analysed off-line using Kretz 4D-view V 5.1 software (GE Kretz Ultrasonography, Zipf, Austria). Tomographic Ultrasonography Imaging (TUI) was used to assess the levator ani muscle in the axial plane in multiple slices of $2.5 \mathrm{~mm}$. The levator ani muscle damage was assessed in the three central slices (the plane of minimal dimensions plus slices 2.5 and $5 \mathrm{~mm}$ cranial to this plane) and the levator urethral gap (LUG) was measured for the left and the right muscle separately. ${ }^{[13]}$ Figure 2 shows an example of a levator ani defect on TUI.

The slices were magnified by a factor 1.3. Each translabial three-dimensional ultrasonography scan was assessed by two different observers independently. Five different observers

Figure 2: Example TUI ultrasound: first images without levator ani defect and second images with bilateral major levator ani defects.
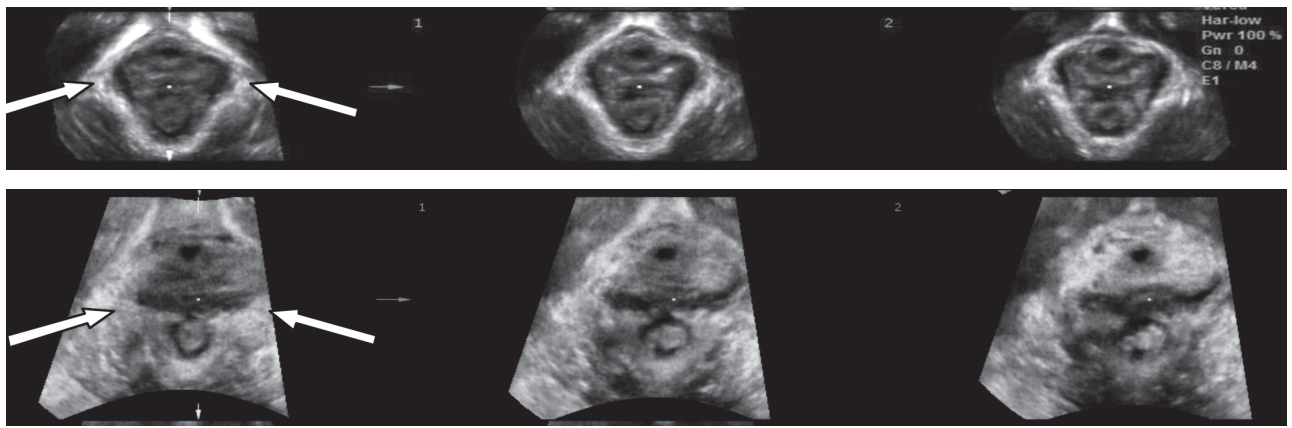
performed and assessed the ultrasonography scans (MW, KJS, KBK, KJBN, FEM); there were no fixed couples of observers.

At the start of the study MW, KJS and KBK had approximately 6 years experience in performing and assessing the translabial three-dimensional ultrasonography scans $(500$ 1000 ultrasonography scans), KJBN approximately 2 years (> 300 ultrasonography scans) and FEM approximately 1 year (> 100 ultrasonography scans). Furthermore all five observers participated in two trainings/consensus meetings before the study started in which approximately 50 images were discussed.

All MRI images were assessed offline using a Dicom viewer (OsiriX, v3.8.1/v5.0.1, Geneva,Switzerland and Impax, version 5.3, Agfa, Belgium). The attachment of the levator ani muscle to the inferior ramus of the pubic symphysis was identified in both the axial and coronal plane. The levator muscle damage was assessed for the left and the right muscle separately. Each MRI scan was assessed by two observers independently. Four different observers assessed MRI scans in different couples (JJF, JS, RGBT, RFAV).

At the start of the study JJF and RFAV had approximately 10 years experience in assessing lower abdominal, colorectal and pelvic floor magnetic resonance images (700-1000 pelvic floor images) while JS and RGBT had approximately 20 years of experience (3000-4000 pelvic floor images). Prior to the start of the study JJF (>100 MRI scans) and JS (>50 MRI scans) had experience in this specific type of MRI scan diagnosing levator ani defects. All observers participated in three consensus meetings/trainings before the study started, including two training sessions given by an international expert, in which approximately 50 images were studied and discussed.

The ultrasonography scans were scored according to the scoring system as described by Dietz et al for the assessment of translabial three-dimensional ultrasonography. ${ }^{[13]}$ In the three central slices, insertion of the levator ani muscle on the pelvic sidewall was assessed as normal or abnormal. A complete avulsion was diagnosed when all three slices showed an absent connection between the levator ani muscle and inferior pubic ramus. Partial avulsion was diagnosed only when one or two slices showed absent connection. No avulsion was diagnosed when all slices showed an intact muscle connection. In doubtful cases, the levator urethral gap was used to discriminate between partial and complete avulsions. When the LUG was $>2.5 \mathrm{~cm}$, a complete avulsion was graded and when the levator urethral gap was measured $<2.5 \mathrm{~cm}$, a partial avulsion was graded. The score from the right and left side were summed. No avulsion was scored if no avulsion was seen in both sides. A complete avulsion was scored if at least one side was scored as a complete avulsion. In all other cases, a partial avulsion was scored. ${ }^{[13,19]}$

Furthermore to facilitate comparison of the outcome after scoring the MRI and threedimensional ultrasonography scans in this study, the scoring system as described by 
DeLancey et al used for describing levator ani defects in the assessment of MRI was also used for describing levator ani defects on translabial three-dimensional ultrasonography scans. ${ }^{[16]}$ The percentage of missing muscle was estimated for the left and right side separately. Score 0 denoted no damage, score 1 denoted less than half of the muscle missing, score 2 denoted more than half of the muscle missing and score 3 denoted a complete defect. The scores from the right and left side were summed. A total score of 0 was categorized as no defect, a defect score of 1-3 was categorized as a minor defect, and a score 4-6 as well as a unilateral score of 3 was categorized as a major levator defect.

Both the translabial three-dimensional ultrasonography images and MRI scans were interpreted independently offline by two observers who were blinded from all clinical data as well as for each other findings. In case disagreement existed, four gynaecologists together (for the ultrasonography scans) and three radiologists together (for the MRI scans), decided on a final conclusion in a consensus meeting, blinded for who had read the examination (minimal time interval of 2 months). There were no comparisons between ultrasonography and MRI in individual patients. Consensus was achieved if the majority of the observers agreed on the final conclusion. An examination was discussed in case there was a difference of at least two points at the 7 point scale or in case there was a difference in scoring category: no defect, minor defect or major defect (in case of the Dietz score: no avulsion, partial avulsion or complete avulsion).

Estimates of the diagnostic performance of translabial three-dimensional ultrasonography in detecting major levator ani defects were expressed in terms of sensitivity, specificity, predictive values, likelihood ratios, each with their $95 \%$-confidence intervals. MRI acted as the clinical reference standard. Sensitivity expresses the proportion with having a levator defect, as detected by the reference standard (MRI), correctly classified as such by the index test (ultrasonography). Specificity expresses the proportion of women without a levator defect correctly identified as such by ultrasonography. The positive predictive value is the proportion of women with a levator defect on ultrasonography who actually have a defect, when evaluated with MRI. The negative predictive value is the proportion of women without a defect on ultrasonography who do not have a levator defect, when evaluated by MRI. The likelihood ratio of a test result indicates how much more likely that result is in patients with a levator defect (as detected on MRI) compared to those without a defect.

Interobserver agreement beyond chance in detecting and grading levator ani defects on translabial three-dimensional ultrasonography imaging was expressed as Cohen's Quadratic Kappa. A kappa of <0.20 denotes poor agreement, 0.21-0.40 fair, 0.41-0.60 moderate, 0.61-0.80 good and 0.81-1.00 very good agreement. ${ }^{[21]}$ The statistical analysis was performed using the statistical software package SPSS version 19.0 (SPSS Inc., Chicago, IL).

We intended to include 140 patients in the study based on previous ultrasonography studies 
which had reported a prevalence of $20-40 \%$ of levator ani defects in patients with POP. ${ }^{[1,2]}$ One MRI study detected levator ani defects in 55\% of the women with POP. Assuming a sensitivity and specificity of $90 \%$ of translabial three-dimensional ultrasonography in detecting levator ani defects in a population of 120 women with POP, at a prevalence of levator ani defects of $40 \%$, we would be able to estimate predictive values with an accuracy of $10 \%$ below or above the point estimate of positive predictive values and negative predictive values. Taking into account $3 \%$ technical problems with MRI scanning or performing translabial three-dimensional ultrasonography resulting in non-evaluable cases and including a safety margin of $10 \%{ }^{[22]}$

Figure 3: Flowchart patient inclusion.

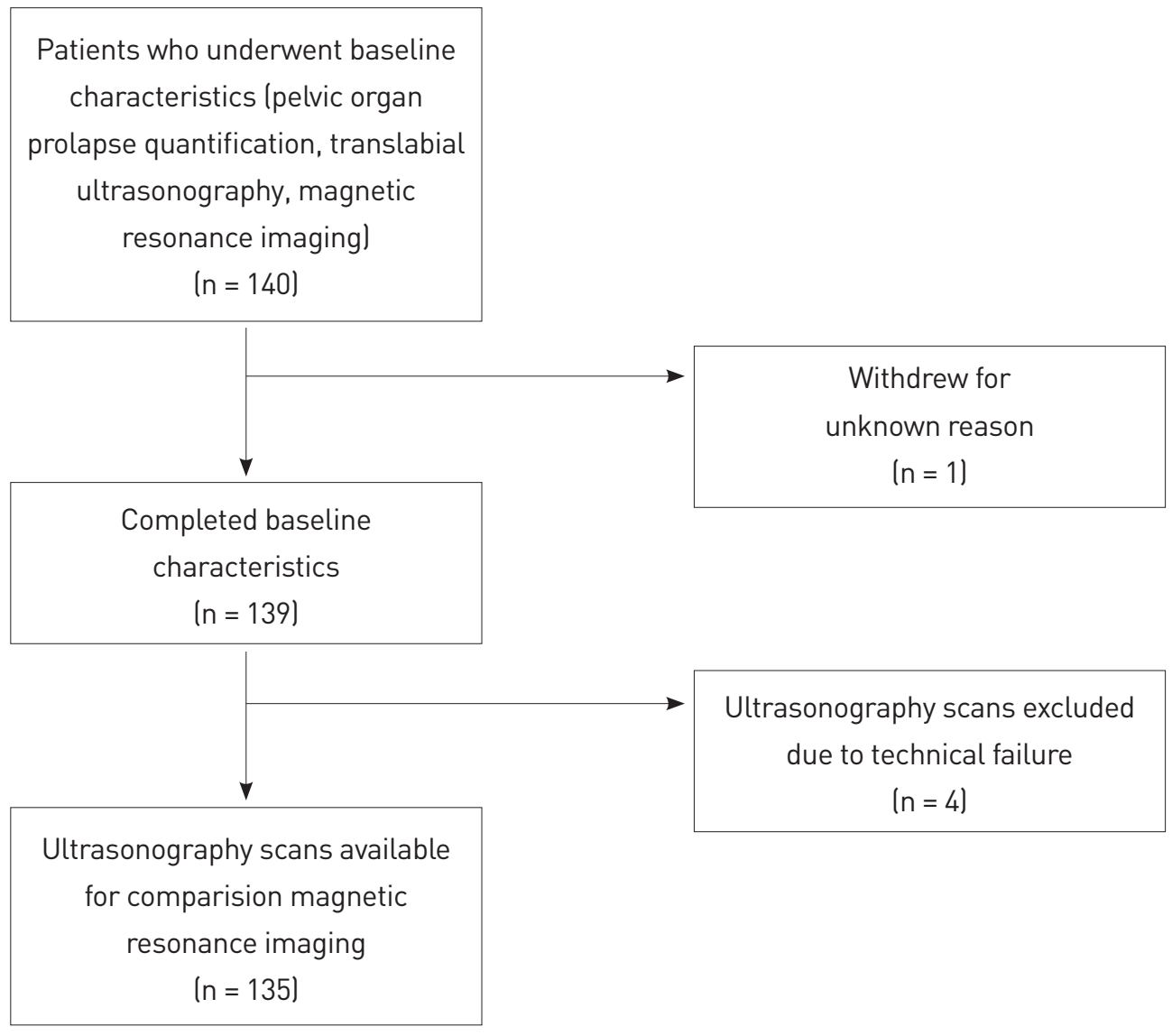




\section{RESULTS}

Between March 2010 until July 2012, 140 patients were included. One patient withdrew from the study after surgery. Of the 139 datasets, four translabial three-dimensional ultrasonography scans were technically incorrectly recorded and therefore could not be read, leaving 135 ultrasonography scans available for the comparison with MRI (see Figure 3). In the consensus meetings, 48 ultrasonography scans out of the 135 and 60 MRI's out of the 139 were discussed because the observers assessed the images differently. Of these disagreements regarding levator defects assessed with ultrasonography, 11 cases were discussed based on a disagreement on the 7 point scale and 37 cases were discussed based on a difference regarding no,minor,major category outcome. Of this 37 cases with a difference in category, 23 cases showed a difference in no/minor defects vs major defects. The disagreements regarding levator defects assessed with MRI, 10 cases were discussed based on a disagreement on the 7 point scale whereas in 50 cases a difference regarding the categories no, minor or major was determined. Of this 50 cases, a difference in the category no/minor versus major was found 38 times.

Patient characteristics are shown in Table 1. In $45 \%$ of patients, surgery was performed due to a high-grade cystocele POPQ stage III or IV.

Table 1: Patient characteristics.

\begin{tabular}{|l|r|}
\hline Age in years, median (range) & $58 \quad(31-78)$ \\
\hline BMI in $\mathrm{kg} / \mathrm{m}^{2}$, median (range) & $26 \quad(17-42)$ \\
\hline Postmenopausal status, $\mathrm{n}(\%)$ & $90 / 139 \quad(65 \%)$ \\
\hline Cystocele POPQ stage III and IV, $\mathrm{n}(\%)$ & $62 / 139 \quad(45 \%)$ \\
\hline Vaginal delivery in history, $\mathrm{n}(\%)$ & $120 / 126 \quad(95 \%)$ \\
\hline Parity, mean (range) & $128 \quad(1-7)$ \\
\hline History of hysterectomy, $\mathrm{n}(\%)$ & $24 / 137 \quad(18 \%)$ \\
\hline
\end{tabular}

$\mathrm{n}=$ number of patients 
Table 2 shows the consensus grading of the levator ani defects using translabial threedimensional ultrasonography compared to the consensus grading using MRI. Out of the 45 major levator ani defects seen on ultrasonography, 32 were confirmed at MRI. Out of the 41 major levator ani defects detected on MRI, nine were missed at translabial three-dimensional ultrasonography.

Table 2: Comparison of consensus Translabial Three-Dimensional Ultrasonography and consensus Magnetic Resonance Imaging findings.

\begin{tabular}{|c|c|c|c|c|c|c|c|c|}
\hline & \multicolumn{4}{|c|}{ MRI } & \multicolumn{4}{|c|}{ MRI } \\
\hline & & $\begin{array}{l}\text { Major } \\
\text { defect }\end{array}$ & $\begin{array}{c}\text { No/minor } \\
\text { defect }\end{array}$ & Total & & $\begin{array}{l}\text { Major } \\
\text { defect }\end{array}$ & $\begin{array}{c}\text { No/minor } \\
\text { defect }\end{array}$ & Total \\
\hline \multirow{3}{*}{$\begin{array}{c}\text { Translabial } \\
\text { ultrasono- } \\
\text { gram }\end{array}$} & $\begin{array}{c}\text { Major defect } \\
\text { ultrasono- } \\
\text { gram* }\end{array}$ & 32 & 13 & 45 & $\begin{array}{l}\text { Complete } \\
\text { avulsion } \\
\text { ultrasono- } \\
\text { gram** }^{*}\end{array}$ & 35 & 32 & 67 \\
\hline & $\begin{array}{c}\text { Major defect } \\
\text { ultrasono- } \\
\text { gram* }\end{array}$ & 9 & 81 & 90 & $\begin{array}{l}\text { No/partial } \\
\text { avulsion } \\
\text { ultrasono- } \\
\text { gram** }\end{array}$ & 6 & 62 & 68 \\
\hline & Total & 41 & 94 & 135 & Total & 41 & 94 & 135 \\
\hline
\end{tabular}

No/minor defect: $0 \%-\leq 50 \%$ missing muscle

Major defect: $\geq 50 \%$ or unilateral $100 \%$ missing muscle

$\mathrm{MRI}=$ magnetic resonance imaging

* Delancey score ultrasound

** Dietz score ultrasound

The consensus grading of the levator ani defects using the Dietz scoring system for translabial three-dimensional ultrasonography compared with the consensus grading using the DeLancey scoring system for MRI shows that 35 of the 67 complete avulsions seen on ultrasonogram were confirmed at MRI. Of the 41 major levator ani defects detected on MRI, 6 were missed at translabial three-dimensional ultrasonogram.

Table 3 contains the diagnostic performance estimates of the consensus read for translabial three-dimensional ultrasonography in detecting major levator ani defects compared to the consensus read for MRI, which acted as the clinical reference standard. The sensitivity of the translabial three-dimensional ultrasonography consensus read for major defects was 0.78 (32/41) (95\% Cl, 0.65 to 0.91$)$ at a specificity of 0.86 (81/94) (95\% Cl, 0.79 to 0.93$)$. Stratifying for BMI and severity of prolapse showed no significant effects of these demographic characteristics on the sensitivity or specificity. The kappa statistic for expressing interobserver agreement beyond chance for two readers of translabial three-dimensional ultrasonography 
Table 3: Diagnostic Characteristics of Consensus of Translabial Three-Dimensional Ultrasonography for Detecting Major Levator Ani Defects Compared With Consensus of Magnetic Resonance Imaging as the Reference Test.

\begin{tabular}{|l|c|c|}
\hline & Delancey score used for both ultrasound and $\mathrm{MRI}$ \\
\hline & & $95 \% \mathrm{Cl}$ \\
\hline Sensitivity & 0.78 & $0.65-0.91$ \\
\hline Specificity & 0.86 & $0.79-0.93$ \\
\hline Positive predictive value & 0.71 & $0.58-0.84$ \\
\hline Positive likelihood ratio & 5.64 & $3.32-9.59$ \\
\hline Negative predictive value & 0.90 & $0.84-0.96$ \\
\hline Negative likelihood ratio & 0.25 & $0.14-0.46$ \\
\hline
\end{tabular}

$\mathrm{Cl}=$ Confidence interval

was 0.67 ( $95 \% \mathrm{Cl}, 0.58$ to 0.76 ) when using the DeLancey scoring system, whereas a kappa of 0.59 ( $95 \% \mathrm{Cl}, 0.46$ to 0.69 ) was found using the Dietz scoring system. The kappa statistic for a dichotomous score (no/minor versus major defect) was respectively 0.53 ( $95 \% \mathrm{Cl} 0.37$ to 0.69 ) and 0.46 ( $95 \% \mathrm{Cl}, 0.32$ to 0.59 ) (Table 4).

Table 4: Interobserver agreement translabial three-dimensional ultrasound and MRI levator ani defects.

\begin{tabular}{|l|c|c|c|c|c|c|}
\hline & $\begin{array}{c}\text { Translabial ultrasound } \\
\text { DeLancey score }\end{array}$ & $\begin{array}{c}\text { Translabial ultrasound } \\
\text { Dietz score }\end{array}$ & \multicolumn{3}{c|}{ MRI } \\
\hline & Kappa & $95 \%$ Cl & Kappa & $95 \%$ Cl & Kappa & $95 \%$ Cl \\
\hline 7 point scale score 0-6 & 0.67 & $0.58-0.76$ & NA & NA & 0.44 & $0.29-0.58$ \\
\hline 3 point scale no-minor-major & 0.60 & $0.50-0.71$ & 0.59 & $0.46-0.69$ & 0.43 & $0.28-0.57$ \\
\hline 2 point scale no/minor - major & 0.53 & $0.37-0.69$ & 0.46 & $0.32-0.59$ & 0.27 & $0.11-0.43$ \\
\hline
\end{tabular}

$\mathrm{MRI}=$ magnetic resonance imaging, $\mathrm{Cl}=$ Confidence interval, $\mathrm{NA}=$ not applicable. 
The interobserver agreement beyond chance for two readers of MRI examination showed a kappa of 0.44 (95\% Cl, 0.29 to 0.59) (Table 4). Interobserver agreement between the two most experienced radiologists in assessing pelvic floor MRI had a kappa of 0.50 ( $95 \% \mathrm{Cl}, 0.26$ to 0.68 ). The scoring systems according to Dietz and DeLancey are compared for grading levator ani defects on ultrasonography scans. More complete avulsions (67) were diagnosed with the Dietz scoring system compared to the DeLancey scoring system (45). Comparison of the two scoring systems, used for assessing levator ani defects in ultrasonography, showed good agreement, with a weighted kappa of 0.67 ( $95 \% \mathrm{Cl}, 0.56$ to 0.75$)$.

\section{DISCUSSION}

In this study in women with POP, we showed that translabial three-dimensional ultrasonography can be used as an alternative for MRI in detecting levator ani defects, with a sensitivity of $78 \%$ and specificity of $86 \%$. Interobserver agreement was good, with moderate interobserver agreement in detecting major levator ani defects (kappa 0.53), illustrating an important shortcoming of translabial three-dimensional ultrasonography.

In another study comparing ultrasonography to MRI findings, Zhuang concluded that levator avulsion can be diagnosed reliably by ultrasonography. In this single center study among 69 Chinese women, the sensitivity of ultrasonography was $1.0(95 \% \mathrm{Cl}, 0.83$ to 1.0$)$ and specificity was $0.88(95 \% \mathrm{Cl}, 0.81$ to 0.94$)$. Although Zhuangs results show a better agreement between ultrasonography and MRI, our findings are in line with their conclusion. ${ }^{[10]}$ The main difference with our study is that our study was performed in a multicenter and multireader setting, giving more information on generalizability of the test accuracy of translabial three-dimensional ultrasonography.

There are several possible explanations for the disagreements between scoring levator ani defects with translabial three-dimensional ultrasonography compared to MRI.

One might argue that the scoring system of DeLancey is not suited for the grading of levator defects assessed with ultrasonography. However, we opted to present this to facilitate comparison between both imaging techniques. Vergeldt has compared the two scoring systems, and reported that agreement was good, especially in patients with no and minor defects. ${ }^{[20]}$ In addition to this we also compared both scoring system for grading levator ani defects in ultrasonography. We also found a good agreement, with a kappa of 0.67 .

The assessment for levator ani defects should ideally be performed in the plane of minimal dimensions of the levator hiatus. In this orthogonal plane there are no defined fixed reference points used in the scoring system for grading levator ani defects, and small differences in the orthogonal plane used for assessment can cause differences between imaging results. To 
diagnose levator ani defects, the plane of minimal dimensions during maximal pelvic floor contraction is assessed. The maximal pelvic floor contraction is however not standardized in $\mathrm{MRI}$ and can cause differences in imaging results. The pathological substrate that is visualized with translabial three-dimensional ultrasonography and MRI may differ as the first is a visible representation of the reflection of sound waves, while MRI is the visible representation of the radio frequency signal emitted by excited hydrogen atoms in the body. Moreover, POP severity may vary from day to day, and is generally more severe at the end of the day. The majority of translabial three-dimensional ultrasonography and MRI examination in the present study were performed on the same day, with in most cases translabial three-dimensional ultrasonography immediately following the MRI. No major bias is expected in this respect. The interobserver agreement in detecting levator ani defects on ultrasonography and MRI has been studied before. For MRI a high interrater agreement for categorical grading of levator ani defects has been reported in a single-center study (kappa $=0.86 ; 95 \% \mathrm{Cl}, 0.83$ to 0.89 ). ${ }^{[23]}$ In contrast, we observed a markedly lower interobserver agreement lweighted Cohen's kappa of 0.44 ]. A similar interobserver agreement was reported by Heilbrun, who also performed a multicenter study. ${ }^{[2]}$ Most likely such multicenter studies represent better performance of a diagnostic test in daily clinical practice as compared to a single center study. The interobserver agreement on ultrasonography findings in our study was also lower than those reported by others like Dietz (weighted Cohen's kappa $=0.83(95 \% \mathrm{Cl}, 0.59$ to 1.00), Zhuang (kappa $=0.86,95 \% \mathrm{Cl}, 0.75$ to 0.96 ) and Volloyhaug (kappa $=0.89$ (95\% Cl, 0.73 to $0.96 .^{(10,12,25)}$ Here also, the multicenter and multireader setting can explain this difference. Most likely such setting is a better reflection of daily clinical practice. Yet, whenever consensus meetings are required to reach a diagnosis using these techniques, this will limit the clinical applicability. A strength of this study is the prospective and multicenter design. However, diagnostic performance studies ideally require a gold standard test with perfect diagnostic performance. For detecting levator ani defect, there is no such test but MRI is considered to be the best available test, and correspondingly was selected as the clinical reference standard in this evaluation. Yet we know that MRI is not error free, which handicaps evaluations of the diagnostic performance of ultrasonography. Based on our study we conclude that translabial three-dimensional ultrasonography is an alternative for MRI in detecting levator defects, though the suboptimal interobserver agreement seems to limits its clinical application. We await further evaluation and external validation of these results, before wider implementation of imaging of levator ani defects in daily clinical practice.

\section{Acknowledgements}

We thank the following experts in the field for their contribution to this study:

Prof. dr. JO DeLancey and Prof. dr. HP Dietz. 


\section{REFERENCES}

1. DeLancey JO, Morgan DM, Fenner DE, Kearney R, Guire K, Miller JM, et al. Comparison of levator ani muscle defects and function in women with and without pelvic organ prolapse. Obstet Gynecol 2007; 109: 295-302.

2. Dietz HP, Simpson JM. Levator trauma is associated with pelvic organ prolapse. BJOG 2008; 115: 979-984.

3. Weemhoff M, Vergeldt TF, Notten K, Serroyen J, Kampschoer PH, Roumen FJ. Avulsion of puborectalis muscle and other risk factors for cystocele recurrence: a 2-year follow-up study. Int Urogynecol J 2011; 23(1):65-71.

4. Margulies RU, Hsu Y, Kearney R, Stein T, Umek WH, DeLancey JO. Appearance of the levator ani muscle subdivisions in magnetic resonance images. Obstet Gynecol 2006; 107:1064-1069.

5. DeLancey JO, Kearney R, Chou Q, Speights S, Binno S. The appearance of levator ani muscle abnormalities in magnetic resonance images after vaginal delivery. Obstet Gynecol 2003; 101:46-53.

6. Kearney R, Miller JM, Delancey JO. Interrater reliability and physical examination of the pubovisceral portion of the levator ani muscle, validity comparisons using MR imaging. Neurourol Urodyn 2006; 25:50-4.

7. Dietz HP, Shek C. Levator avulsion and grading of pelvic floor muscle strength. Int Urogynecol J Pelvic Floor Dysfunct 2008; 19:633-6.

8. Gainey HL. Post-partum observation of pelvic tissue damage. Am J Obstet Gynecol 1943; 46:457-66.

9. Singh K, Jakab M, Reid WM, Berger LA, Hoyte L. Threedimensional magnetic resonance imaging assessment of levator ani morphologic features in different grades of prolapse. Am J Obstet Gynecol 2003; 188:910-5.

10. Zhuang Rong R, Song Yang F, Chen Zi Q, et al. Levator avulsion using a tomographic ultrasound and magnetic resonance-based model. Am J Obstet Gynecol 2011; 205:232.e1

11. Dietz HP, Steensma AB. The prevalence of major abnormalities of the levator ani in urogynaecological patients. BJOG 2006; 113:225-230.

12. Dietz HP, Chantarasorn V, Shek KL. Levator avulsion is a risk factor for cystocele recurrence. Ultrasound Obstet Gynecol 2010; 36:76-80.

13. Dietz HP, Bernardo MJ, Kirby A, Shek KL. Minimal criteria for the diagnosis of avulsion of the puborectalis muscle by tomographic ultrasound. Int Urogynecol J 2011; 22:699-704.

14. Bump RC, Mattiasson A, Bo K, Brubaker LP, DeLancey JO, Klarskov P et al. The standardization of terminology of female pelvic organ prolapse and pelvic floor dysfunction. Am J Obstet Gynecol 1996; 175:10-17.

15. Morgan DM, Umek W, Stein T, Hsu Y, Guire K, DeLancey JO. Interrater reliability of assessing levator ani muscle defects with magnetic resonance images. Int Urogynecol J Pelvic Floor Dysfunct 2007; 18:773-778.

16. Kearney R, Miller JM, Ashton-Miller JA, DeLancey JO. Obstetric factors associated with levator ani muscle injury after vaginal birth. Obstet Gynecol 2006; 107:144-149.

17. http://www.trialregister.nl/trialreg/index.asp. Retrieved May 1, 2010.

18. Talasz H, Kofler M, Lechleitner M. Misconception of the Strain maneuver. International Urogynecology Journal and Pelvic Floor Dysfunction 2010; 22:1197-8.

19. Dietz HP, Abbu A, Shek KL. The levator-urethra gap measurement: a more objective means of determining levator avulsion? Ultrasound Obstet Gynecol 2008; 32:941-9418.

20. Vergeldt TFM, Weemhoff M, Notten KJB, Kessels AGH, Kluivers KB. Comparison of two scoring systems for diagnosing levator ani muscle damage. Int Urogynecol J 2013; 24:1501-6.19.

21. Altman D.G. Practical statistics for medical research. London: Chapman \& Hall/CRC, 1999. 
22. Notten KJ, Weemhoff M, Kluivers KB, Schweitzer KJ, Mulder F, Stoker J et al. Protocol for translabial 3D-ultrasonography for diagnosing levator defects (TRUDIL): a multicentre cohort study for estimating the diagnostic accuracy of translabial 3D-ultrasonography of the pelvic floor as compared to MR imaging. BMC Womens Health 2011; 3;11:23.

23. Morgan DM, Umek W, Stein T, Hsu Y, Guire K, DeLancey JO. Interrater reliability of assessing levator ani muscle defects with magnetic resonance images. Int Urogynecol J Pelvic Floor Dysfunct 2007; 18: 773-8.

24. Heilbrun ME, Nygaard IE, Lockhart ME, Richter HE, Brown MB, Kenton KS, Rahn DD et al. Correlation between levator ani muscle injuries on magnetic resonance imaging and fecal incontinence, pelvic organ prolapse, and urinary incontinence in primiparous women. Am J Obstet Gynecol 2010; 202:488.

25. Volloyhaug I,Wong V, Shek KL, Dietz HP. Does levator avulsion cause distension of the genital hiatus and perineal body? Int Urogynecol J 2013; 24: 1161-5. 

RECURRENT ANTERIOR VAGINAL WALL PROLAPSE?

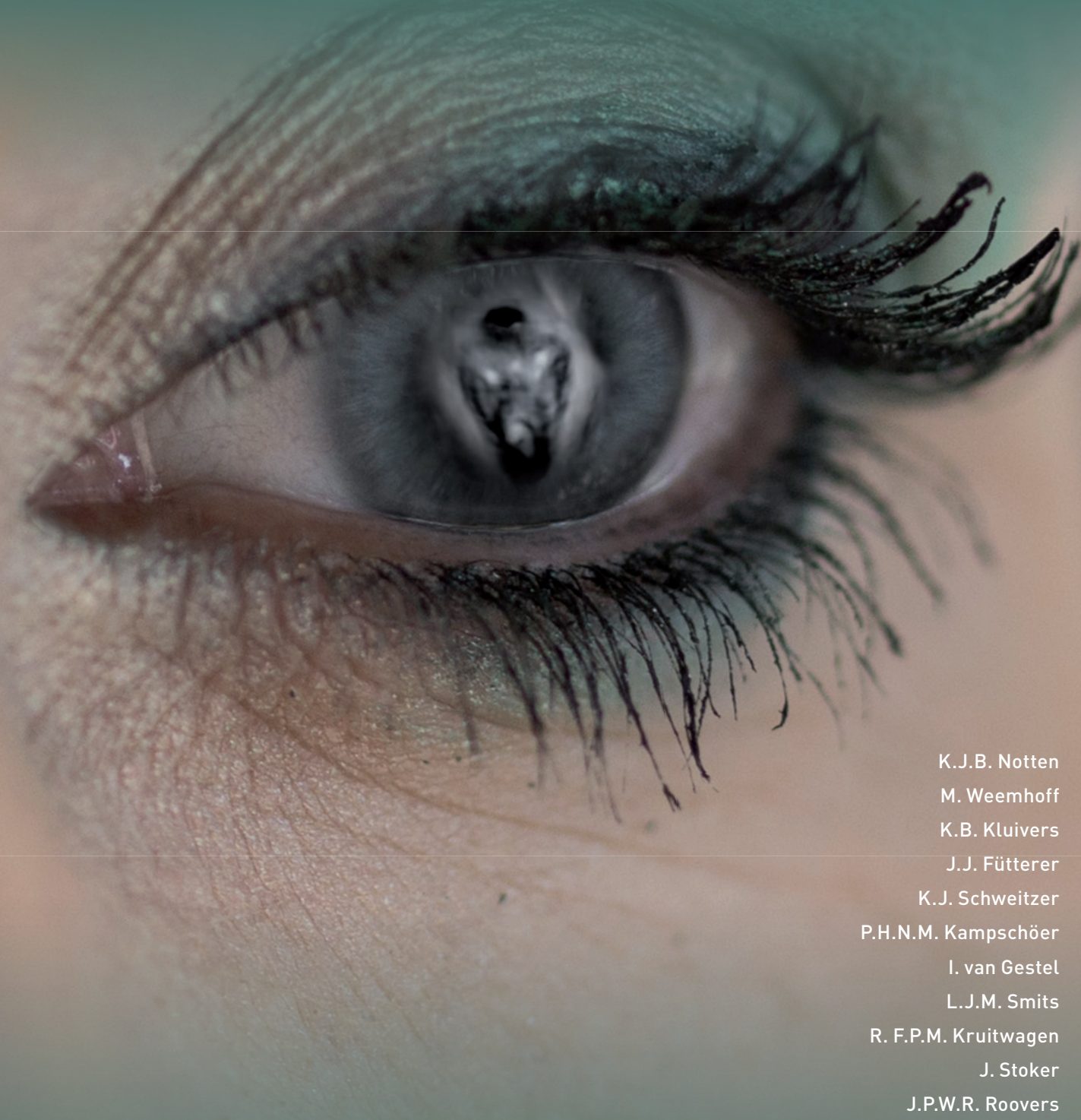




\section{ABSTRACT}

\section{Objective}

To assess whether major levator ani muscle defects are predictive for recurrent objective and subjective anterior vaginal wall prolapse.

\section{Design}

Multicenter prospective cohort study

\section{Setting}

Nine Dutch teaching hospitals

\section{Population}

One hundred forty women with Pelvic Organ Prolapse Quantification system stage 2 or more anterior vaginal wall prolapse, indicated for primary anterior colporrhaphy with or without concomitant prolapse surgery except for mesh or incontinence surgery, were included.

\section{Methods}

Prior to surgery, women completed validated disease specific quality of life questionnaires (Urinary Distress Inventory (UDI), Defecation Distress Inventory (DDI) and EuroQol-5D questionnaire). Furthermore all women underwent POP-Q staging, translabial 3 dimensional (3D) ultrasound and Magnetic Resonance Imaging (MRI) to assess levator ani defects.

At 6 and 12 months after surgery, POP-Q staging was performed and patients were asked to complete the same questionnaires.

\section{Main outcomes}

Association between major levator ani defects and objective or subjective recurrence 12 months after anterior colporrhaphy.

\section{Results}

76 women (54.7\%) had a recurrent anterior vaginal wall prolapse l $\geq P O P-Q$ stage 2 ). Only 12 women out of 135 (8.9\%) reported recurrent prolapse symptoms. Both anatomical and subjective recurrence were reported in 10 patients (7.2\%). Major levator ani defects were detected in 67 patients with translabial 3D ultrasound and in 41 patients with MRI. Major levator ani defects were not significantly associated with recurrent prolapse lultrasound; $\mathrm{p}=0.2 ; \mathrm{OR} 1.6,95 \% \mathrm{Cl}$, 0.8-3.1, MRI; $\mathrm{p}=0.4 ;$ OR 1.4, 95\% Cl, 0.7-2.9). 


\section{Conclusion}

Major levator ani defects do not predict recurrent anterior vaginal wall prolapse following anterior colporraphy.

\section{Key words}

prolapse, anterior colporrhaphy, levator defects, recurrence, ultrasound, MRI

\section{INTRODUCTION}

Pelvic organ prolapse (POP) is a common condition affecting about one out of three women. The first choice surgical treatment of anterior vaginal wall prolapse is anterior colporrhaphy, which is known to have a high re-operation rate of up to $30 \%$ because of primary failure or secondary recurrence of signs and symptoms of POP. ${ }^{[1]}$ Because of this high re-operation rate, prolapse recurrence after pelvic floor surgery constitutes a major health care problem. There have been a number of studies investigating risk factors for POP after pelvic floor surgery. ${ }^{[2,3,4]}$ Levator ani defects are defined as a detachment of the puborectalis muscle from the inferior pubic ramus affecting $15-30 \%$ of women following vaginal delivery and are associated with recurrent POP. ${ }^{[5,6,7]}$ In retrospective studies, only major levator ani muscle defects have been shown to be associated with POP in studies using magnetic resonance imaging (MR imaging) ${ }^{[8]}$ and translabial 3 dimensional (3D) ultrasound. ${ }^{\left[{ }^{[9]}\right.}$ In a surgical audit of patients 3-6 years after anterior colporraphy Dietz and co-workers reported a relative risk of 3 to 4 for anterior vaginal wall prolapse in women with a levator ani defect. ${ }^{[10]}$ Model et al. also observed an association between objective POP after previous pelvic floor surgery and the presence of levator ani defect in women with a previous hysterectomy lodds ratio (OR) 2.5; 95\% Confidence interval (CI) 1.4-4.5), anterior repair (OR 2.1; 95\% Cl, 0.9-4.7) or incontinence or POP procedure (OR 2.3; 95\% Cl, 1.2-4.4). ${ }^{[3]}$ Weemhoff et al. reported that a complete avulsion of the levator ani muscle is a risk factor for anatomical recurrence (OR 2.4; 95\% Cl, 1.3-4.7). No association was found between partial avulsions of the levator ani muscle and anatomical recurrence. ${ }^{[2]}$

This prospective multicenter cohort study was designed to assess whether major levator ani defects diagnosed with translabial 3D ultrasound or MR imaging predict objective or subjective recurrence of anterior vaginal wall prolapse 12 months after anterior colporraphy. 


\section{METHODS}

A multicenter prospective cohort study was performed in nine teaching hospitals in the Netherlands. ${ }^{[11]}$ Women with Pelvic Organ Prolapse Quantification system (POP-Q) stage 2 or more anterior vaginal wall prolapse, indicated for primary anterior colporrhaphy with or without concomitant prolapse surgery were asked to participate. The exclusion criteria were insufficient knowledge of the Dutch language, contra-indication for undergoing MR imaging or patients who were indicated for mesh surgery or concomitant incontinence surgery. The study was approved for all participating institutions by the institutional review board of the Maastricht University Medical Centre, Netherlands (number 08-2-093). ${ }^{[12]}$ Women were recruited from June 2010 until November 2012. Prior to surgery, POP was staged according to the POP-Q staging system of the International Continence Society. ${ }^{[13]}$ The women were asked to complete the Dutch version of validated questionnaires (Urinary Distress Inventory (UDI) ${ }^{[14,15]}$, Defecation Distress Inventory $(D D I)^{[16]}$ and EuroQol-5D questionnaire ${ }^{[17]}$ and all women underwent translabial 3D ultrasound and MR imaging to assess major levator ani defects. Subsequently at 6 and 12 months after surgery a physical examination was performed including POP-Q staging, and women were again asked to complete the same questionnaires. The surgical procedures were performed by, or under direct supervision of, a gynaecologist with special interest and experience in pelvic floor surgery. Surgeons were blinded for the imaging results prior to surgery.

POP-Q staging after surgery was performed by an independent examiner who was experienced in performing POP-Q and was not the surgeon. This examiner was blinded for the translabial $3 \mathrm{D}$ ultrasound results, the MR imaging results and the questionnaire outcome.

Anatomical recurrence was defined as an anterior vaginal wall prolapse stage 2 or more according to the POP-Q classification. ${ }^{[13]}$ Subjective recurrence was defined as (1) feeling and/or (2) seeing a vaginal bulge, with at least a judgment of one of these two symptoms as moderately bothersome, or both of these two symptoms as somewhat bothersome, according to the scoring system of the validated UDI questionnaire. Compound recurrence was defined as the presence of both subjective and anatomical recurrence.

Data were recorded in a webbased registry and all participants received a case number. The observers of the imaging modalities, the women and the attending gynaecologists were blinded to all imaging and questionnaires outcomes, as well as for the clinical data.

The translabial 3D ultrasound was performed preoperatively using GE Voluson E8 system with a 4-8 MHz curved array transabdominal volume transducer covered with a condom. The translabial 3D ultrasound examinations were performed with the women in the supine position with slightly flexed legs. Women were requested to empty their bladder prior to the examination. The transducer was positioned on the introitus, with slight pressure and good 
tissue contact. Imaging was performed at rest, on maximum pelvic floor muscle contraction and on maximum Valsalva manoeuvre. In the mid-sagittal plane, four reference points (the end of the central axis of the symphysis pubis, the urethra, the anorectal canal and the levator muscle) were visualised. ${ }^{[10]}$ In this plane the minimal antero-posterior diameter of the levator hiatus, from the posterior margin of the symphysis pubis to the anterior margin of the puborectal muscle was identified. Two 4D volume cines were recorded containing a maximum pelvic floor muscle contraction and two 4D volume cines containing a Valsalva manoeuvre.

The recorded volumes were analysed off-line using Kretz 4D-view V 5.1 software (GE Kretz Ultrasound, Zipf, Austria). All scans were assessed by two out of five gynaecologists, and there were no fixed couples. These gynaecologists were experienced in assessing these images (experience in years: 1-6 and number of pelvic floor examinations assessed: 100-1000).

Tomographic Ultrasound Imaging (TUI) was used to assess the levator ani muscle in the axial plane in multiple slices of $2.5 \mathrm{~mm}$. The levator ani muscle damage was assessed for the left and the right muscle separately. The slices were magnified by a factor 1.3. The diagnosis was confirmed, if at least the reference slice (at the level of the plane of minimal dimensions) and the two slices cranial to the reference slice showed a defect. This method has been described by Dietz and has been shown to be reproducible. ${ }^{[18,19,20]}$

The MR imaging examination was performed preoperatively with the patient in supine position with parallel and slightly flexed legs. Women were requested to empty their bladder prior to the examination. No premedication was given. The urethra, bladder, vagina, and rectum were not opacified. Imaging was performed at rest. MR images were acquired using either a 1.5 or 3 tesla MR scanner (Siemens/GE/Philips) and a pelvic phased array coil. MR images of the pelvis were obtained in the sagittal plane using either a Half-Fourier acquisition singleshot turbo spin-echo sequence (2000 ms/90 ms repetition time/echo time; $150^{\circ}$ flip angle) or true fast imaging with steady state precession. The entire pelvis from symphysis to second or third lumbar vertebrae was scanned. Consequently axial and coronal T2-weighted turbo/ fast spin echo sequence ( $>3500 \mathrm{~ms}$, < 100ms repetition time/ echo time; $150^{\circ}$ flip angle, slice thickness $3 \mathrm{~mm}$ and $0.5 \times 0.5$ in plane resolution) was acquired covering the entire pelvis from symphysis to the fifth lumbar vertebrae.

All images were assessed offline using a Dicom viewer (OsiriX, v3.8.1/v5.0.1, Geneva, Switzerland and Impax, version 5.3, Agfa, Belgium). The attachment of the levator ani muscle to the ramus inferior of the symphysis pubis was identified in both the axial and coronal plane. The levator ani muscle damage was assessed for the left and the right muscle separately. Levator ani damage was graded according to the scoring system described by DeLancey. ${ }^{\left[{ }^{[3}\right.}$ All scans were assessed by two out of four radiologists, and there were no fixed couples. These radiologists were experienced in assessing these images lexperience in years: 10-20 
and number of pelvic floor MR examinations assessed: 700-4000).

In case of disagreement (Ultrasound: 48 cases, MR imaging: 60 cases ), four gynaecologists together (for the translabial 3D ultrasound scans) and three radiologists together (for the MR imaging scans), decided on a final conclusion in a consensus meeting, blinded for previous assessment of the examination (minimal time interval of 2 months). The outcome of this consensus meeting was used in these particular cases as a definite assessment.

Statistical analysis was conducted using SPSS Version 19.0 (SPSS Inc., Chicago, IL). Levator defects as a risk factor for anatomical recurrence were tested in a univariate analysis. We used Pearson's Chi ${ }^{2}$ test to assess differences between the recurrence and the nonrecurrence group for categorical variables. Logistic regression models were employed to calculate (adjusted) OR's and $95 \% \mathrm{Cl}$ for potential risk factors. To quantify the predictive value of MR imaging and translabial 3D ultrasound for predicting recurrence within 12 months after surgery, we computed sensitivity, specificity and positive and negative predictive values for a fixed threshold. The Last-Observation-Carried-Forward (LOCF) method was used in case of missing data. ${ }^{[21,22]}$ For all statistical testing, a $p$ value of $<0.05$ was considered to be statistically significant.

Calculating the optimal sample size, we took under consideration that ultrasound studies have reported a prevalence of $20-40 \%$ of levator ani defects in women with POP. ${ }^{[1,23]}$ One MR imaging study detected levator ani defects in 55\% of the women with POP. Assuming a sensitivity and specificity of $90 \%$ of translabial 3D ultrasound for diagnosing levator ani defects in a population of 120 women with POP, with a prevalence of levator ani defects of $40 \%$, we would be able to estimate predictive values with an accuracy of $10 \%$ below or above the point estimate of positive predictive values and negative predictive values. In order to be able to detect a difference in recurrence rate after anterior colporrhaphy of $25 \%$ or more (35\% in women with a levator ani defect versus 10\% in women without levator ani defect), with an alpha of $5 \%$ and a power of $80 \%$, a population of 102 women with at least POP-Q stage 2 prolapse in the anterior compartment, of whom 41 (40\%) women with a levator ani defect, will be sufficient. Taking into account 3\% technical problems with MR imaging or performing translabial 3D ultrasound, resulting in non- evaluable cases and including a safety margin of $10 \%$, we intended to include 140 women in the study. ${ }^{[11]}$

\section{RESULTS}

Between March 2010 and July 2012, 140 women were included. One woman withdrew from the study after the operation for unknown reason. Of the remaining 139 datasets, 4 ultrasound scans were technically incorrectly recorded and could therefore not be assessed, leaving 
135 translabial 3D ultrasound scans and 139 MR images available for detecting levator ani defects. Twelve months postoperatively, 123 patients visited for physical examination. Follow up data on anatomic recurrence was therefore available for 123 women. From the other 16 women who did not visit at 12 months, POP-Q examination data were available from 6 months earlier. By carrying the last observation forward we have information on anatomic recurrence of 139 women. Twelve months postoperatively, 121 women filled in the validated questionnaires; therefore follow-up data on subjective feelings of recurrence was available for 121 women. Of the other 18 women who did not complete the questionnaires, 14 women did complete the questionnaire at 6 months follow-up. By carrying the last observation forward we have information of subjective recurrence of 135 women. Four women did not complete the questionnaires at both follow-up moments. The database at 12 months follow up, contains a complete (translabial 3D ultrasound, physical examination and questionnaire) dataset for 135 of 140 women (93.5\%); see Table 1.

The baseline characteristics of the study population is shown in Table 1.The median age was 57 years (range 31 to 78 years) and median Body Mass Index (BMI) was $26 \mathrm{~kg} / \mathrm{m}^{2}$ (range 17 to $42 \mathrm{~kg} / \mathrm{m} 2$ ). A postmenopausal status was reported in 90 women (65\%). The preoperative clinical examination in 62 women showed an anterior vaginal wall prolapse POP-Q stage 3 or $4(45 \%)$.

Table 1: Patient characteristics.

\begin{tabular}{|l|r|r|}
\hline Age in years (median) & $57 \quad(31-78)$ \\
\hline BMI in kg/m² (median) & $26 \quad(17-42)$ \\
\hline Postmenopausal status, $\mathrm{n}(\%)$ & $90 / 139 \quad(65 \%)$ \\
\hline Cystocele POP-Q stage 3 and 4, n(\%) & $62 / 139 \quad(45 \%)$ \\
\hline $\begin{array}{l}\text { Vaginal delivery in history (\%) } \\
\text { Solitair repair anterior compartment }\end{array}$ & $120 / 126 \quad(95 \%)$ \\
\hline Concomittant repair apical compartment & $36 / 139 \quad(26 \%)$ \\
\hline $\begin{array}{l}\text { BMI = Body Mass Index } \\
\text { POP-Q = Pelvic Organ Prolapse Quantification system }\end{array}$ & $69 / 139 \quad(50 \%)$ \\
\hline
\end{tabular}


Twelve months postoperatively, 76 women out of 139 (54.7\%) had a recurrent anterior vaginal wall prolapse POP-Q stage 2 or more. Only 12 women out of $135(8.9 \%)$ reported symptoms of recurrence. Ten women (7.2\%) had both anatomical recurrence and subjective feelings of a recurrence; see Table 2 .

Of the 135 women, of which ultrasound imaging was available, 67 women (49.6\%) had a major levator ani defect detectable on translabial 3D ultrasound examination. Of the 139 women of which MR imaging was available, 43 (30.9\%) women were diagnosed with major levator ani defects. There was no significant association between objective prolapse after pelvic floor surgery and the presence of a major levator ani defect diagnosed with either translabial 3D ultrasound

Table 2: Recurrent anterior vaginal wall 12 months after anterior repair.

\begin{tabular}{|l|c|c|}
\hline & N (\%) \\
\hline Anatomic recurrence & $76 / 139 \quad(54.7)$ \\
\hline Subjective recurrence & $12 / 135 \quad(8.6)$ \\
\hline Compound recurrence & $10 / 136 \quad$ (7.2) \\
\hline
\end{tabular}

$\mathrm{N}=$ number of patients

Table 3: Association between major levator ani defects and outcome recurrence.

\begin{tabular}{|c|c|c|c|c|}
\hline Major levator defect & Outcome & OR & $\mathbf{p}$ & $95 \% \mathrm{Cl}$ \\
\hline \multirow{3}{*}{$\begin{array}{l}\text { Translabial } \\
\text { ultrasound }\end{array}$} & Objective recurrence & 1.6 & 0.19 & $0.8-3.1$ \\
\hline & Subjective recurrence & 2.2 & 0.19 & $0.7-7.3$ \\
\hline & Compound recurrence & 1.7 & 0.44 & $0.4-6.8$ \\
\hline \multirow{3}{*}{ MR imaging } & Objective recurrence & 1.4 & 0.36 & $0.7-2.9$ \\
\hline & Subjective recurrence & 1.6 & 0.47 & $0.5-5.0$ \\
\hline & Compound recurrence & 1.6 & 0.49 & $0.4-6.0$ \\
\hline $\begin{array}{l}\text { OR }=\text { odds ratio } \\
\mathrm{p}=\mathrm{P} \text { value },<0.05 \text { is } \\
95 \% \mathrm{Cl}=95 \% \text { confid } \\
\mathrm{MR}=\text { Magnetic Reso }\end{array}$ & $\begin{array}{l}\text { ificant } \\
\text { e interval } \\
\text { ce imaging }\end{array}$ & & & \\
\hline
\end{tabular}


( $p=0.2 ;$ OR 1.6, 95\% Cl, 0.8-3.1), or MR imaging ( $p=0.4 ; \mathrm{OR} 1.4,95 \% \mathrm{Cl}, 0.7-2.9)$. There was also no statistically significant association between subjective recurrence or compound recurrence and the presence of a major levator ani defect diagnosed with translabial 3D ultrasound or MR imaging; see Table 3. The diagnostic test characteristics for major levator ani defects detected with translabial 3D ultrasound and MR imaging as a test to predict anatomical anterior vaginal wall recurrence are depicted in Table 4. The positive predictive values were between 0.08 and 0.61 .

Table 4: Predictive value of detecting major levator ani defects on translabial 3D ultrasound and MR imaging for recurrence 12 months after surgery.

\begin{tabular}{|c|c|c|c|c|c|c|}
\hline & & \multicolumn{2}{|c|}{ MRI } & \multicolumn{3}{|c|}{ Ultrasound } \\
\hline & & & $95 \% \mathrm{Cl}$ & & \multicolumn{2}{|c|}{$95 \% \mathrm{Cl}$} \\
\hline \multirow{4}{*}{ Anatomic recurrence } & Sensitivity & 0.34 & $0.24-0.46$ & 0.55 & 0.43 & -0.66 \\
\hline & Specificity & 0.73 & $0.60-0.83$ & 0.56 & 0.43 & -0.69 \\
\hline & PPV & 0.61 & $0.44-0.75$ & 0.60 & 0.47 & -0.72 \\
\hline & NPV & 0.48 & $0.38-0.58$ & 0.52 & 0.39 & -0.64 \\
\hline \multirow{4}{*}{ Subjective recurrence } & Sensitivity & 0.38 & $0.14-0.68$ & 0.54 & 0.25 & -0.81 \\
\hline & Specificity & 0.71 & $0.62-0.79$ & 0.51 & 0.42 & -0.60 \\
\hline & PPV & 0.13 & $0.04-0.24$ & 0.11 & 0.05 & -0.21 \\
\hline & NPV & 0.92 & $0.84-0.96$ & 0.91 & 0.81 & -0.97 \\
\hline \multirow{4}{*}{ Compound recurrence } & Sensitivity & 0.40 & $0.12-0.74$ & 0.50 & 0.19 & -0.81 \\
\hline & Specificity & 0.71 & $0.62-0.78$ & 0.51 & 0.42 & -0.60 \\
\hline & PPV & 0.09 & $0.03-0.23$ & 0.08 & 0.03 & -0.17 \\
\hline & NPV & 0.94 & $0.87-0.98$ & 0.93 & 0.83 & -0.98 \\
\hline \multicolumn{2}{|c|}{ MRI = Magnetic Resonance Imaging } & \multicolumn{5}{|c|}{ NPV = negative predictive value } \\
\hline \multicolumn{2}{|c|}{ PPV = positive predictive value } & \multicolumn{5}{|c|}{$95 \% \mathrm{Cl}=95 \%$ confidence interval } \\
\hline
\end{tabular}




\section{DISCUSSION}

\section{Main findings}

In this prospective multicenter cohort study we could not confirm the results of previous studies that the detection of major levator ani defects at imaging predicts recurrent anterior compartment prolapse 12 months after anterior colporrhaphy. Twelve months after anterior colporrhaphy surgery, we found an anatomic (objective) recurrence rate of $54.7 \%$.

\section{Strengths and Limitations}

The most critical advantage of our study design is the availability of preoperative data, especially preoperative POP staging and pelvic floor status established with translabial 3D ultrasound and MR imaging. Furthermore the multicenter setting, in which five gynaecologists and four radiologists from different centres where involved in assessing ultrasound and MR images, is a benefit for the generalizability of the results.

We also acknowledge the limitations of this study. To deal with missing data we used the LOCF method. ${ }^{[21,22]}$ Using missing data methods can introduce bias. Unfortunately, no universally applicable method of handling missing values can be recommended. However referring to our primary aim anatomic recurrence, of the 139 women, 123 women visited 12 months postoperatively. Of the 16 women of which anatomic recurrence data was missing, all women visited the 6 months visit. The majority (10) of the 16 women of whom data was missing at the 12 months visit, already had an anatomic recurrence (i.e $\geq P O P-Q$ stage 2 ) at 6 months follow up, meaning that no major bias was expected by imputing the data. Another limitation is that our study was not powered for subjective and compound recurrence, but only for anatomical recurrence.

\section{Interpretations}

The anatomical anterior vaginal wall prolapse recurrence rate in our study is consistent with the recurrence rate described in other studies. ${ }^{[10,24]}$ However our results on levator ani defects are not consistent with data obtained by other research groups that imply that major levator ani defects are a risk factor for POP recurrence after anterior colporrhaphy. ${ }^{[2,3,10]}$

We think that the prospective design of our study is the main factor that explains the difference with findings of retrospective studies. In the retrospective studies, the translabial 3D ultrasound examination for diagnosing levator ani defects was performed after surgery, usually at the same time POP-Q staging for diagnosing a recurrence took place, and not preoperatively. ${ }^{[2,3,10]}$ We can imagine that the existence of POP can influences the ultrasound appearance of the pelvic floor mimicking a levator ani defect. Furthermore the surgery itself 
can influence the ultrasound appearance of the pelvic floor anatomy and therefore levator ani defects can be interpreted differently. These facts can lead to systematic bias in the retrospective studies.

\section{CONCLUSION}

In this multicenter, prospective cohort study the presence of major levator ani defects at translabial 3D ultrasound or MR imaging did not predict recurrence of the anterior compartment following anterior colporraphy. We therefore do not recommend pelvic floor imaging for detecting levator ani defects in the routine diagnostic work up of a POP patient. 


\section{REFERENCES}

1. Olsen AL, Smith VJ, Bergstrom JO, Colling JC, Clark AL. Epidemiology of surgically managed pelvic organ prolapse and urinary incontinence. Obstet Gynecol 1997; 89:501-50.

2. Weemhoff M, Vergeldt TF, Notten K, Serroyen J, Kampschoer PH, Roumen FJ. Avulsion of puborectalis muscle and other risk factors for cystocele recurrence: a 2-year follow-up study. Int Urogynecol $J$ 2012; 23: 65-71.

3. Model AN, Shek KL, Dietz HP. Levator defects are associated with prolapse after pelvic floor surgery. Eur J Obstet Gynecol Reprod Biol 2010; 153: 220-3.

4. Wong V, Shek K, Rane A, Goh J, Krause H, Dietz HP. Is levator avulsion a predictor of cystocele recurrence following anterior vaginal mesh placement? Ultrasound Obstet Gynecol 2013; 42: 230-4.

5. Dietz H, Lanzarone V. Levator trauma after vaginal delivery. Obstet Gynecol 2005; 106: 707-712.

6. Shek K, Dietz H. Intrapartum risk factors of levator trauma. BJOG 2010; 117: 1485-1492.

7. Dietz H, Gillespie A, Phadke P. Avulsion of the pubovisceral muscle associated with large vaginal tear after normal vaginal delivery at term. Aust NZ J Obstet Gynaecol 2007; 47:341-344.

8. DeLancey JO, Morgan DM, Fenner DE, Kearney R, Guire K, Miller JM et al. Comparison of levator ani muscle defects and function in women with and without pelvic organ prolapse. Obstet Gynecol 2007; 109:295-302.

9. Dietz HP, Simpson J. Levator trauma is associated with pelvic organ prolapse. BJOG 2008; 115:979-84.

10. Dietz HP, Chantarasorn V, Shek KL. Levator avulsion is a risk factor for cystocele recurrence. Ultrasound Obstet Gynecol 2010; 36:76-80.

11. Notten KJB, Weemhoff M, Kluivers KB, Schweitzer KJ, Mulder F, Stoker J et al. Protocol for translabial 3D-ultrasonography for diagnosing levator defects (TRUDIL): a multicenter cohort study for estimating the diagnostic accuracy of translabial 3D-ultrasonography of the pelvic floor as compared to MR imaging. BMC Womens Health 2011; 11:23.

12. http://www.trialregister.nl/trialreg/index.asp

13. Bump RC, Mattiasson A, Bo K, Brubaker LP, DeLancey JO, Klarskov P et al. The standardization of terminology of female pelvic organ prolapse and pelvic floor dysfunction. Am J Obstet Gynecol 1996; 175:10-17.

14. Shumaker SA, Wyman JF, Uebersax JS, McClish D, Fantl JA. Health-related quality of life measures for women with urinary incontinence: the Incontinence Impact Questionnaire and the Urogenital Distress Inventory Continence Program in Women (CPW) Research Group. Qual Life Res 1994; 3:291-306.

15. Vaart CH, Leeuw JR, Roovers JP, Heintz AP. Measuring health-related quality of life in women with urogenital dysfunction: the urogenital distress inventory and incontinence impact questionnaire revisited. Neurourol Urodyn 2003; 22:97-104.

16. Brummen HJ, Bruinse HW, Pol G, Heintz AP, Vaart CH. Defecatory symptoms during and after the first pregnancy: prevalences and associated factors. Int Urogynecol J Pelvic Floor Dysfunct 2006; 17:224-230.

17. Macran S, Kind P. "Death" and the valuation of health-related quality of life. Med Care 2001; 39:217-27.

18. Dietz HP, Steensma AB. The prevalence of major abnormalities of the levator ani in urogynaecological patients. BJOG 2006; 113:225-230.

19. Dietz HP. Quantification of major morphological abnormalities of the levator ani. Ultrasound Obstet Gynecol 2007; 29:329-334.

20. Dietz HP, Bernando MJ, Kirby A, Shek KL. Minimal criteria for the diagnosis of avulsion of the puborectalis muscle by tomographic ultrasound. Int Urogynecol J 2011; 22:699-704. 
21. Gadbury GL, Coffey CS, Allison DB. Modern statistical methods for handling missing repeated measurements in obesity trial data: beyond LOCF. Obes Rev 2003; 4:175-84.

22. Mallinckrodt $\mathrm{CH}$, Clark WS, David SR. Accounting for dropout bias using mixed-effects models. J Biopharm Stat 2001; 11:9-21.

23. Slieker-ten Hove MC, Pool-Goudzwaard AL, Eijkemans MJ, Steegers- Theunissen RP, Burger CW, Vierhout ME. The prevalence of pelvic organ prolapse symptoms and signs and their relation with bladder and bowel disorders in a general female population. Int Urogynecol J Pelvic Floor Dysfunct 2009; 20:1037-1045.

24. Sand PK, Koduri S, Lobel RW, Winkler HA, Tomezsko J, Culligan PJ et al. Prospective randomized trial of polyglactin 910 mesh to prevent recurrence of cystoceles and rectoceles. Am J Obstet Gynecol 2001; 184:1357-1362. 
LEVATOR HIATAL AREA AS A RISK FACTOR FOR CYSTOCELE RECURRENCE AFTER SURGERY: A PROSPECTIVE STUDY

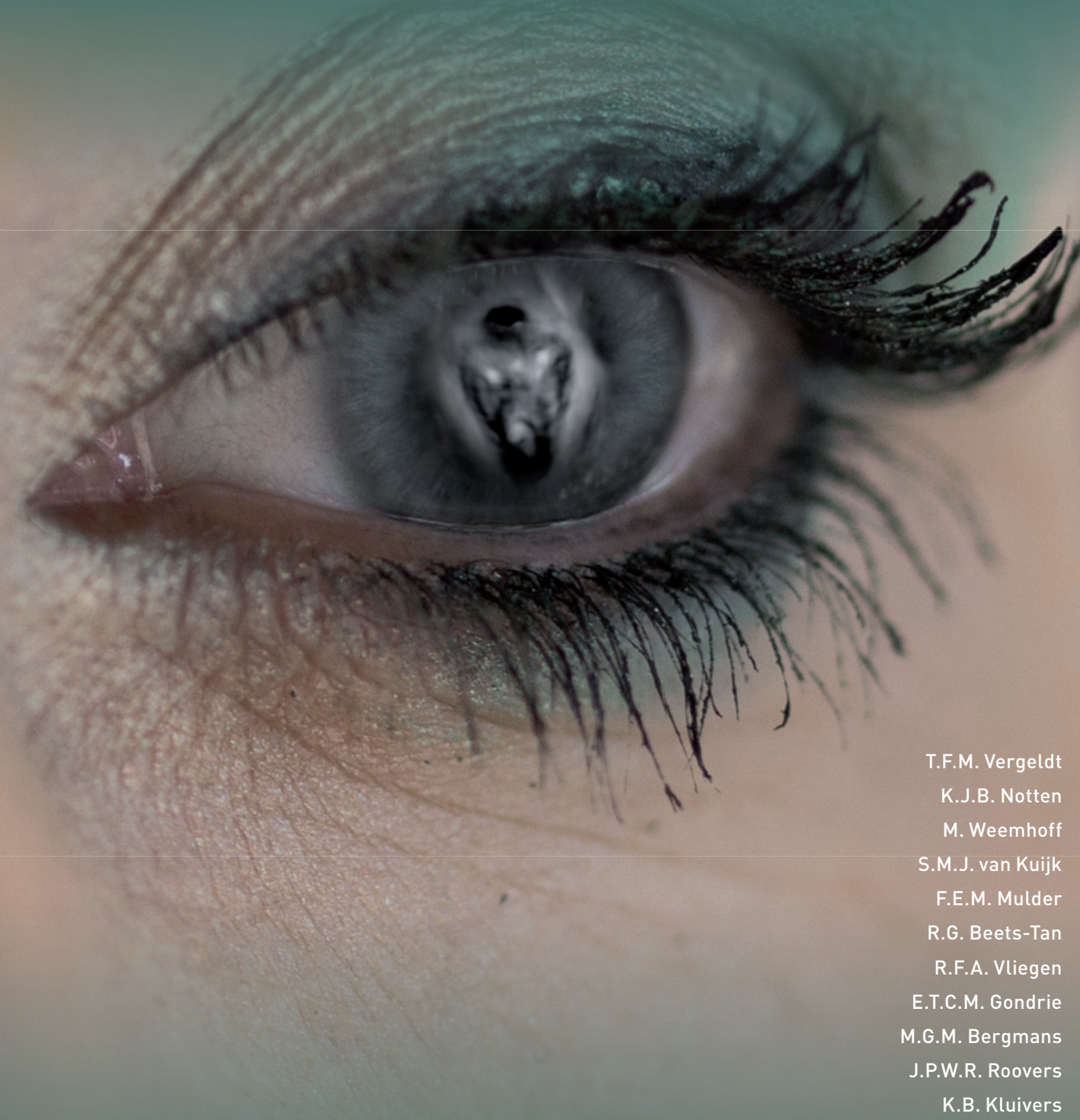




\section{ABSTRACT}

\section{Objective}

To investigate whether increased levator hiatal area, measured preoperatively, was independently associated with anatomical cystocele recurrence 12 months after anterior colporrhaphy.

\section{Design}

Multicentre prospective cohort study.

\section{Setting}

Nine teaching hospitals in the Netherlands.

\section{Population}

Women planned for conventional anterior colporrhaphy without mesh.

\section{Methods}

Women underwent physical examination, translabial three-dimensional (3D) ultrasound and Magnetic Resonance Imaging (MRI) prior to surgery. At 12 months after surgery physical examination was repeated.

\section{Main Outcome Measures}

Women with and without anatomical cystocele recurrence were compared to assess the association with levator hiatal area on 3D ultrasound, levator hiatal area on MRI and potential confounders. Receiver Operating Characteristic (ROC) curve was created to quantify the discriminative ability of using levator hiatal area to predict anatomical cystocele recurrence.

\section{Results}

Of 139 included women, 76 (54.7\%) had anatomical cystocele recurrence. Preoperative stage 3 or 4 and increased levator hiatal area during Valsalva on ultrasound were significantly associated with cystocele recurrence with odds ratios of 3.47 (95\% confidence interval (CI) 1.66$7.28)$ and $1.06(95 \% \mathrm{Cl}, 1.01-1.11)$ respectively. The area under the $\mathrm{ROC}$ curve was $0.60195 \% \mathrm{Cl}$, $0.51-0.70$ ) for levator hiatal area during Valsalva on ultrasound and 0.65 ( $95 \% \mathrm{Cl}, 0.55-0.71$ ) for preoperative POP-Q stage. 


\section{Conclusion}

Increased levator hiatal area during Valsalva on ultrasound prior to surgery and preoperative stage 3 or 4 were independent risk factors for anatomical cystocele recurrence after anterior colporrhaphy. Increased levator hiatal area as sole factor to predict anatomical cystocele recurrence after surgery showed poor test characteristics.

\section{Key words}

Levator hiatal area, cystocele recurrence, translabial 3D ultrasound

\section{INTRODUCTION}

Female pelvic organ prolapse (POP) is a common condition and its etiology is multifactorial. ${ }^{[1]}$ Combinations of anatomical, physiological, genetic, lifestyle, and reproductive factors interact throughout a woman's lifespan and contribute to pelvic floor dysfunction. ${ }^{[2]}$ Symptoms of POP can have a great negative impact on women's social, physical and psychological well-being. ${ }^{[3]}$ In case of symptomatic POP, options include expectant management, pessary treatment and surgery. ${ }^{[4]}$ POP is a prevalent condition with more than $11 \%$ of women reporting POP symptoms in a general female population in the Netherlands. ${ }^{[5]}$ The lifetime risk of surgery for POP in the general female population is $11-20 \% .{ }^{[6-9]}$ POP surgery is known to have high reoperation rates. ${ }^{[6]}$ Identification of risk factors for POP and its recurrence is important with regard to preoperative counseling and individualized treatment. ${ }^{[0]}$

The size of the levator ani hiatus seems to play a role in the etiology of POP. ${ }^{[11]}$ On pelvic floor imaging, the levator ani hiatus is defined as the area within the levator ani muscle, bordered by the levator ani muscle, the symphysis pubis and the inferior pubic ramus, through which the urethra, vagina and rectum pass. ${ }^{[12]}$ The size of the levator hiatal area varies with pubovisceral muscle activity. The levator hiatal area can be visualized by Magnetic Resonance Imaging (MRI) and translabial ultrasound. MRI has superior resolution capability, but until recently could not be used for dynamic scanning of the pelvic floor. Translabial three-dimensional (3D) ultrasound has the advantage of being more accessible, less expensive and can offer realtime imaging in different positions and during pubovisceral muscle activity like contractions or Valsalva manoeuvres. ${ }^{[12]}$ Studies using translabial 3D ultrasound have shown a significant association between an increased levator hiatal area, especially during Valsalva, and POP. ${ }^{[11,13-18]}$ A levator hiatal area of more than $25 \mathrm{~cm}^{2}$ during Valsalva has been defined as abnormal distensibility or 'ballooning' of the levator hiatus. ${ }^{14]}$

There are currently no prospective data available to investigate the association between levator hiatal area as measured by translabial 3D ultrasound or MRI preoperatively, and POP 
recurrence after surgery. The present study reports on a secondary analysis of the TRUDIL study, in which the diagnostic accuracy of translabial 3D ultrasound in the diagnosis of levator ani defects was assessed. ${ }^{[19,20]}$

The aim of this study was to investigate whether an increased levator hiatal area, measured preoperatively, was independently associated with anatomical cystocele recurrence 12 months after anterior colporrhaphy, and if so, to determine the ideal cut-off value of the levator hiatal area to predict cystocele recurrence.

\section{Materials and methods}

A multicentre prospective cohort study was performed in 9 hospitals in the Netherlands. The primary aim of this study was to assess the diagnostic accuracy of translabial 3D ultrasound in the diagnosis of levator ani defects in women with POP, using MRI as reference test. ${ }^{[19,20]}$ All patients who agreed to participate gave written informed consent before enrolment. Ethical approval for this study and local approval was obtained on the $22^{\text {nd }}$ of February 2010 , number 08-2-093, NTR2220 by the institutional review board of the Maastricht University Medical Centre. From March 2010 to July 2012, women who were planned for conventional anterior colporrhaphy (i.e. without the use of mesh-materials) because of a cystocele stage 2 or more according to the Pelvic Organ Prolapse Quantification (POP-Q) classification system, where included. ${ }^{[21]}$ Anterior colporrhaphy was performed alone or in combination with other POP procedures. There was no standardised protocol for the anterior colporrhaphy. The surgeon and his trainee were free to perform the procedure as they were used to, reflecting daily clinical practice. The intention to use mesh, previous POP surgery, concomitant incontinence surgery, the inability to understand the Dutch language, and contra-indications for undergoing MRI (e.g. cardiac pacemaker, artificial valves, prosthesis, claustrophobia) were exclusion criteria. Patients who agreed to participate underwent physical examination and received translabial 3D ultrasound and MRI prior to surgery. At 6 and 12 months after surgery physical examination was repeated. The Last-Observation-Carried-Forward (LOCF) method was used in case of missing data. ${ }^{[22,23]}$

Physical examination was performed by staging POP according to the POP-Q classification system. At the follow-up visit 12 months after surgery, the physical examination was performed by an independent examiner who was not the surgeon, and who was blinded for the results of the ultrasound and MRI examinations. Anatomical recurrence was defined as a cystocele POP-Q stage 2 or more.

The translabial 3D ultrasound of the pelvic floor was performed in supine position with hips flexed and slightly abducted and after voiding. A GE Voluson E8 system (GE Kretz Ultrasound, Zipf, Austrial was used with a 4.8 MHz curved abdominal transducer covered with gel and a condom. The transducer was placed against the perineum. Imaging was performed at rest, 
on maximum pelvic floor muscle contraction and during Valsalva manoeuvre. Dimensions of the levator hiatus were determined in the axial plane. Levator hiatal area was measured as the area bordered by the levator ani muscle, the symphysis pubis and the inferior ramus pubis (Figure 1).

Figure 1: Levator hiatal area measured on translabial 3D ultrasound in the axial plane.

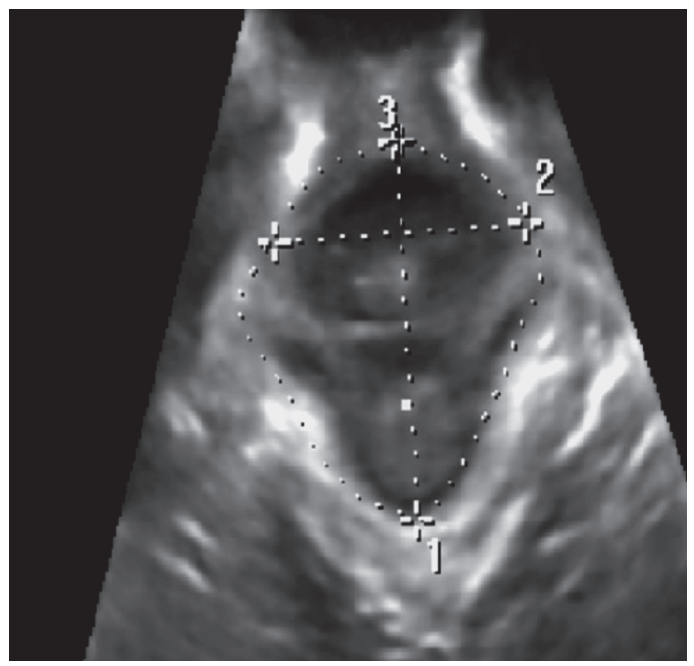

$3 \mathrm{D}=$ three-dimensional

During contraction, the level of minimum hiatal dimensions, identified as the minimum distance between the posterior margin of the symphysis pubis to the anterior margin of the levator ani muscle, was determined. At rest, the levator hiatal area was measured in the neutral position of the levator ani muscle before a levator ani muscle contraction. During Valsalva, the maximum anteroposterior diameter in the midsagittal plane was used for analysis. ${ }^{[24]}$ Volumes were recorded 3 times during contraction and during Valsalva, and the best images were chosen for analysis. For the assessment of levator ani defects the slices 2.5 and $5 \mathrm{~mm}$ cranial to the plane of minimum hiatal dimensions were also used. Levator ani defects were scored as described by Dietz et al. ${ }^{[25]}$

The recorded data sets were analysed offline using Voluson GE Kretz 4D-view V 5.1 software (GE Kretz Ultrasound, Zipf, Austria). The MRI was performed with the patient in supine position with parallel and slightly flexed legs. Patients were requested to empty their bladder prior to the examination. No premedication was given. The urethra, bladder, vagina, and rectum were not opacified. MRI scans were acquired using either a 1.5 or 3 tesla MR scanner (Siemens/GE/Philips) and a surface coil. MRI scans of the pelvis were obtained in the sagittal plane using either a Half-Fourier acquisition single-shot turbo spin-echo sequence 
(2000 ms/90 ms repetition time/echo time; $150^{\circ}$ flip angle) or true fast imaging with steady state precession. The entire pelvis from symphysis to second or third lumbar vertebrae was scanned. Consequently axial and coronal T2-weighted turbo/fast spin echo sequence l $>3500 \mathrm{~ms},<100 \mathrm{~ms}$ repetition time/ echo time; $150^{\circ}$ flip angle, slice thickness $3 \mathrm{~mm}$ and 0.5 $x 0.5$ in plane resolution) was acquired covering the entire pelvis from symphysis to the fifth lumbar vertebrae. In addition a 3D T2-weighted turbo/fast spin echo sequence $(<1 \times 1 \times 1 \mathrm{~mm})$ was acquired. All images were assessed offline using a Dicom viewer (OsiriX, v3.8.1/v5.0.1, Geneva, Switzerland). Dimensions of the levator hiatus were determined at rest in the axial plane. The levator hiatus area was measured as the area bordered by the levator ani muscle, the symphysis pubis and the inferior ramus pubis.

The ultrasound volumes were interpreted independently offline by 2 examiners from a pool of 5 , who were blinded for the associated clinical data. There were no fixed couples. These observers were experienced in assessing these images (experience in years: 1-20 and number of pelvic floor exams assessed: 200-4000) and all participated in 2 training sessions before the study started. The MRI scans were interpreted independently offline by 2 examiners from a pool of 4, who were blinded for the associated clinical data. There were no fixed couples. These radiologists were experienced in assessing these images lexperience in years: 1-20, number of pelvic floor images assessed: 200-4000). Furthermore all experts participated in 3 training sessions before the study started, including a training given by an international expert, in which 50 images were discussed.

The statistical analysis was performed using the statistical software package SPSS version 19.0 (SPSS Inc., Chicago, IL). Intraclass Correlation Coefficients (ICC) were calculated to estimate the interobserver reliability between the assessments by two independent observers for levator hiatal area at rest on 3D ultrasound, levator hiatal area during contraction on 3D ultrasound, levator hiatal area during Valsalva on 3D ultrasound and levator hiatal area at rest on MRI. An ICC of <0.20 denotes poor agreement, 0.21-0.40 fair, 0.41-0.60 moderate, 0.61-0.80 good and 0.81-1.00 very good agreement. 26 Interobserver agreement in detecting major levator ani defects on 3D ultrasound and on MRI has been published elsewhere. ${ }^{[20]}$ Women with and without anatomical cystocele recurrence 12 months after surgery were compared to assess the association with age, body mass index (BMI), parity, preoperative POP-Q stage, concomitant POP surgery, major levator ani defects on 3D ultrasound, major levator defects on MRI, levator hiatal area at rest on 3D ultrasound, levator hiatal area during contraction on 3D ultrasound, levator hiatal area during Valsalva on 3D ultrasound and levator hiatal area at rest on MRI. A p value of $<0.05$ was considered to be statistically significant. Multivariable logistic regression, including all factors with a $p$ value of $<0.10$ 
in univariable analysis, was used to determine the association between potential risk factors and anatomical cystocele recurrence through odds ratios (OR) and $95 \%$ confidence intervals (CI). The discriminative ability of statistically significant associated factors (in combination and as separate factors) to predict anatomical cystocele recurrence was further quantified as the area under the Receiver Operating Characteristic (ROC) curve. An area of 1.0 represents a perfect test, while an area of 0.5 represents a worthless test. [27] The difference between the areas under the curves was tested using the method of DeLong et al. ${ }^{[28]}$ In case appropriate, the ROC curve was also used to assess the trade-off between sensitivity and specificity and determine the ideal cut-off value of the levator hiatal area to predict cystocele recurrence. Sensitivity expresses the proportion of women with cystocele recurrence correctly predicted by an increased levator hiatal area. Specificity expresses the proportion of women without cystocele recurrence correctly predicted by no increased levator hiatal area. The positive likelihood ratio indicates how much more likely an increased levator hiatal area is in women with cystocele recurrence compared to women without cystocele recurrence. The negative likelihood ratio indicates how much more likely a not increased levator hiatal area is in women without cystocele recurrence compared to women with cystocele recurrence. The positive predictive value is the proportion of women with an increased levator hiatal area who have cystocele recurrence. The negative predictive value is the proportion of women without cystocele recurrence who do not have an increased levator hiatal area.

\section{RESULTS}

From March 2010 to July 2012, 140 women were included in 9 hospitals. One patient withdrew from the study after surgery. For the remaining 139 patients, patient characteristics are shown in Table 1 (next page).

Twelve months postoperatively, 123 patients attended the follow-up visit. From the other 16 patients, POP-Q examination data were available from the follow-up visit 6 months earlier. By carrying the last observation forward, information on anatomic recurrence was available of all 139 patients. Of these 139 women, 76 (54.7\%) had anatomical cystocele recurrence POP-Q stage 2 or more 12 months after surgery.

Of the 139 datasets, 5 ultrasound datasets were excluded because of inadequately recorded volumes. The patient characteristics of these 5 women were similar to the total population. All $139 \mathrm{MRI}$ datasets were recorded adequately for assessment. 
Table 1: Characteristics of women prior to the anterior colporrhaphy.

\begin{tabular}{|l|c|c|c|}
\hline Variable & N & Outcome \\
\hline Age in years, mean (range) & 139 & 57.4 & (31-78) \\
\hline BMl in kg/m ${ }^{2}$, mean (range) & 116 & 25.7 & (17.5-41.9) \\
\hline Parity, mean (range) & 128 & (1-7) \\
\hline Preoperative PoP-Q stage 3 or 4, $\mathrm{n}(\%)$ & 139 & 62 & $(44.6 \%)$ \\
\hline Concomitant surgery & & 69 & $(49.6 \%)$ \\
\hline Concomitant repair apical compartment, $\mathrm{n}(\%)$ & 139 & 55 & $(39.6 \%)$ \\
\hline Concomitant repair posterior compartment, $\mathrm{n}(\%)$ & 139 & 66 & $(48.9 \%)$ \\
\hline
\end{tabular}

$\mathrm{BMI}=$ Body Mass Index, $\mathrm{POP}-\mathrm{Q}=$ Pelvic Organ Prolapse Quantification system

as measured on translabial three-dimensional ultrasound

The measurements of the levator hiatal area on translabial 3D ultrasound at rest, during contraction and during Valsalva and on MRI at rest, in the total population, in women with cystocele recurrence and in women without cystocele recurrence are shown in Table 2.

Table 2: Measurements of levator hiatal area.

\begin{tabular}{|l|l|l|l|}
\hline & $\begin{array}{l}\text { Overall } \\
\text { population, } \\
\mathbf{n = 1 3 9}\end{array}$ & $\begin{array}{l}\text { Women with } \\
\text { recurrence, } \\
\mathbf{n}=\mathbf{7 6}\end{array}$ & $\begin{array}{l}\text { Women without } \\
\text { recurrence, } \\
\mathbf{n}=\mathbf{6 3}\end{array}$ \\
\hline Ultrasound at rest in $\mathrm{cm}^{2}$, mean (range) & $23.8(13.7-54.1)$ & $24.0(15.3-54.1)$ & $23.2(13.7-42.3)$ \\
\hline Ultrasound during contraction in $\mathrm{cm}^{2}$, mean (range) & $19.3(12.0-36.7)$ & $19.6(12.0-32.6)$ & $19.0(12.0-36.7)$ \\
\hline Ultrasound during Valsalva in $\mathrm{cm}^{2}$, mean (range) & $34.0(16.8-67.4)$ & $35.8(18.9-67.4)$ & $32.0(16.8-47.6)$ \\
\hline MRI at rest in $\mathrm{cm}^{2}$, mean (range) & $26.1(12.3-70.0)$ & $26.3(13.5-46.2)$ & $26.0(12.3-70.0)$ \\
\hline
\end{tabular}

$\mathrm{MRI}=$ magnetic resonance imaging 
Hundred sixteen women (86.6\%) had levator hiatal area during Valsalva on 3D ultrasound of more than $25 \mathrm{~cm}^{2}$. The interobserver reliability between the assessments by two independent observers for levator hiatal area was good, with an ICC of $0.78(95 \% \mathrm{Cl}, 0.69-0.85)$ at rest on $3 \mathrm{D}$ ultrasound, an ICC of $0.64(95 \% \mathrm{Cl}, 0.48-0.75)$ during contraction on 3D ultrasound, an ICC of 0.75 (95\% Cl, 0.65-0.83) during Valsalva on 3D ultrasound and an ICC of 0.74 (95\% Cl, 0.63-0.82) at rest on MRI. Univariable and multivariable analyses are depicted in Table 3.

Table 3: Risk factors for anatomical cystocele recurrence.

\begin{tabular}{|c|c|c|c|c|c|c|c|}
\hline & & \multicolumn{3}{|c|}{ Univariable analysis } & \multicolumn{3}{|c|}{ Multivariable analysis } \\
\hline Potential risk factors & $\mathbf{N}$ & OR & $95 \% \mathrm{Cl}$ & p-value & OR & $95 \% \mathrm{Cl}$ & p-value \\
\hline Age, years & 139 & 1.00 & $0.97-1.03$ & 0.99 & & & \\
\hline $\mathrm{BMI}, \mathrm{kg} / \mathrm{m}^{2}$ & 116 & 0.96 & $0.87-1.07$ & 0.46 & & & \\
\hline Parity, number & 128 & 1.10 & $0.73-1.65$ & 0.65 & & & \\
\hline $\begin{array}{l}\text { Preoperative POP-Q } \\
\text { stage } 3 \text { or } 4\end{array}$ & 139 & 3.02 & $1.49-6.10$ & $<0.01$ & 3.47 & $1.66-7.28$ & $<0.01$ \\
\hline Concomitant surgery & 137 & 0.80 & $0.38-1.68$ & 0.56 & & & \\
\hline $\begin{array}{l}\text { Major levator ani defect } \\
\text { on ultrasound }\end{array}$ & 135 & 1.57 & $0.80-3.10$ & 0.19 & & & \\
\hline $\begin{array}{l}\text { Major levator ani defect on } \\
\text { MRI }\end{array}$ & 139 & 1.41 & $0.68-2.92$ & 0.36 & & & \\
\hline $\begin{array}{l}\text { Levator hiatal area at } \\
\text { rest on ultrasound, } \mathrm{cm}^{2}\end{array}$ & 134 & 1.02 & $0.97-1.09$ & 0.44 & & & \\
\hline $\begin{array}{l}\text { Levator hiatal area } \\
\text { during contraction, } \mathrm{cm}^{2}\end{array}$ & 133 & 1.03 & $0.95-1.10$ & 0.50 & & & \\
\hline $\begin{array}{l}\text { Levator hiatal area } \\
\text { during Valsalva, } \mathrm{cm}^{2}\end{array}$ & 134 & 1.06 & $1.01-1.10$ & 0.01 & 1.06 & $1.01-1.11$ & 0.02 \\
\hline $\begin{array}{l}\text { Levator hiatal area } \\
\text { during Valsalva of }>25 \mathrm{~cm}^{2}\end{array}$ & 134 & 2.07 & $0.75-5.73$ & 0.16 & & & \\
\hline $\begin{array}{l}\text { Levator hiatal area } \\
\text { at rest on MRI, } \mathrm{cm}^{2}\end{array}$ & 139 & 1.00 & $0.96-1.05$ & 0.85 & & & \\
\hline
\end{tabular}

$\mathrm{OR}=$ Odds Ratio, 95\% Cl = 95\% Confidence Interval, $\mathrm{BMI}=$ Body Mass Index, $\mathrm{POP}-\mathrm{Q}=$ Pelvic Organ

Prolapse Quantification system, MRI = magnetic resonance imaging 
Preoperative POP-Q stage 3 or 4 and increased levator hiatal area during Valsalva on 3D ultrasound were significantly associated with cystocele recurrence in both univariable and multivariable analysis. Multivariable analysis showed that preoperative POP-Q stage 3 or 4 and increased levator hiatal area during Valsalva were independent risk factors for anatomical cystocele recurrence after surgery with an $\mathrm{OR}$ of $3.47(95 \% \mathrm{Cl}, 1.66-7.28)$ and $1.06(95 \% \mathrm{Cl}$, $1.01-1.11$ ) respectively.

Figure 2: ROC curve for separate and combined risk factors for anatomical recurrence.

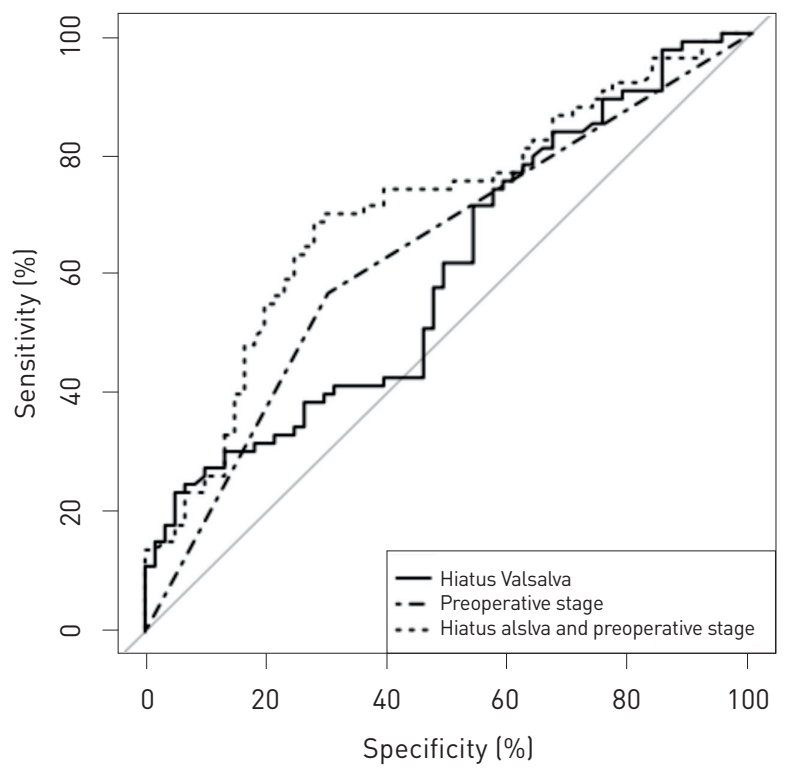

In Figure 2 the ROC curves are shown. The area under the ROC curve for levator hiatal area during Valsalva was 0.60 (95\% $\mathrm{Cl}, 0.51-0.70)$, indicating poor discriminative ability of using levator hiatal area during Valsalva as sole risk factor for predicting anatomical cystocele recurrence. The area under the ROC curve for preoperative POP-Q stage was 0.65 (95\% $\mathrm{Cl}, 0.55-0.71$ ). Using levator hiatal area during Valsalva combined with preoperative POP-Q stage 3 or 4 could discriminate significantly better between patients who were going to have anatomical cystocele recurrence than using only levator hiatal area during Valsalva $(p=0.02)$ or using only preoperative POP-Q stage $(p=0.05)$, with an area under the ROC curve of 0.70 (95\% Cl, 0.61-0.79).

Test characteristics for the different cut-off values of levator hiatal area during Valsalva as a test to predict anatomical cystocele recurrence are depicted in Table 4. The likelihood ratios of all cut-off values of the levator hiatal measurements during Valsalva were between 0.5 and 1.7, except for the cut-off value of $20 \mathrm{~cm}^{2}$ showing a negative likelihood ratio of 0.1 . 
Table 4: Test characteristics for levator hiatal area during Valsalva as a predictor for anatomical cystocele recurrence.

\begin{tabular}{|l|c|c|c|c|c|c|}
\hline & Sensitivity & Specificity & LR+ & LR- & PPV & NPV \\
\hline Cut-off $20 \mathrm{~cm}^{2}$ & $98.6 \%$ & $9.8 \%$ & 1.1 & 0.1 & $56.7 \%$ & $85.7 \%$ \\
\hline Cut-off $25 \mathrm{~cm}^{2}$ & $90.4 \%$ & $18.0 \%$ & 1.1 & 0.5 & $56.9 \%$ & $61.1 \%$ \\
\hline Cut-off $30 \mathrm{~cm}^{2}$ & $71.2 \%$ & $42.6 \%$ & 1.2 & 0.7 & $59.8 \%$ & $55.3 \%$ \\
\hline Cut-off $35 \mathrm{~cm}^{2}$ & $42.5 \%$ & $60.7 \%$ & 1.1 & 1.0 & $56.4 \%$ & $46.8 \%$ \\
\hline Cut-off $40 \mathrm{~cm}^{2}$ & $30.1 \%$ & $82.0 \%$ & 1.7 & 0.9 & $66.7 \%$ \\
\hline
\end{tabular}

LR+ = Positive Likelihood Ratio, LR- = Negative Likelihood Ratio, PPV = Positive Predictive Value, NPV = Negative Predictive Value, $95 \% \mathrm{Cl}=95 \%$ Confidence Interval

\section{DISCUSSION}

\section{Main findings}

In this multicentre prospective cohort study we observed that an increased levator hiatal area during Valsalva, measured preoperatively with translabial 3D ultrasound, and preoperative $P O P-Q$ stage 3 or 4 were independent risk factors for anatomical cystocele recurrence 12 months after anterior colporrhaphy.

\section{Strengths and limitations}

A limitation of our study was that cystocele recurrence was defined as anatomical recurrence. It is known that anatomical recurrence rate is higher than symptomatic recurrence rate. ${ }^{[29]}$ Although subjective outcomes were available in the study population, the sample size in this study was too small to examine the association between levator hiatal area and symptomatic recurrence. The follow-up after surgery was 12 months. Anatomical recurrence rate was $54.7 \%$, which is in accordance to other research. ${ }^{[29-32]}$

\section{Interpretation}

The observations in this study have been described before. Preoperative POP-Q stage 3 or 4 was also an independent risk factor for POP recurrence after surgery in previous studies. ${ }^{[10,29-31]}$ Age, BMI, parity and concomitant surgery were not significantly associated with POP recurrence, which confirms the findings by others as well. ${ }^{[10,29]}$ In this study, a major levator ani 
defect on 3D ultrasound and on MRI was not an independent risk factor for POP recurrence, which is in contrast with previous studies that have shown a significant correlation between levator ani defects and POP recurrence. ${ }^{[29,33-36]}$ All these studies were singlecentre compared to our multicentre study. The studies of Weemhoff et al ( $n=156)$, Rodrigo et al ( $n=334)$, Dietz et al $(n=83)$ and Model et al $(n=737)$ had a follow-up of more than 2 years. ${ }^{[29,33-35]}$ These studies differed from the present study in the fact that in these studies ultrasound was performed postoperatively while in the present study ultrasound was performed preoperatively. In one study of Morgan et al ( $n=83$ ) levator defects were assessed with MRI preoperatively. ${ }^{[36]}$ Their follow-up at six weeks after surgery showed that anterior vaginal wall support was not as optimal in women with major levator defects as in women without major levator defects. They did not include recurrence on longer follow-up.

Increased levator hiatal area was only a significant risk factor for POP recurrence when it was measured during Valsalva and not when it was measured at rest or during contraction. This implies that static MRI is not suitable for diagnosing levator hiatal area in the prediction of POP recurrence after surgery. Our research cannot explain why levator hiatal area during Valsalva was significantly associated with POP recurrence while levator hiatal area at rest or during contraction were not. We can hypothesize that distensibility and elasticity play a role in the development of POP, which are more visible during Valsalva.

The interobserver reliability between the assessments by two independent observers for levator hiatal area was good. To our best knowledge, there are currently no other studies that have prospectively examined the correlation between levator hiatal area measured prior to surgery and recurrence of POP after surgery. Rodrigo et al have performed a retrospective cohort study in which the levator hiatal area during Valsalva was measured at the followup visit after surgery, which included polypropylene mesh augmentation in $74 \%$ of women. ${ }^{[34]}$ A significant correlation between levator hiatal area during Valsalva and recurrent POP after surgery was found, with an OR of 1.04 (95\% Cl, 1.01-1.06). It is known that levator hiatal area during Valsalva is reduced after POP surgery. ${ }^{[37]}$ It is unknown whether levator hiatus measurements are influenced by mesh augmentation or by POP in itself. In other words, it is unknown whether the findings in the study by Rodrigo et al would have been the same if these measurements had been performed preoperatively.

Dietz et al have suggested a cut-off value of $25 \mathrm{~cm}^{2}$ for increased levator hiatal area during Valsalva, based on an area under the ROC curve of 0.76 ( $95 \% \mathrm{Cl}, 0.72-0.80$ ), a sensitivity of 0.52 and a specificity of 0.83 for detecting anatomical POP. ${ }^{[14]}$ In the present study, levator hiatal area during Valsalva on 3D ultrasound of more than $25 \mathrm{~cm}^{2}$ versus less than $25 \mathrm{~cm}^{2}$ was not a risk factor for POP recurrence. When analyzing increased levator hiatal area during Valsalva as a test for predicting anatomical cystocele recurrence after surgery, the test characteristics were poor, and this held true for all cut-off values considered. Likelihood 
ratios were close to 1.0, which indicates poor predictive value. An exception was the cut-off value of $20 \mathrm{~cm}^{2}$ showing a negative likelihood ratio of 0.1 , which indicates that a levator hiatal area during Valsalva of less than $20 \mathrm{~cm}^{2}$ was strongly predictive of the absence of anatomical cystocele recurrence. ${ }^{[38]}$ The differences in results between our study and the study by Dietz et al may be attributed partly to a different study population. In our study, women with cystocele recurrence were compared to women with no cystocele recurrence after conventional anterior colporrhaphy, while in the study of Dietz women with POP were compared to women without POP.

\section{CONCLUSION}

In conclusion, this multicentre prospective cohort study demonstrated that an increased levator hiatal area during Valsalva prior to surgery and a preoperative POP-Q stage 3 or 4 were independent risk factors for anatomical cystocele recurrence 12 months after anterior colporrhaphy. Using increased levator hiatal area during Valsalva to predict anatomical cystocele recurrence after surgery does not have additional value due to poor test characteristics. However, a levator hiatal area during Valsalva of less than $20 \mathrm{~cm}^{2}$ was strongly predictive of the absence of anatomical cystocele recurrence. 


\section{REFERENCES}

1. Dietz HP. The aetiology of prolapse. Int Urogynecol J Pelvic Floor Dysfunct 2008; 19:1323-9.

2. Delancey JO, Kane Low L, Miller JM, Patel DA, Tumbarello JA. Graphic integration of causal factors of pelvic floor disorders: an integrated life span model. Am J Obstet Gynecol 2008; 199:610 e1-5.

3. Abdel-Fattah M, Familusi A, Fielding S, Ford J,Bhattacharya S. Primary and repeat surgical treatment for female pelvic organ prolapse and incontinence in parous women in the UK: a register linkage study. BMJ Open 2011; 1:e000206.

4. Jelovsek JE, Maher C,Barber MD. Pelvic organ prolapse. Lancet 2007; 369:1027-38.

5. Slieker-ten Hove MC, Pool-Goudzwaard AL, Eijkemans MJ, Steegers-Theunissen RP, Burger CW,Vierhout ME. Symptomatic pelvic organ prolapse and possible risk factors in a general population. Am J Obstet Gynecol 2009; 200:184 e1-7.

6. Olsen AL, Smith VJ, Bergstrom JO, Colling JC,Clark AL. Epidemiology of surgically managed pelvic organ prolapse and urinary incontinence. Obstet Gynecol 1997; 89:501-6.

7. Wu JM, Matthews CA, Conover MM, Pate V, Jonsson Funk M. Lifetime risk of stress urinary incontinence or pelvic organ prolapse surgery. Obstet Gynecol 2014; 123:1201-6.

8. Smith FJ, Holman CD, Moorin RE,Tsokos N. Lifetime risk of undergoing surgery for pelvic organ prolapse. Obstet Gynecol 2010; 116:1096-100.

9. de Boer TA, Slieker-Ten Hove MC, Burger CW, Kluivers KB,Vierhout ME. The prevalence and factors associated with previous surgery for pelvic organ prolapse and/or urinary incontinence in a crosssectional study in The Netherlands. Eur J Obstet Gynecol Reprod Biol 2011; 158:343-9.

10. Salvatore S, Siesto G,Serati M. Risk factors for recurrence of genital prolapse. Curr Opin Obstet Gynecol 2010; 22:420-4.

11. Khunda A, Shek KL,Dietz HP. Can ballooning of the levator hiatus be determined clinically? Am $J$ Obstet Gynecol 2012; 206:246 e1-4.

12. Majida M, Braekken IH, Bo K, Benth JS,Engh ME. Validation of three-dimensional perineal ultrasound and magnetic resonance imaging measurements of the pubovisceral muscle at rest. Ultrasound Obstet Gynecol 2010; 35:715-22.

13. Dietz HP, Shek C,Clarke B. Biometry of the pubovisceral muscle and levator hiatus by threedimensional pelvic floor ultrasound. Ultrasound Obstet Gynecol 2005; 25:580-5.

14. Dietz HP, Shek C, De Leon J,Steensma AB. Ballooning of the levator hiatus. Ultrasound Obstet Gynecol 2008; 31:676-80.

15. Majida M, Braekken I, Bo K, Benth J,Engh M. Anterior but not posterior compartment prolapse is associated with levator hiatus area: a three- and four-dimensional transperineal ultrasound study. BJOG 2011; 118:329-37.

16. Chen $R$, Song $Y$, Jiang $L$, Hong $X, Y e ~ P$. The assessment of voluntary pelvic floor muscle contraction by three-dimensional transperineal ultrasonography. Arch Gynecol Obstet 2011; 284:931-6.

17. Dietz HP, Franco AV, Shek KL,Kirby A. Avulsion injury and levator hiatal ballooning: two independent risk factors for prolapse? An observational study. Acta Obstet Gynecol Scand 2012; 91:211-4.

18. Pineda M, Shek K, Wong V,Dietz HP. Can hiatal ballooning be determined by two-dimensional translabial ultrasound? Aust N Z J Obstet Gynaecol 2013; 53:489-93.

19. Notten KJ, Weemhoff M, Kluivers KB, Schweitzer KJ, Mulder F, Stoker J, et al. Protocol for translabial 3D-ultrasonography for diagnosing levator defects (TRUDIL): a multicentre cohort study for estimating the diagnostic accuracy of translabial 3D-ultrasonography of the pelvic floor as compared to MR imaging. BMC Womens Health 2011; 11:23. 
20. Notten KJ, Kluivers KB, Futterer JJ, Schweitzer KJ, Stoker J, Mulder FE, et al. Translabial threedimensional ultrasonography compared with magnetic resonance imaging in detecting levator ani defects. Obstet Gynecol 2014; 124:1190-7.

21. Bump RC, Mattiasson A, Bo K, Brubaker LP, DeLancey JO, Klarskov P, et al. The standardization of terminology of female pelvic organ prolapse and pelvic floor dysfunction. Am J Obstet Gynecol 1996; 175:10-7.

22. Gadbury GL, Coffey CS,Allison DB. Modern statistical methods for handling missing repeated measurements in obesity trial data: beyond LOCF. Obes Rev 2003; 4:175-84.

23. Mallinckrodt $\mathrm{CH}$, Clark WS,David SR. Accounting for dropout bias using mixed-effects models. J Biopharm Stat 2001; 11:9-21.

24. Staer-Jensen J, Siafarikas F, Hilde G, Bo K,Engh ME. Ultrasonographic evaluation of pelvic organ support during pregnancy. Obstet Gynecol 2013; 122:329-36.

25. Dietz HP, Bernardo MJ, Kirby A,Shek KL. Minimal criteria for the diagnosis of avulsion of the puborectalis muscle by tomographic ultrasound. Int Urogynecol J 2011; 22:699-704.

26. Altman DG. Practical statistics for medical research. Londen: Chapman \& Hall/CRC 1999.

27. Metz CE. Basic principles of ROC analysis. Semin Nucl Med 1978; 8:283-98.

28. DeLong ER, DeLong DM,Clarke-Pearson DL. Comparing the areas under two or more correlated receiver operating characteristic curves: a nonparametric approach. Biometrics 1988; 44:837-45.

29. Weemhoff M, Vergeldt TF, Notten K, Serroyen J, Kampschoer PH, Roumen FJ. Avulsion of puborectalis muscle and other risk factors for cystocele recurrence: a 2-year follow-up study. Int Urogynecol $J$ 2012; 23:65-71.

30. Diez-Itza I, Aizpitarte I,Becerro A. Risk factors for the recurrence of pelvic organ prolapse after vaginal surgery: a review at 5 years after surgery. Int Urogynecol J Pelvic Floor Dysfunct 2007; 18:1317-24.

31. Whiteside JL, Weber AM, Meyn LA,Walters MD. Risk factors for prolapse recurrence after vaginal repair. Am J Obstet Gynecol 2004; 191:1533-8.

32. Vollebregt A, Fischer K, Gietelink D,van der Vaart $\mathrm{CH}$. Primary surgical repair of anterior vaginal prolapse: a randomised trial comparing anatomical and functional outcome between anterior colporrhaphy and trocar-guided transobturator anterior mesh. BJOG 2011; 118:1518-27.

33. Dietz HP, Chantarasorn V,Shek KL. Levator avulsion is a risk factor for cystocele recurrence. Ultrasound Obstet Gynecol 2010; 36:76-80.

34. Rodrigo N, Wong V, Shek KL, Martin A,Dietz HP. The use of 3-dimensional ultrasound of the pelvic floor to predict recurrence risk after pelvic reconstructive surgery. Aust N Z J Obstet Gynaecol 2014; 54:206-11.

35. Model AN, Shek KL,Dietz HP. Levator defects are associated with prolapse after pelvic floor surgery. Eur J Obstet Gynecol Reprod Biol 2010; 153:220-3.

36. Morgan DM, Larson K, Lewicky-Gaupp C, Fenner DE,DeLancey JO. Vaginal support as determined by levator ani defect status 6 weeks after primary surgery for pelvic organ prolapse. Int J Gynaecol Obstet 2011; 114:141-4.

37. Andrew BP, Shek KL, Chantarasorn V,Dietz HP. Enlargement of the levator hiatus in female pelvic organ prolapse: cause or effect? Aust N Z J Obstet Gynaecol 2013; 53:74-8.

38. Deeks JJ,Altman DG. Diagnostic tests 4: likelihood ratios. BMJ 2004; 329:168-9. 


\section{GENERAL DISCUSSION}

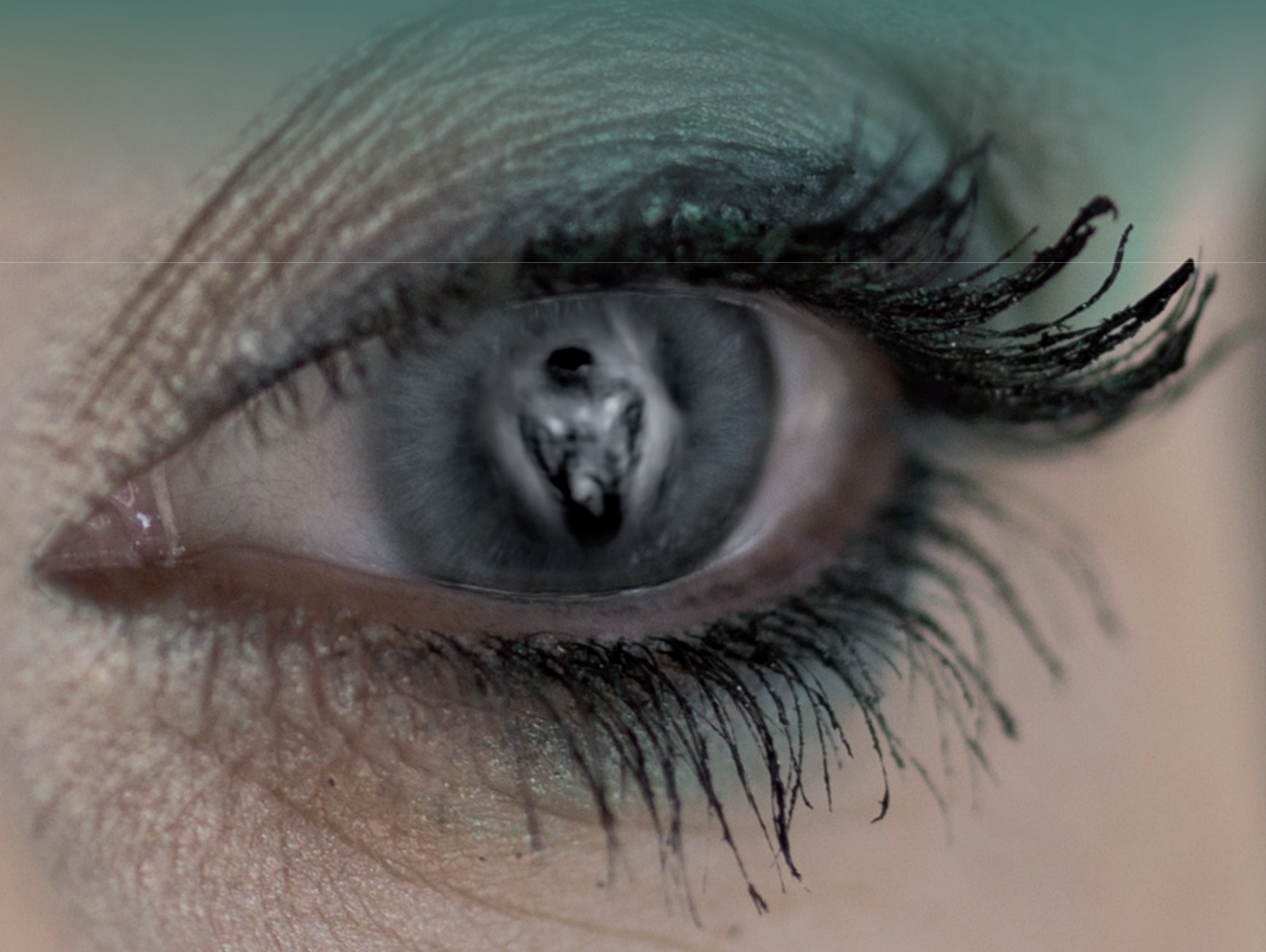


The main focus of this thesis was the description of the results of the TRUDIL trial, a prospective multicenter cohort study on the diagnosis and clinical relevance of levator ani defects in women with pelvic organ prolapse (POP). Furthermore patients' preferences were investigated between two surgical techniques for the management of anterior vaginal wall prolapse.

\section{LITERATURE REVIEW LEVATOR ANI DEFECTS}

Since approximately 60 years levator ani trauma is described in literature. The last couple of years levator ani muscle trauma emerged in the literature as a major contributing factor in POP pathophysiology. This type of injury is only observed in women who have given birth vaginally or have at least entered the second stage of labour. ${ }^{[1]}$ In $13-36 \%$ of women who had delivered vaginally for the first time, trauma of the levator ani was identified. ${ }^{[2]}$ Besides being associated with an increased risk of primary POP, levator ani muscle injury has been reported to lead to an increased risk of recurrence after surgical POP repair. ${ }^{[3,4]}$ It is intriguing that, until now, so little attention is paid in preventing this trauma.

A lot of literature is available regarding levator ani defects and its implications. But, as shown in chapter 3 , the results of different studies are inconsistent. Even though the aims of the studies are often very similar, there are many differences in the methods used and primary outcomes that are reported. As a result of this heterogeneity it is difficult to interpret and implement the findings of these individual studies into daily clinical practice.

\section{DIAGNOSING LEVATOR ANI DEFECTS WITH IMAGING TECHNIQUES}

Imaging of the pelvic floor and especially detecting levator ani muscle defects is a rapidly evolving topic in literature. Diagnostic performance studies ideally require a gold standard test with perfect diagnostic performance. For detecting levator ani defects, there is no such test. Detailed anatomy of the pelvic floor and particularly the levator muscle in cadavers was seen on MRI. ${ }^{[5]}$

Although not error free, MRI, because of it's exquisite soft tissue discrimination, is considered to be the best available reference test.

Due to developments in translabial 3D ultrasound it is nowadays also possible to visualize the levator ani muscle with ultrasound. This method is easy accessible for gynaecologists and available at lower costs. Some hospitals already have incorporated the translabial ultrasound in daily practice and based treatment decisions on ultrasound findings regarding 
levator ani defects. Indeed, several ultrasound and MRI studies have shown an association between major levator ani muscle defects and POP and its recurrence after surgery. ${ }^{[6-9]}$ An important shortcoming of these studies however is the fact that pelvic floor ultrasound was performed at the follow up visit and not preoperatively which may have caused bias. It is noteworthy that none of these studies evaluated and compared these techniques in a prospective setting in order to standardise assessment.

We performed a prospective multicenter and multireader trial comparing levator defects determined with translabial 3D ultrasound and MRI as the reference test in a group of women with at least anterior vaginal wall prolapse POP-Q 2 (chapter 4). It was found that translabial 3D ultrasound is an alternative for MRI in detecting levator defects with a sensitivity of $78 \%$ and specificity of $86 \%$. Yet we know that MRI is not error free, which handicaps evaluations of the diagnostic performance of ultrasound. Taken the fact in consideration that MRI is not error free, ultrasound can only perform worse than the reference test. A sensitivity of $78 \%$ and specificity of $86 \%$ seems therefore a good diagnostic performance. The interobserver agreement however was only moderate in detecting major levator ani defects (kappa 0.53), illustrating an important shortcoming of translabial 3D ultrasound in its clinical application (chapter 5). Maybe interobserver agreements can be improved by further developing guide-lines for assessing ultrasound scans. More important, we need to be sure that assessing levator defects lead to clinically relevant outcomes in women with prolapse before considering methods to improve the technique.

\section{CLINICAL INTERPRETATION OF LEVATOR ANI MUSCLE DEFECTS}

To assess the clinical relevance of having levator ani defects in respect to the risk of recurrence in women with anterior colporrhaphy, with or without concomitant prolapse surgery, we established subjective and objective recurrence 12 months after surgery (chapter 6). The anatomic recurrence rate in this study was $54.7 \%$ which is in accordance with previous studies. However, in contrast to other studies, stating that major levator ani defects are a risk factor for POP recurrence after anterior colporrhaphy, we found no significant association between objective or subjective prolapse after pelvic floor surgery and the presence of a major levator ani defect diagnosed with either translabial 3D ultrasound $(p=0.2 ;$ OR 1.6, 95\% $\mathrm{Cl}, 0.8-3.1$ ), or MR imaging ( $\mathrm{p}=0.4$; OR 1.4, 95\% Cl, 0.7-2.9). ${ }^{[10-13]}$

Reasons for this discrepant findings are probably due to differences in study designs (timing of pelvic floor ultrasound, timing of follow up), and multicenter versus single center studies. It is possible that other research groups did not find the same results because of the fact that they only assessed translabial 3D ultrasound postoperatively instead of 
preoperatively. One might consider that the differences between the studies could be a lack of power in our study. However we powered our study at 30\% levator ani defects and found $49 \%$ (ultrasound) levator ani defects in our study population. Because we didn't found an association, or not even a trend, between levator ani defects and recurrences, identifying such a defect has no therapeutic consequences for women with prolapse.

Besides levator ani defects, also an increased levator hiatal area, measured preoperatively with translabial 3D ultrasound, could be predictive for a recurrence after anterior colporrhaphy in women with anterior vaginal wall prolapse. And indeed we found that, besides a preoperative POP-Q stage 3 or 4 , an increased levator hiatal area on ultrasound during Valsalva was an independent risk factor for anatomical anterior vaginal wall recurrence 12 months after anterior colporrhaphy (chapter 7). Unfortunately, using increased levator hiatal area during Valsalva as a test for predicting anatomical anterior vaginal wall recurrence after surgery, showed poor test characteristics (AUC of 0.6).

Because, for different reasons, both diagnosing levator ani defects as well as increased levator hiatal area have no therapeutic consequences. At present, using translabial 3D ultrasound in the daily work up of a POP patient, has no additional value and therefore should not be incorporated.

\section{PATIENT PREFERENCES}

Health professionals and patients may or may not share the same preferences related to the patient's treatment. Increased patient involvement in medical decision making is an important part of quality improvement since it has been associated with improved health outcomes. ${ }^{[14]}$ In that respect, health care professionals are increasingly encouraged to involve patients in treatment decisions, recognizing patients as experts of their own health and their preferences for treatment options.

To provide insight in patients' preferences regarding the current surgical management of women with anterior vaginal prolapse, we identified factors that influenced patients choice for specific surgery techniques, the anterior colporrhaphy compared to mesh surgery (chapter 2). Anterior colporrhaphy still is the first choice technique for a primary repair but is known to have a high recurrence rate. The introduction of vaginal polypropylene implants has decreased the recurrence rate. However the complication rate is higher compared to anterior colporrhaphy. ${ }^{[15]}$ Vollebregt et al. ${ }^{[16-17]}$ stated in recent research that both surgical interventions appear to be safe and that mesh surgery creates better anatomical correction. However mesh use leads to higher costs compared 
to anterior colporrhaphy repair. In this study long term follow-up was not available to demonstrate possible higher costs if anatomical recurrences after anterior colporrhaphy will subsequently become symptomatic with the need for re-operations.

Based on identified risk factors (risk of recurrence, risk of exposure (only in mesh), infection and dyspareunial of both surgery techniques in our population, anterior colporrhaphy is preferred by patients in the majority of the choices, followed by a preference for mesh surgery in a quarter of all choice sets (chapter 2). We think that in the medical decisionmaking context, information from the current study should be used to inform women with POP who are indicated for a primary repair of the anterior vaginal wall.

\section{CONCLUDING MESSAGE}

Regarding the clinical implications for the management of women with POP, the results of the TRUDIL trial provide results of a validation study regarding the translabial 3D ultrasound. This fairly new diagnostic method is in some hospitals already incorporated in the daily practice without sufficient evidence. Since levator ani defects or increased levator hiatal area (ballooning hiatus) in our population are not predictive for recurrence, routine imaging in the standard management of women with symptoms of POP is not recommended. If for some reason there is an interest to detect levator ani muscle defects with imaging modalities, for instance for research purposes, it is not necessary to prefer MRI over translabial 3D ultrasound. 


\section{REFERENCES}

1. Dietz H, Lanzarone V. Levator trauma after vaginal delivery. Obstet Gynecol 2005; 106: 707-712.

2. Schwertner-Triepelmann N, Thakar R, Sultan AH, Tunn R. Obstetric levator ani muscle injuries: current status. Ultrasound Obstet Gynecol 2012; 39:372-83.

3. Model A.N, Shek K.L, Dietz H.P (2010) Levator defects are associated with prolapse after pelvic floor surgery. Eur J Obstet Gynecol Reprod Biol 2010; 153:220-3.

4. Wong V, Shek K, Rane A, Goh J, Krause H, Dietz H.P. Is levator avulsion a predictor of cystocele recurrence following anterior vaginal mesh placement? Ultrasound Obstet Gynecol 2013; 42 (2):230-4.

5. Strohben K, Ellis JH, Strohbehn JA, DeLancey JO. Metic resonance imaging of he levator ani with anatomic correlation. Obstet Gynecol 1996; 87:277-85.

6. DeLancey JO, Kearney R, Chou Q, Speights S, Binno S. The appearance of levator ani muscle abnormalities in magnetic resonance images after vaginal delivery. Obstet Gynecol 2003; 101:46- 53.

7. Dietz HP, Simpson JM Levator trauma is associated with pelvic organ prolapse. BJOG 2008; 115:979 984.

8. DeLancey JO, Morgan DM, Fenner DE, Kearney R, Guire K, Miller JM et al Comparison of levator ani muscle defects and function in women with and without pelvic organ prolapse. Obstet Gynecol 2007; 109:295-302.

9. Dietz HP, Chantarasorn V, Shek KL. Levator avulsion is a risk factor for cystocele recurrence. Ultrasound Obstet Gynecol 2010; 36:76 80.

10. Slieker-ten Hove MC, Pool-Goudzwaard AL, Eijkemans MJ, Steegers- Theunissen RP, Burger CW, Vierhout ME. The prevalence of pelvic organ prolapse symptoms and signs and their relation with bladder and bowel disorders in a general female population. Int Urogynecol J Pelvic Floor Dysfunct 2009; 20:1037-1045.

11. Delancey JO, Kane Low L, Miller JM, Patel DA, Tumbarello JA. Graphic integration of causal factors of pelvic floor disorders: an integrated life span model. Am J Obstet Gynecol 2008; 199:610 e1-5.

12. Abdel-Fattah M, Familusi A, Fielding S, Ford J, Bhattacharya S. Primary and repeat surgical treatment for female pelvic organ prolapse and incontinence in parous women in the UK: a register linkage study. BMJ Open 2011; 1 (2):e000206.

13. Dietz HP, Shek C, Clarke B. Biometry of the pubovisceral muscle and levator hiatus by threedimensional pelvic floor ultrasound. Ultrasound Obstet Gynecol 2005; 25:580-5.

14. Robinson JH, Callister LC, Berry JA, Dearing KA. Patient-centered care and adherence: definitions and applications to improve outcomes. J Am Acad Nurse Pract 2008; 20:600-607.

15. Sivaslioglu AA, Unlubilgin E, Dolen I. A randomized comparison of polypropylene Mesh surgery with site-specific surgery in the treatment of cystocele. Int Urogynecol J 2008; 19:467-471.

16. Vollebregt A. Thesis chapter 6 Cost-utility analysis of trocar guided transobturator mesh versus anterior colporrhaphy for primary cystocele repair: a randomised trial. Submitted

17. Altman D, Väyrynen T, Engh ME, Axelsen S, Falconer C; Nordic Transvaginal Mesh Group. Anterior colporrhaphy versus transvaginal mesh for pelvic-organ prolapse. N Engl J Med 2011; 364:1826-36. 


\section{SAMENVATTING}

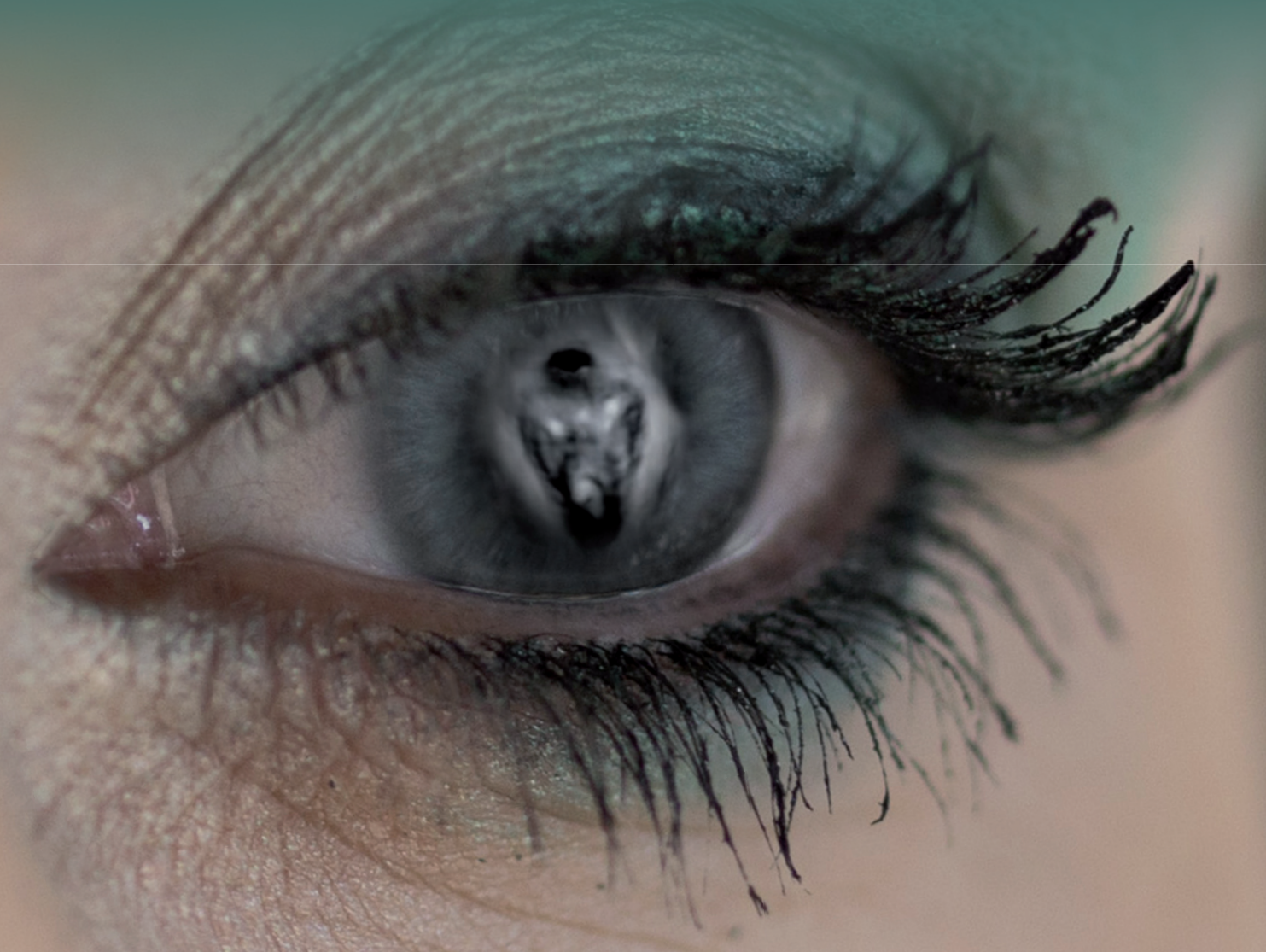




\section{SAMENVATTING}

Hoofdstuk 1 beschrijft de hoofdlijnen van dit proefschrift. Verzakkingen, en het opnieuw optreden van verzakking na een operatie (recidief), vormen een belangrijk gezondheidsprobleem. De etiologie van de ontwikkeling van verzakkingen is nog onduidelijk, maar lijkt multifactorieel te zijn. Er zijn aanwijzingen dat defecten aan de levator ani spier een sleutelrol spelen in het ontstaan van een verzakking maar ook bij het terugkeren van een verzakking na een operatie. Door ontwikkelingen in beeldvormende technieken is het mogelijk om defecten aan de levator ani spier met behulp van de translabiale 3D echografie en met MRI te beoordelen. MRI wordt beschouwd als de referentie test. Veel aspecten van de translabiale echografie zijn echter nog niet geheel duidelijk. Het doel van deze prospectieve multicenter cohort studie was om de translabiale 3D echografie te valideren voor het diagnosticeren van levator ani defecten. Het tweede doel van deze studie was, het vaststellen of levator ani defecten een recidief verzakking kunnen voorspellen.

Voorkeuren van patiënten voor 2 operatie technieken, namelijk de klassieke voorwand operatie en de mesh operatie die beiden gebruikt worden voor het herstellen van een blaasverzakking, werden onderzocht in hoofdstuk 2. Een discreet keuze-experiment werd gebruikt om de voorkeuren van patiënten te beoordelen. Discrete keuze-experimenten zijn een attribuut gebaseerde onderzoeksmethode voor het meten van voorkeuren. In dit experiment werden de patiënten gevraagd te kiezen tussen de twee scenario's: mesh chirurgie of klassieke voorwand chirurgie. Deze chirurgische behandelingen verschilden in vier kenmerken: 1) recidief, 2) exposure (blootstelling mesh door vagina epitheel), 3) infectie percentage, 4) dyspareunie (pijn bij vrijen). Deze studie toonde aan dat naast het risico op een recidief, andere aspecten zoals infectie risico, dyspareunie en exposure een belangrijke rol spelen bij het maken van een keuze voor een chirurgische behandeling voor een blaasverzakking. De resultaten uit deze studie laten zien dat de klassieke voorwand operatie de voorkeur heeft van patiënten voor de behandeling van een eerste operatie bij een blaasverzakking. In een kwart van de keuze sets werd er gekozen voor de mesh operatie. De resultaten van deze studie vormen een gemiddelde voorkeur van een geselecteerde groep patiënten maar geven aan dat patiënten goed geïnformeerd moeten worden over het bestaan en de omvang van de mogelijke voordelen en risico's van zowel de klassiek voorwand operatie als mesh operatie zodat patiënten hun eigen, individuele keuzes ten aanzien van een behandeling kunnen maken.

In hoofdstuk 3 presenteren we een overzicht van een literatuurstudie waarin onderzocht werd wat de diagnostische waarde is van de translabiale $3 \mathrm{D}$ echo voor het vaststellen van 
levator ani defecten en het meten van een ballooning hiatus lvergroot oppervlakte van de levator hiatus). Het tweede doel was om vast te stellen, of levator ani defecten en een ballooning hiatus worden geassocieerd met primaire verzakkingen. Daarnaast evalueren we of levator ani defecten en een ballooning hiatus de slagingskans van een verzakkingsoperatie kunnen voorspellen. Er werd een systematisch literatuuronderzoek verricht waarbij gebruikt gemaakt werd van geautomatiseerde gegevensbestanden waaronder Medline (via PubMed), Embase (via OvidSP), en de Cochrane bibliotheek. We beperkten de zoektocht naar studies die werden gepubliceerd in het Engels. Er werden 27 artikelen die voldeden aan de inclusiecriteria geselecteerd.

De resultaten van de huidige literatuur suggereren dat de translabiale 3D echografie reproduceerbaar is voor het vaststellen van levator ani defecten en voor het vaststellen van een ballooning hiatus in studies waarbij het onderzoek in 1 centrum uitgevoerd is. Externe validatie waarbij meerdere centra deelnemen dient nog bekeken te worden. Levator ani defecten zijn, in een geselecteerde populatie van patiënten met bekkenbodem problemen, geassocieerd met verzakkingen en met recidief verzakkingen na een eerdere operatie. Vergelijkende studies waarbij levator ani defecten bekeken worden in asymptomatische patiënten in vergelijking met patiënten met een verzakking zijn nog niet uitgevoerd. Slechts weinig onderzoek is gedaan om de diagnostische prestaties vast te stellen van de translabiale $3 \mathrm{D}$ echografie om levator ani defecten te detecteren of om de hiatus te meten.

In hoofdstuk 4 wordt het studie protocol van de TRUDIL beschreven (multicenter prospectieve cohort studie). In deze studie werden 140 vrouwen met minstens een ICS POP-Q stadium 2 , geïndiceerd voor een klassieke voorwand operatie, gevraagd om deel te nemen aan deze studie. Voorafgaand aan de operatie werd een MRI en een translabiale 3D echo gemaakt. Er werd verder gevraagd om gevalideerde ziektespecifieke kwaliteit van leven vragenlijsten in te vullen voor de operatie en ook op zes en twaalf maanden na de operatie. Inwendig onderzoek om de ernst van de verzakking vast te stellen werd uitgevoerd op dezelfde tijdstippen. Het belangrijkste doel van onze studie was om de diagnostische nauwkeurigheid van translabiale 3D echo van de bekkenbodem te schatten ten opzichte van MRI, de referentie standaard, voor de diagnose van levator ani defecten bij vrouwen met een verzakking. Het tweede doel van deze studie was om de mate van overeenstemming tussen onderzoekers te schatten. Een derde doel was om te bepalen of levator ani defecten een risicofactor zijn voor het optreden van een recidief na een verzakkingoperatie. Een vierde doel was om de kosteneffectiviteit van de invoering van de translabiale $3 \mathrm{D}$ echografie in de work-up van een patiënt met een verzakking in een beslissing analytisch model te schatten.

Hoofdstuk 5 beschrijft de diagnostische betrouwbaarheid van de translabiale 3D echografie 
in termen van sensitiviteit en specificiteit. Ook werd de interobserver overeenstemming vastgesteld tussen twee onderzoekers van de echo en van de MRI. Er werden 135 preoperatieve translabiale echo's vergeleken met MRI beelden voor de detectie van levator ani defecten. De echo beelden werden geanalyseerd door 5 verschillende gynaecologen, terwijl de MRI beelden werden geanalyseerd door 4 radiologen waarbij een gestandaardiseerd protocol werd gebruikt. De diagnostische waarde van translabiale 3D echografie voor de diagnose van major levator ani defecten in vergelijking met MRI als een referentie standaard, toonde een sensitiviteit van $78 \%$ en een specificiteit van $86 \%$. De interobserver overeenstemming tussen de onderzoekers van de translabiale 3D echografie liet een kappa van 0.67 zien. De interobserver overeenkomst tussen de radiologen liet een kappa van 0.44 zien. Op basis van ons onderzoek concluderen wij dat translabiale 3D echo een alternatief is voor het detecteren van levator ani defecten ten opzichte van de MRI. Echter de suboptimale interobserver overeenkomst beperkt de klinische toepasbaarheid. We wachten op verdere evaluatie en externe validatie van deze resultaten, voordat bredere implementatie van deze beeldvorming van levator ani defecten in de dagelijkse klinische praktijk geadviseerd wordt.

Hoofdstuk 6 is een voortzetting van hoofdstuk 5, waarin de relatie tussen de levator ani defecten en recidief verzakking werd vastgesteld in hetzelfde cohort. POP-Q onderzoek werd gebruikt om een anatomisch recidief vast te stellen, 12 maanden na de operatie. Gevalideerde vragenlijsten werden gebruikt om een subjectieve en compound (combinatie vansubjectieveklachten en anatomisch recidief) recidiefvast testellen. Twaalf maanden na de operatie hadden 76 vrouwen van de $139(54,7 \%)$ een recidief blaasverzakking met een POP-Q stadium 2 of meer. Slechts 12 vrouwen van de $135(8,9 \%)$ rapporteerden subjectieve klachten (gevoel van verzakking). Compound recidief werd in slechts 10 vrouwen gezien (7,2\%). Van de 135 vrouwen werd bij 66 vrouwen (48,9\%) een major levator ani defect vastgesteld op de translabiale 3D echoscopie. Van de 139 vrouwen waarvan MRI beelden beschikbaar waren, werden 43 vrouwen $(30,9 \%)$ gediagnosticeerd met een major levator ani defect. Er was geen significant verband tussen een anatomische verzakking na bekkenbodem chirurgie en de aanwezigheid van een major levator ani defect gediagnosticeerd met ofwel translabiale $3 \mathrm{D}$ echoscopie ( $p=0.2$, Odds ratio (OR)1.6, 95\% confidence interval (CI), 0.8-3.1) of MRI ( $p=0.4$, OR 1.4, 95\% Cl, 0.7-2.9). Er was ook geen statistisch significant verband tussen een subjectief recidief of compound recidief en de aanwezigheid van een major levator ani defect vastgesteld met de translabiale 3D echografie of met de MRI. We kunnen concluderen dat de aanwezigheid van een major levator ani defect geen recidief na een klassieke voorwand operatie kan voorspellen. 
Hoofdstuk 7 bevat de resultaten betreffende hiatus oppervlakte metingen. In het TRUDIL cohort werden niet alleen levator defecten gemeten, maar ook de levator hiatus oppervlakte werd preoperatief gemeten bij elke patiënt met behulp van een gestandaardiseerd protocol. Ballooning hiatus is in de literatuur beschreven als een risicofactor voor een verzakking en voor een recidief verzakking na een operatie. Deze bevindingen zijn voornamelijk afkomstig uit retrospectieve studies en/of single center studies. Het doel van deze studie was om te bepalen of een ballooning hiatus preoperatief gemeten, geassocieerd is met een recidief verzakking, 12 maanden na een klassieke voorwand operatie, in een prospectieve multicenter multi-onderzoeker instelling.

Van de 139 datasets, werden 5 datasets uitgesloten vanwege niet goed opgenomen volumes. Een in grootte toegenomen hiatus tijdens Valsalva bleek een onafhankelijke risicofactor te zijn voor een anatomisch recidief van de blaasverzakking na een operatie met een OR van 1.06 ( $p=0.02,95 \% \mathrm{Cl}, 1.01-1.10)$. De oppervlakte onder de curve (area under the curve (AUC)) van de receiver operating curve (ROC curve) voor de hiatus als maat om een anatomisch recidief te voorspellen was 0.60 (95\% $\mathrm{Cl}, 0.51-0.70)$. Op basis van de resultaten van dit onderzoek kunnen we concluderen dat er een kleine associatie gevonden is tussen een grote hiatus gemeten met de translabiale 3D echografie en een recidief verzakking. Echter, het vaststellen van een ballooning hiatus tijdens Valsalva om een anatomisch recidief van een blaasverzakking na de operatie te voorspellen, heeft geen extra waarde gezien de matige test kenmerken.

Hoofdstuk 8 geeft een algemene beschrijving van de resultaten uit dit proefschrift. Verder bevat dit hoofdstuk klinische implicaties voor de dagelijkse work-up van een patiënt met een verzakking. 


\section{SUMMARY}

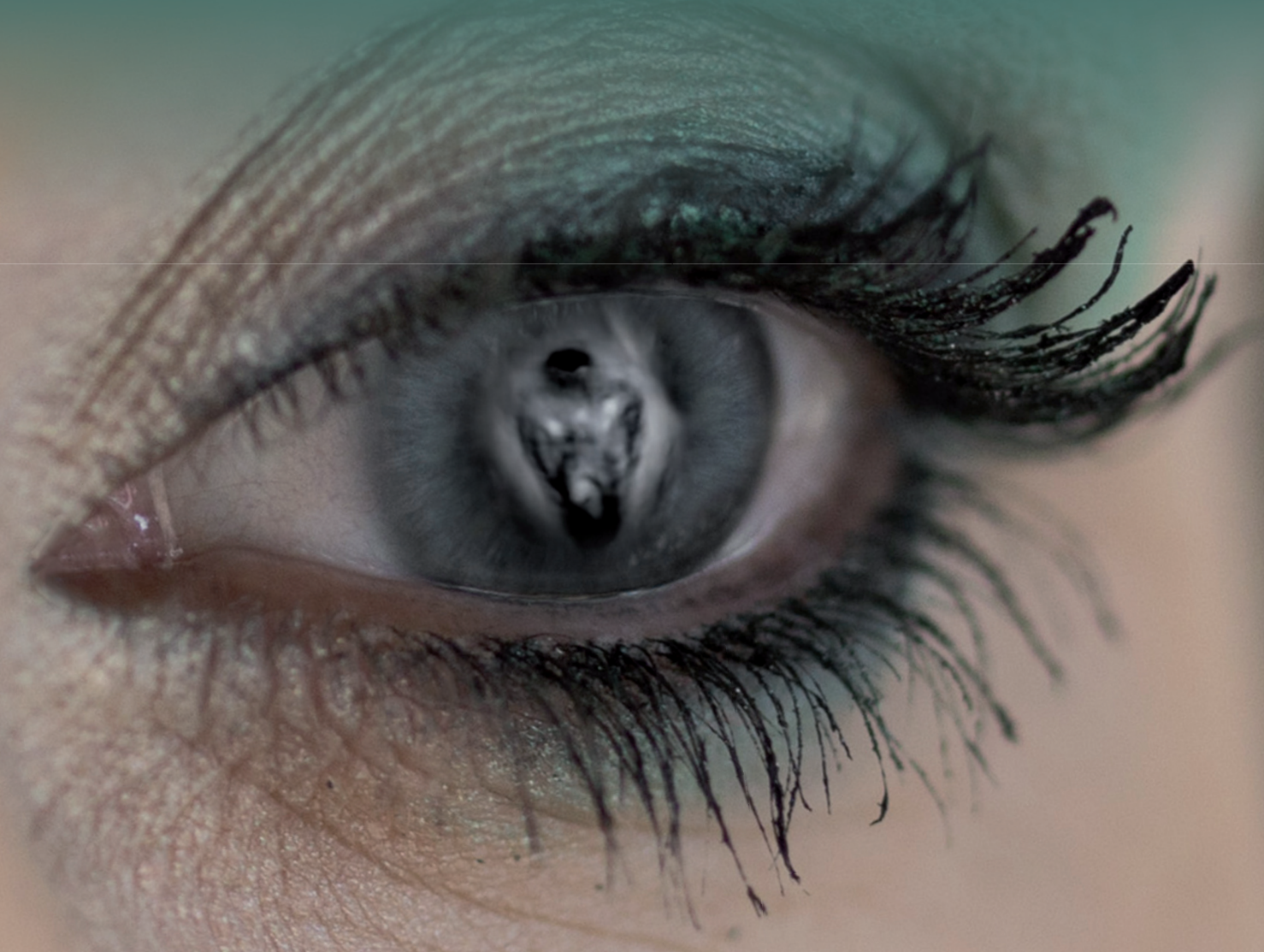




\section{SUMMARY}

Chapter 1 described the general outline of this thesis. Pelvic organ prolapse (POP) and its recurrence constitutes a major healthcare problem. The aetiology of the development of POP is still unclear, but seems to be multifactorial. Injury of the musculus levator ani seems to play a key role in the development of primary POP as well as in the development of recurrent POP. Due to advances in imaging techniques it is possible to assess levator ani defects with translabial tree dimensional (3D) ultrasound. However many aspects of the translabial ultrasound remains unclear. The aim of this prospective multicenter cohort study was to validate translabial 3D ultrasound for diagnosing levator defects compared to the reference standard magnetic resonance (MR) imaging. Furthermore the clinical relevance of levator ani defects were to establish in anterior vaginal wall recurrence after the standard surgery technique anterior colporrhaphy.

Patients' preferences for anterior colporrhaphy or mesh surgery as surgical correction of anterior vaginal wall prolapse was investigated in Chapter 2. A labelled discrete choice experiment was used to assess patients' preferences. Discrete choice experiments are an attribute-based survey method for measuring preferences. In this experiment patients were asked to choose between two treatment scenarios: mesh surgery or anterior colporrhaphy. These surgical treatments differed in four treatment attributes: 1) recurrence rate, 2) exposure rate, 3) infection rate, 4) dyspareunia. This study showed that next to the risk of recurrence other aspects like risk of infection, dyspareunia and exposure play an important role in the patients' preference for the surgical treatment of anterior vaginal wall prolapse. In addition, the results represent an average preference of a sample of patients and indicate that anterior colporrhaphy is preferred in the majority of the choices, followed by a preference for mesh surgery in a quarter of all choice sets. In order for patients to construct their own individual preferences, they should be well informed about the existence and magnitude of the potential benefits and risks related to either anterior colporrhaphy or mesh surgery.

In Chapter 3 we presented a systematic review in which we aimed to establish the diagnostic accuracy of translabial 3D ultrasound for diagnosing levator defects and for measuring "ballooning hiatus". Furthermore we studied if levator defects and a "ballooning hiatus" are associated with primary POP. In addition we evaluated whether if levator defects or a "ballooning hiatus" can predict the success rate of POP surgery. We performed a systematic literature search through computerized databases rom January the $1^{\text {st }} 2003$ to June the $1^{\text {st }} 2014$. We selected 27 articles which met our inclusion criteria. 
In conclusion, current literature suggests that translabial 3D ultrasound in single center settings is reproducible for diagnosing levator ani defects and "ballooning hiatus"; external validation in a multicenter setting is needed. In a selected population of patients with pelvic floor dysfunction, levator ani defects are associated with POP and recurrent POP after surgery. Studies on levator ani defects in asymptomatic patients and comparison with POP patients are lacking. Only little research is performed on the diagnostic performance of translabial 3D ultrasound to detect levator ani defects or to measure hiatal biometry.

In Chapter 4, the protocol of the multicenter prospective TRUDIL trial was outlined. In this trial 140 women with at least an ICS POP-Q stage 2 , indicated for anterior colporrhaphy were included. Prior to surgery, patients underwent MR imaging and translabial 3D ultrasound examination of the pelvic floor. Patients were asked to complete validated disease specific quality of life questionnaires before surgery and at six and twelve months after surgery. Pelvic examination was performed at the same time points. The main objective of our study was to estimate the diagnostic accuracy of translabial 3D ultrasound as compared to MR imaging, the reference standard, for diagnosing levator defects in women with POP. The second aim of this study was to estimate the level of agreement between observers and determine whether levator defects are a risk factor for recurrence after POP surgery. In addition, we planned to estimate the cost-effectiveness of introducing translabial 3D ultrasound in the work-up of a patient with POP in a decision analytic model.

The assessment of the levator ani muscle has been evaluated using translabial 3D ultrasound compared to the reference test MR imaging in 140 women with at least POP-Q stage 2 indicated for anterior colporrhaphy.

Chapter $\mathbf{5}$ described the diagnostic accuracy of the translabial ultrasound in terms of sensitivity and specificity. Furthermore the inter-observer reliability was established. Preoperatively, 135 translabial ultrasound images were compared to MR images for the detection of levator defects. The ultrasound images were analyzed by 5 different gynecologists while the MR images were analyzed by 4 radiologists using a standardized protocol. The diagnostic value of translabial 3D ultrasound for diagnosing major levator defects compared to MR imaging as a reference standard showed in a group of 135 women with POP a sensitivity of $78 \%$ and a specificity of $86 \%$. The inter-observer agreement between two investigators of a translabial 3D ultrasound scan for diagnosing levator defects showed a kappa of 0.67 . The inter-observer agreement between radiologists showed a kappa of 0.44. Based on our study we conclude that translabial 3D ultrasound 
is an alternative for MR imaging in detecting levator defects, though the suboptimal interobserver agreement seems to limit its clinical application. We await further evaluation and external validation of these results, before wider implementation of imaging of levator ani defects in daily clinical practice.

Chapter 6 was a continuation of chapter 5, in which the relationship between levator defects and recurrent anterior vaginal wall prolapse was established in the same cohort. POP-Q staging was used for anatomical recurrence 12 months postoperatively. To establish subjective en compound recurrence, validated questionnaires were used. Twelve months postoperatively 76 patients out of $139(54,7 \%)$ had a recurrent anterior vaginal wall prolapse POPQ stage 2 or more. Only 12 patients out of $135(8,9 \%)$ reported subjective recurrence. Compound recurrence was established in only 10 patients $(7,2 \%)$. From the 135 patients, 66 patients (48.9\%) had a major levator ani defect detectable on translabial 3D ultrasound examination. From 139 patients of which MR imaging was available, 43 patients (30.9\%) were diagnosed with major levator ani defects. There was no significant association between objective POP after pelvic floor surgery and the presence of a major levator ani defect diagnosed with either translabial 3D ultrasound $(\mathrm{p}=0.2$; Odds Ratio (OR) 1.6, 95\% Confidence Interval (CI), 0.8-3.1), or MR imaging ( $p=0.4 ; \mathrm{OR} 1.4,95 \% \mathrm{Cl}$, 0.7-2.9). There was also no statistically significant association between subjective recurrence or compound recurrence and the presence of a major levator ani defect diagnosed with translabial 3D ultrasound or MR imaging. In conclusion, the presence of major levator ani defects at translabial 3D ultrasound or MR imaging did not predict POP recurrence of the anterior compartment following anterior colporrhaphy.

Chapter 7 contains results about hiatal area measurements. In the TRUDIL cohort, not only levator defects were measured in the post processing procedure, but also hiatal area was preoperatively measured in every patient using a standardized protocol. Ballooning hiatus is described in literature as a risk factor for POP and its recurrence. These outcomes were found in retrospective studies and/or single center studies. The aim of this study was to define if a larger hiatal area i.e ballooning hiatus measured preoperatively, is associated with POP recurrence 12 months after anterior colporrhaphy, in a prospective multicenter multi- investigator setting. Of the 139 datasets, 5 datasets were excluded because of inadequately recorded volumes. An increased hiatal area during Valsalva was found to be an independent risk factor for anatomical anterior vaginal wall prolapse recurrence with an OR of $1.06(p=0.02 ; 95 \% \mathrm{Cl}, 1.01-1.10)$. Receiver Operating Characteristic (ROC) curve was created to quantify the discriminative ability of using levator hiatal area to predict anatomical anterior vaginal wall recurrence. The area 
under the ROC curve for levator hiatal area during Valsalva on ultrasound was 0.60 195\% $\mathrm{Cl}, 0.51-0.70)$. Based on the results of this study we can conclude that there is a slight association found between a larger hiatal area measured with translabial 3D ultrasound and POP recurrence. However, using increased levator hiatal area during Valsalva to predict anatomical cystocele recurrence after surgery does not have additional value due to poor test characteristics.

Chapter $\mathbf{8}$ provides a general discussion of the results presented in this thesis and the main results are discussed. Furthermore, suggestions for implications in the work up of POP patients are given. 


\section{WHY SHOULD YOU CARE ABOUT MY RESEARCH?}

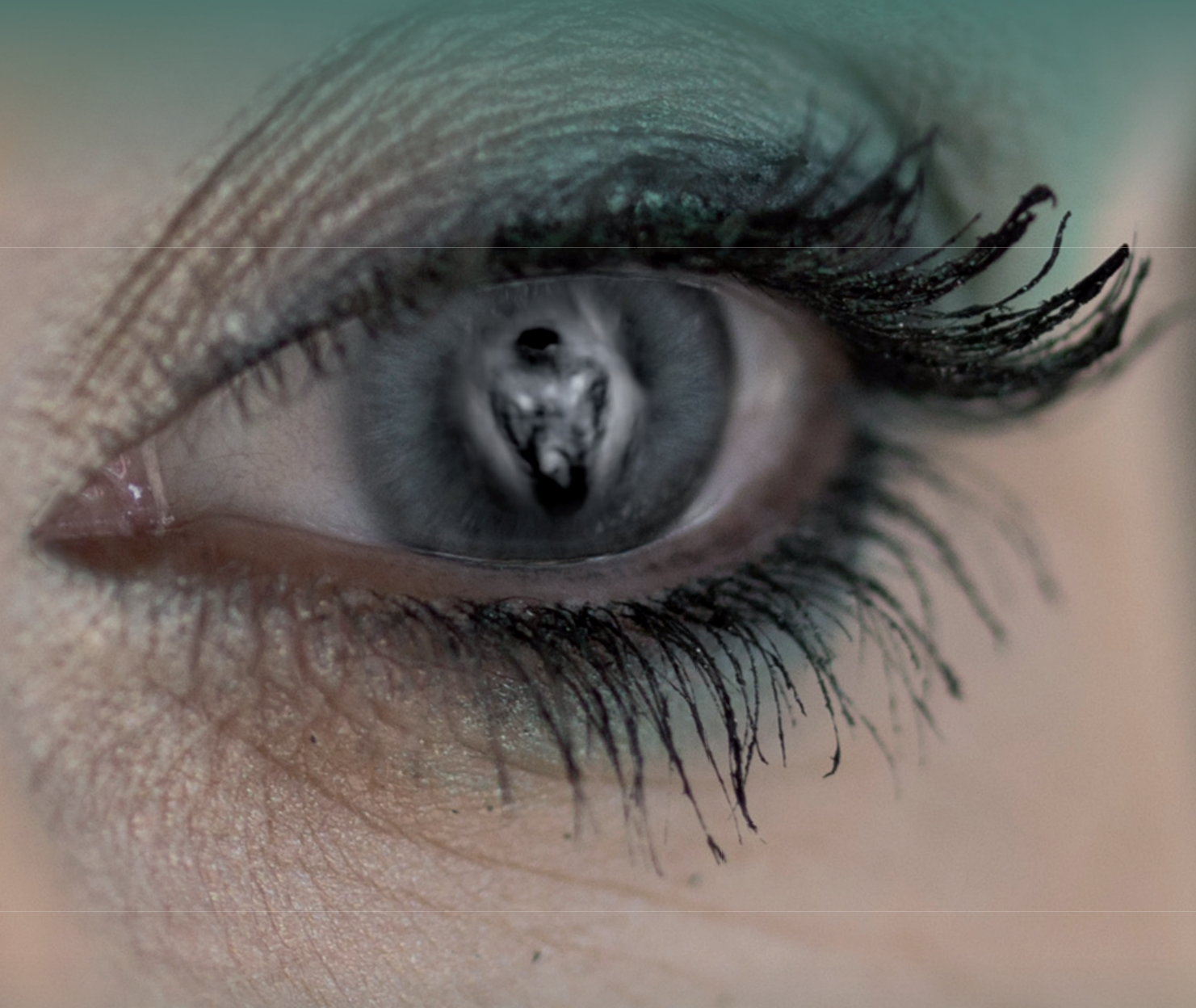




\section{WHY SHOULD YOU CARE ABOUT MY RESEARCH?}

Pelvic organ prolapse (POP) has a multifactorial aetiology. The symptoms of a weakened pelvic floor can range from mild to debilitating, and it can affect women's ability to lead an active life, and even maintain sexual intimacy. More than half of women above age 40 develop POP. The lifetime risk for POP surgery is about $11 \%$. About 30-50 percent of women who underwent POP surgery are confronted with recurrent POP. POP does not only constitute a major health care problem, but can also cause emotional distress and a decrease in women's Quality of Life. One of the alleged important factors in developing POP and recurrent POP, is vaginal birth in which an important pelvic floor muscle called the levator ani muscle, is damaged. The levator ani muscle plays an important role in the support of the pelvic floor and in the maintenance of continence. Severe levator ani muscle damage has been stated to be the missing link between understanding the aetiology of POP and it's recurrence after surgery. Advancements in imaging allows assessment of the levator ani muscle with translabial 3D ultrasound and with MRI, of which the latter is currently the reference standard. Previous research from different research groups found an association between severe damage of the muscle and POP, and its recurrence. Based on these limited and mainly retrospective data, some hospitals worldwide already incorporated the translabial 3D ultrasound in daily practice despite the fact that until now no validation of this technique took place. Translabial 3D ultrasound has multiple benefits over MRI; it is cheaper, more easily accessible for gynaecologists and there are no contraindications for using it. If in fact we are able to predict which women are prone for recurrent POP based on major levator ani defects, we can consider a different surgery technique to repair the prolapse. This other surgery technique is called mesh surgery which it is known for lower risks of recurrence but higher costs and complication risk compared to the first choice surgery with native tissue. In the Netherlands mesh surgery is mostly used when women develop a recurrent prolapse.

In the Trudil study we investigated if it is possible to assess levator ani muscle defects with translabial 3D ultrasound and if levator ani defects indeed can predict recurrence in women with an anterior vaginal wall prolapse one year after surgery (with native tissue). The results of this research showed that in fact it is possible to detect levator ani muscle defects with translabial 3D ultrasound in women with POP compared to MRI. Unfortunately we found that grading these defects (assessing the severity of such defect) is rather difficult and therefore extensive training of gynaecologists or ultrasonographers is needed before the technique could be actually implemented in daily practice. However, slightly unexpected, we did not found an association between levator ani defects and recurrent prolapse 12months after surgery with native tissue. Based on this findings we can state that using pelvic floor imaging for the assessment of the integrity of this levator ani muscle in predicting recurrent POP is a waste of 
time, money and effort. In itself, this results seem disappointing because we hoped to confirm that levator ani muscle defects indeed are the missing link in the aetiology of POP. However it is also important to inform gynaecologists that the presence of levator ani muscle damage itself is not relevant for treatment decisions. In respect to valorisation we can thus state that our study results lead to less health costs and less burden on patients due to less unnecessary extended clinical examination. In addition to the above mentioned results we acknowledge that, when confirmed in another trial, this line of research is in our opinion ending.

In the same population we also investigated patients preferences of the current surgical treatment options. The first choice surgical treatment of anterior vaginal wall prolapse as mentioned above, is surgery with native tissue. This surgery technique is known for reoperation rates of up to $30 \%$ because of recurrence. The introduction of vaginal polypropylene implants (mesh surgery) has decreased the recurrence rate, but the complication rates are higher compared to native tissue surgery. For that reason, mesh surgery is mostly performed for recurrent POP. Specific complications of mesh surgery are related to the host response against the foreign body and are expressed by healing problems. So, although the use of vaginal mesh reduces the risk on recurrent prolapse, mesh-specific complications might negatively affect quality of life. In respect to successful surgery outcomes, doctors are really focussed on both a low risk of recurrence and low complication rates but unfortunately such a technique is not available yet. Thus far, patients' perspectives regarding type of POP surgery are under addressed. Patients preferences, either accept mesh specific complications in order to benefit from a lower risk of recurrence, or accept a higher risk of recurrence in order to avoid mesh-related complications, are not known yet. We investigated which properties (benefits/complications) are most important in making this choice. Our results showed that patients considered four properties as important (risk of recurrence, risk of infection, risk of painful intercourse and risk of exposure, the latter only possible in mesh surgery). Balancing the surgery-related benefits, i.e. a lower risk of recurrence against risks like infection, exposure and painful intercourse, native tissue surgery was preferred in $74 \%$ of the choices as a primary correction of anterior vaginal wall prolapse, followed by a preference for mesh in $26 \%$. This means that the current status ensures that patients now choose for a surgery with higher risk of recurrence but lower complications. By incorporating "lower" hypothetical values of the mesh risks in our model, we found that if the meshes considerably improve in lower risk of infection and exposure, patients tend to favour mesh surgery over native tissue as a primary correction of prolapse. This model could also be expanded for obtaining patients surgery preferences for recurrent prolapse. It could well be, that in respect to recurrent surgery, patients accept different values of risks or benefits. These results are important for manufacturers of mesh implants. 


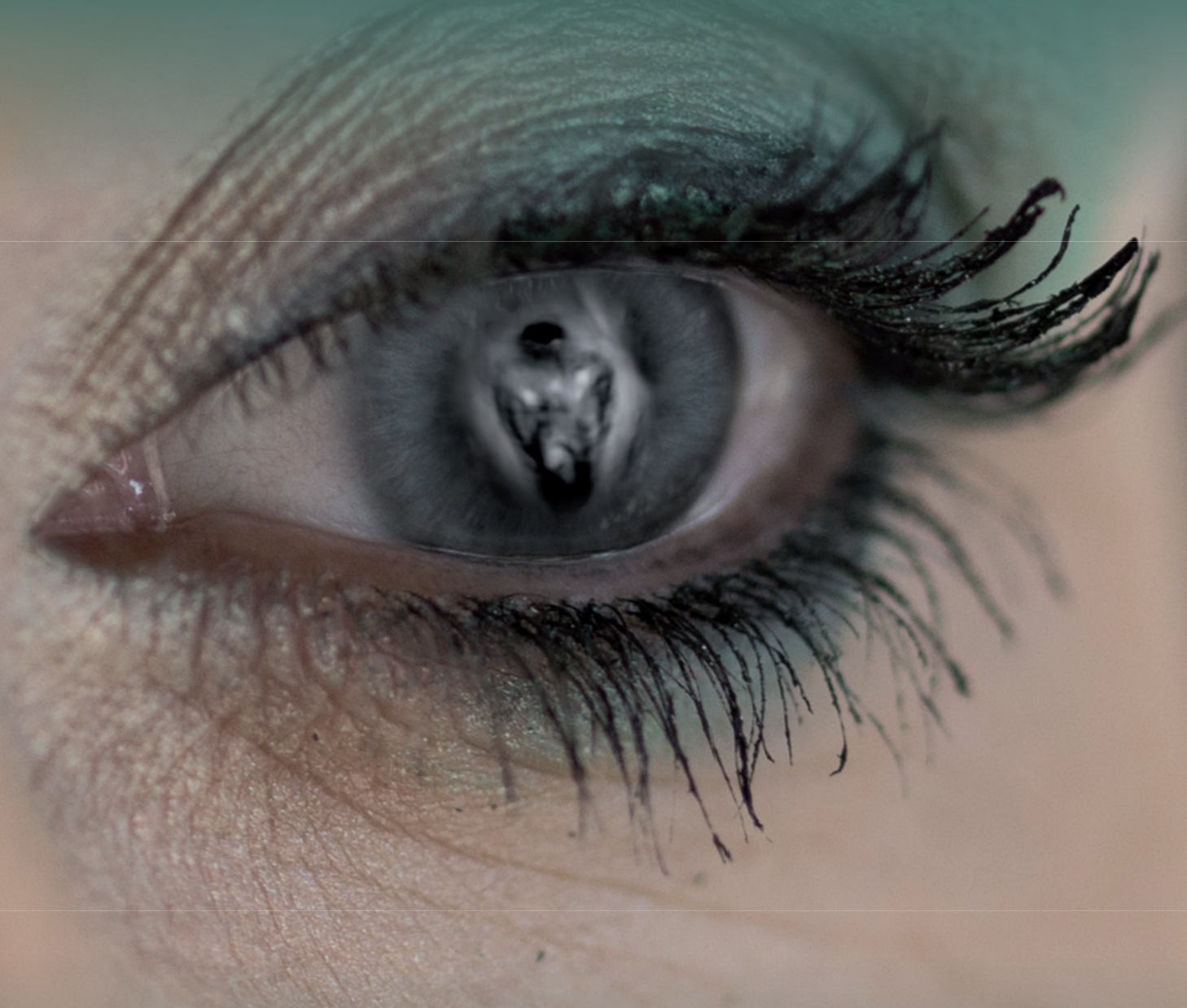




\section{DANKWOORD}

Het zit er op! Na een aantal bewogen, maar vooral leerzame jaren mag ik met trots zeggen dat we een mooi project hebben afgerond. Ik heb heel veel waardevolle mensen om me heen gehad die me gesteund, geïnspireerd en geholpen hebben tijdens dit project. Een aantal van hen wil ik graag in het bijzonder bedanken.

Allereerst hartelijk dank aan alle vrouwen die aan de onderzoeken van dit proefschrift hebben deelgenomen. Dank ook aan de arts-assistenten en gynaecologen van de deelnemende centra voor het uitvoeren van de benodigde klinische onderzoeken.

Hartelijk dank aan de leden van de beoordelingscommissie bestaande uit: prof. Dr. J.G. Nijhuis, prof. Dr. J. Deprest, Dr. G. van Koeveringe, Prof. Dr. L.P.S Stassen en Prof. Dr. H. van der Vaart, voor het kritisch doornemen van mijn proefschrift.

Een bijzondere dank gaat uit naar Dr. Mirjam Weemhoff , die ik met trots mijn co-promotor mag noemen. Jij bent diegene die mij het vertrouwen gaf om aan dit project te mogen beginnen. Ik kan me nog zo goed jouw telefoontje herinneren in 2009 toen je me vroeg of ik interesse had om onderzoek met je te doen, wat was ik blij! Ik wil je bedanken voor je begeleiding, je tijd en vooral de vrijheid die je me gaf om mijn eigen inbreng te geven. Je bent als persoon en als professional een enorme inspiratie voor velen. Ik ben trots dat ik je eerste promovenda mag zijn en ik weet zeker dat er nog heel veel goede promovendi zullen volgen want je bent een fijne begeleider.

Prof. Dr. Jan-Paul Roovers die als andere waardevolle co-promotor begon maar inmiddels mijn promotor is. Daar zat je dan in Amsterdam en je kreeg er ineens een promovenda bij die je niet kende en waar in het begin ook weinig contact mee was. Wat zul jij wel niet allemaal gedacht hebben toen wij onze "relatie" ietwat stuntelig zijn begonnen. Pas toen ik er achter kwam na de geboorte van je jongste dochter dat je eigenlijk een Limburger bent, toen was het ijs gebroken (-). Ik vraag me af hoe jij je zo goed staande weet te houden met zo een drukke baan en daarnaast nog zoveel neventaken, je bent een inspiratie. Op gebied van schrijven heb ik ontzettend veel van je mogen leren, heel veel dank hiervoor.

Prof. Dr. Kruitwagen (beste Roy), halverwege het traject werd mij gevraagd of jij mijn promotor mocht worden omdat er tot dan toe eigenlijk nog geen echte promotor was. We hebben een afspraak ingepland en ik heb je een samenvatting van anderhalf uur gegeven over waar we tot dan toe mee bezig waren geweest. Je enthousiasme vergeet ik niet meer, 
je ging meteen brainstormen en probeerde zaken op te pakken waarvan jij dacht dat je er een waardevolle inbreng in kon hebben. Ik heb me altijd welkom gevoeld en ik ben blij dat je hemel en aarde bewogen hebt om een schrijfstage voor me te regelen.

Kirsten Kluivers, Karlijn Schweitzer en Femke Mulder zonder jullie was het nooit gelukt! Dank voor die vele uren achter de Voluson en daarna achter de computer om alle beelden te beoordelen totdat jullie er waarschijnlijk tureluurs van werden. We hebben samen mooi onderzoek gedaan en ik hoop dat jullie er ook trots op zijn.

Beste prof. Dr. Stoker (beste Jaap), prof. Dr. Beets (beste Regina), dr. Vliegen (beste Roy) en dr. Futterer (beste Jurgen of JJ al weet ik nog steeds niet waar dit voor staat), heel erg bedankt voor jullie besluit tot deelname aan dit onderzoek. Dit onderzoek heeft wat mij betreft bewezen dat multidisciplinair onderzoek een sleutel tot succes kan zijn. Wat hebben jullie een ontzettende inzet gehad! Dank voor de fijne samenwerking!

Dear prof Delancey and prof Dietz, thank you both for your inspiration, time and input in our research. You were both fabulous!

Beste Danielle Geraedts, jij was mijn reddende engel toen ik het administratieve gedeelte van mijn werk niet meer zag zitten. Wat was ik dankbaar dat jij in mijn leven kwam als research nurse. Niet meer de hele dag bezig hoeven zijn om echo's en MRI's op één dag te plannen, of patiënten 10x terug te bellen. Door jou kon ik meer tijd besteden aan alle andere relevante zaken, enorm veel dank hiervoor.

Alle MRI laboranten uit Heerlen, Maastricht, Nijmegen en Amsterdam dank voor jullie inzet!

Brigitte Essers enorm bedankt voor het opzetten en analyseren van de PREMEK. Je zult vast vele momenten gekend hebben dat je het niet meer met me zag zitten (ik ook) maar je bleef volhouden maar belangrijker nog je bleef altijd aardig en je was een steun. Dank je wel.

Beste Prof. Dr. Dirksen, beste Carmen, enorm veel dank voor de uren die we gewerkt hebben aan de kosteneffectiviteit analyses (die we vervolgens niet konden gebruiken) en het begeleiden van de PREMEK. Je was een inspiratie.

Sander van Kuijk, ik had werkelijk nooit gedacht dat ik ook maar iets van statistiek zou begrijpen. Maar door jou werd statistiek leuk en ja soms lukte het me zelfs om kleine discussies met je te voeren. Wie had dat ooit gedacht? Dank voor de fijne samenwerking. 
Judith en Anouk! Mijn twee pareltjes die de PREMEK gaande hebben gehouden.

Judith ik zie je nog binnen komen met de vraag of je kon helpen met onderzoek omdat het een beetje spaak liep op de universiteit en je veel tijd ging krijgen. Wat we op dat moment meteen wisten was dat je een topper bent en dat heb je bewezen. Ik ben trots op je dat je nu als anios werkt en je het super doet. Binnenkort in opleiding tot huisarts, wauw, schrijf me maar alvast in als patient. Anouk jou heb ik leren kennen in Venlo en jij wist van aanpakken. Alles deed je om beter te worden. Je was een kei met SPSS en ik mag oprecht zeggen dat jij me dit allemaal goed geleerd hebt. Dank voor je hulp.

Beste Katinka, Moniek, Monique, Brenda en Nathalie, dank voor de koffie momenten en de tijd die jullie me gaven om even bij jullie te klagen. Ik was altijd blij dat ik even bij jullie in het "hok" kon bijkletsen en met een big smile datzelfde hok ook weer kon verlaten.

Beste research nurses (Jolanda Willems, Mireille Vencken, Monique Tjon, Marijke Hogenkamp, Mieke Kersten, Cindy Verstegen en Anneke Heutinck ) betrokken bij de Trudil, heel veel dank voor jullie inzet jullie zijn zo belangrijk voor onderzoek dit kunnen we niet genoeg benadrukken.

Christine Willekes... dank! Bij jou begon het allemaal. Je maakt iedereen enthousiast voor het vak. Jij motiveerde me terwijl vele anderen zeiden dat ik misschien maar moest overwegen om iets anders te doen vanwege mijn gezondheid. Jij gaf me de kans na meerdere teleurstellingen om een WESP/GEZP stage bij je te regelen en het lukte. Bedankt voor onze bijzondere band!

Suzanne (suusje), mijn lieve vriendin, waar moet ik beginnen? Niets wat ik kan opschrijven zal onze band goed kunnen beschrijven. Als er iets vervelends is denk ik, ik moet Suus bellen, als er iets positiefs is denk ik ook, ik moet Suus bellen. Dat is wat mij betreft echte vriendschap. Je was er tijdens moeilijke momenten maar ook tijdens de mooiste momenten in mijn leven. Ik ben je ontzettend dankbaar voor onze bijzondere band. Maar ik ben er nog meer trots op dat je mijn paranimf bent, wat hebben we hier naar uitgekeken!

Tineke, mijn andere paranimf. We werden aan elkaar voorgesteld toen jij semi-arts was bij Mirjam en ik net als arts-onderzoeker was begonnen. Wat mij betreft was er meteen een klik. Samen hebben we nogal wat uurtjes aan onderzoek besteedt en wat was dat gezellig en leuk! Ik heb enorme waardering voor je als ik zie hoe jij zaken aanpakt. Enorm gestructureerd, snel en ook nog overal voor in. Als ik maar weer eens een idee had sprong 
je meteen aan boord zonder er lang over na te denken. Zo ook ons avontuurtje naar Rio, wat vond ik het fijn dat je met me mee ging, samen praten op congressen ging toch altijd makkelijker dan alleen. Van collega ben je uitgegroeid naar vriendin en dat maakt me trots. Hopelijk kunnen we snel de rollen omdraaien en kunnen we naar jouw promotie toe leven! Dank lieve Tineke dat je mijn paranimf wilt zijn.

Lieve Tamara, oftewel Tante Taar, bedankt voor al die jaren. We deelden letterlijk leed en daarna pas lief maar we hebben ons er doorheen gesleept en kijk ons nu! Jij en Jos zijn ongelooflijk belangrijk voor mij (ons)! Op naar de vele volgende jaren samen en het delen van voornamelijk LIEF.

Pap en mam wat hebben we allemaal toch niet moeten meemaken samen. Ik kan oprecht zeggen dat we onze portie wel gehad hebben met heel veel ziekte momenten. Maar ik ben wie ik ben dankzij jullie. Ondanks mijn vele ziek zijn, ziekenhuisopnamen, opnamen centra Heideheuvel, Davos, Fransiscusoord en ga zo maar door vonden jullie 1 ding belangrijk en dat was vertrouw op jezelf dan kan je bereiken wat je maar wilt. De Maas liep regelmatig over door mijn tranen maar jullie waren er altijd om te motiveren, te steunen, te inspireren en te kalmeren. Tijdens ons leven hebben we heel veel mooie mensen ontmoet die de kracht hadden, ondanks hun eigen moeilijke situatie, om het meest positieve uit hun leven te halen en dat wilde ik ook! Mijn droom heb ik kunnen vervullen, ik ben gynaecoloog in opleiding en hopelijk snel gepromoveerd, jullie hebben mij de basis hiervoor gegeven. Ik hoop dat wij nog heel veel jaren van jullie mogen genieten. Dank voor alles!

Lieve lieve lieve Dennis, ik weet dat ik niet te sentimenteel voor je mag doen maar goh wat ben ik blij dat ik jou aan mijn zijde heb. Ik weet dat ik soms niet aan je kon uitleggen waarom ik mijn prioriteiten weer moest verleggen naar mijn werk en dat dit soms ook wel wat discussie momenten heeft opgeleverd, maar je hebt me nooit iets in de weg gelegd. Je hebt er altijd voor gezorgd dat ik me vol op mijn werk kon storten en je had het thuis altijd super geregeld. Je bent een super papa voor onze twee kindjes en ik zou willen dat je veel trotser op jezelf zou zijn. Je hebt heel veel te bieden en ik ben blij dat wij elkaar 13 jaar geleden weer gevonden hebben. Dank dat je er voor me bent!

En dan de ALLERBELANGRIJKSTE mensjes in mijn leven... mijn lieve Yentl en Lennon. Jullie brengen iedere dag weer een lach op mijn gezicht ook al heb ik het even moeilijk. Die armpjes om me heen en die kusjes en knuffels iedere dag die maken alles de moeite waard! Ik hou van jullie... 


\section{CURRICULUM VITAE}

Kim Josephina Bernadette Notten werd geboren op 5 februari 1980 te Maastricht.

In 2001, na een turbulent leven i.v.m. ziekte, haalde zij haar VWO diploma aan het Leeuwenborgh college te Maastricht waarna ze startte met de opleiding biomedische wetenschappen in Amsterdam.

In 2003 mocht ze eindelijk starten aan de felbegeerde studie geneeskunde aan de Universiteit Maastricht alwaar zij in januari 2010 haar artsexamen behaalde.

Direct na het afstuderen ging zij als arts onderzoeker van de TRUDIL aan de slag in het MUMC onder begeleiding van Dr. Mirjam Weemhoff (MUMC) en Prof. Dr. Jan-Paul Roovers (AMC).

In Juni 2011 werd zij als anios Obstetrie en Gynaecologie aangenomen in het Viecuri waarna zij per 1 Januari 2013 mocht starten met haar specialisatie tot gynaecoloog in het Atrium medisch centrum te Heerlen (opleiders Dr. P. Mercelina en Dr. F. Roumen). Het academische deel van de specialisatie werd voortgezet in het MUMC lopleiders Prof. R. Kruitwagen en Dr. G. Dunselman).

Ze is getrouwd met Dennis van Sint Fiet en is moeder van een dochter Yentl en een zoon Lennon. 


\section{LIST OF PUBLICATIONS / JOURNAL PAPERS}

Van der Heyden JL, van Kuijk SM, van der Ham DP, Notten KJ, Janssen T, Nijhuis JG, Willekes C, Porath M, van der Post JA, Halbertsma F, Pajkrt E, Mol BW. Subsequent Pregnancy after Preterm Prelabor Rupture of Membranes before 27 Weeks' Gestation. AJP Rep 2013 Oct; 3(2):113-8.

Van der Heyden JL, van der Ham DP, van Kuijk S, Notten KJ, Janssen T, Nijhuis JG, Willekes C, Porath M, van der Post JA, Halbertsma F, Mol BW, Pajkrt E. Outcome of pregnancies with preterm prelabor rupture of membranes before 27 weeks' gestation: a retrospective cohort study. Eur J Obstet Gynecol Reprod Biol 2013;170(1):125-30.

Vergeldt TF, Weemhoff M, Notten KJB, Kessels AG, Kluivers KB. Comparison of two scoring systems for diagnosing levator ani muscle damage. Int Urogynecol J 2013; 24(9):1501-6.

Weemhoff M, Vergeldt TFM, Notten KJB, Serroyen J, Kampschoer PHNM, Roumen FJME. Avulsion of puborectalis muscle and other risk factors for cystocele recurrence:

a 2 year follow-up study. Int Urogynecol J 2012; 23:65-71.

Notten KJB, Weemhoff M, Kluivers KB, Schweitzer KJ, Mulder F, Stoker J, Beets-Tan RG, Futterer JJ, Vliegen RF, Evers JL, Link G, Bergmans MG, Kampschöer PH, Gondrie ET, van Gestel I, van Dooren I, Dirksen C, Smits LJ, Bossuyt PM, Roovers JP. Protocol for Translabial 3D-Ultrasonography for diagnosing levator defects (TRUDIL): a multicentre cohort study for estimating the diagnostic accuracy of translabial 3D-ultrasonography of the pelvic floor as compared to MR imaging. BMC Women's Health 2011; 11:23.

Kamps M, Moser A, Notten K, Slangen B. Kwaliteit van leven en seksuele problemen na gynaecologische kanker. NTOG 2010; vol.123;56-58 (DUTCH) 


\section{INTERNATIONAL CONFERENCE PRESENTATIONS}

Notten KJB, Weemhoff M, Kluivers KB, Fütterer JJ, Schweitzer KJ, Kampschöer PHNM, van Gestel I, Smits LJM, Kruitwagen RFPM, Stoker J, Roovers JPWR. Are levator ani defects predictive for recurrent anterior vaginal wall prolapse? Oral presentation ICS 2014, Rio de Janeiro (price best abstract)

Notten KJB, Weemhoff M, Roovers JPWR, Schweitzer K, Futterer J, Stoker J, Mulder F, Beets-Tan R, Vliegen R, Kluivers KB. The TRUDIL study: Translabial Ultrasound for Diagnosing Levatordefects compared to MR imaging. Oral presentation IUGA 2013, Dublin.

Notten KJB, Essers B, Weemhoff M, Rutten AGH, Donner J, Gestel van I, Kruitwagen RFPM, Roovers JPWR, Dirksen C. Do patients prefer mesh or anterior colporrhapy for primary correction of cystocele: A labeled discrete choice experiment. Oral presentation IUGA 2013, Dublin.

Notten KJB, Weemhoff M, Kluivers KB, Schweitzer KJ, Mulder F, Stoker J, Beets-Tan RGH, Futterer JJ, Vliegen RFA, Smits LJM, Roovers JPWR. Diagnosing levator defects on 3D transperineal ultrasound compared to MR imaging. Oral presentation ISUOG 2012, Kopenhagen.

Vergeldt TF, Weemhoff M, Notten KJB, Kessels AG, Kluivers KB. Comparison of two scoring systems for diagnosing levator ani muscle damage. Oral presentation ISUOG 2012, Kopenhagen. (Price for best presentation in section urogynecology)

Gerver J, Notten KJB, Link G, Gestel I, Winden LAAP, Kessels AGH , Weemhoff M. Learning Curve of 3D/4D translabial ultrasound for diagnosing levator ani defects. Oral presentation ISUOG 2012, Kopenhagen§ 


\section{INTERNATIONAL CONFERENCE POSTERS}

Vergeldt TFM, Notten KJB, Weemhoff M, van Kuijk SMJ, Mulder FEM, Beets-Tan RG, Vliegen RFA, Gondrie ETCM, Bergmans MGM, Roovers JPWR, Kluivers KB. Levator hiatal area as a risk factor for cystocele recurrence after surgery: a prospective study. Poster presentation ICS 2014, Rio de Janeiro.

Weemhoff M, Notten KJB, Kluivers KB, Hoeks AP, Evers JHG Kessels AG, Hoogland HJ. Optimizing the imaging quality of pelvic floor ultrasound. Poster IUGA 2013, Dublin. 
"It always seems impossible until it's done..."

Nelson Mandela

...but it's done! 